June 2002 ・ NREL/TP-500-26645

\title{
The Mechanical Design, Analysis, and Testing of a Two-Bladed Wind Turbine Hub
}

\author{
J. Cotrell
}

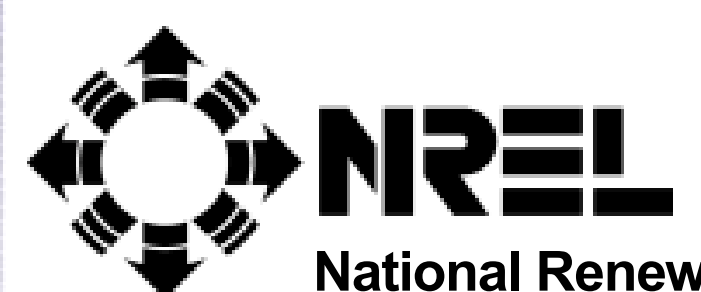

National Renewable Energy Laboratory

1617 Cole Boulevard

Golden, Colorado 80401-3393

NREL is a U.S. Department of Energy Laboratory

Operated by Midwest Research Institute $\bullet$ Battelle $\bullet$ Bechtel

Contract No. DE-AC36-99-G010337 


\title{
The Mechanical Design, Analysis, and Testing of a Two-Bladed Wind Turbine Hub
}

\author{
J. Cotrell
}

Prepared under Task No. WER2.1460

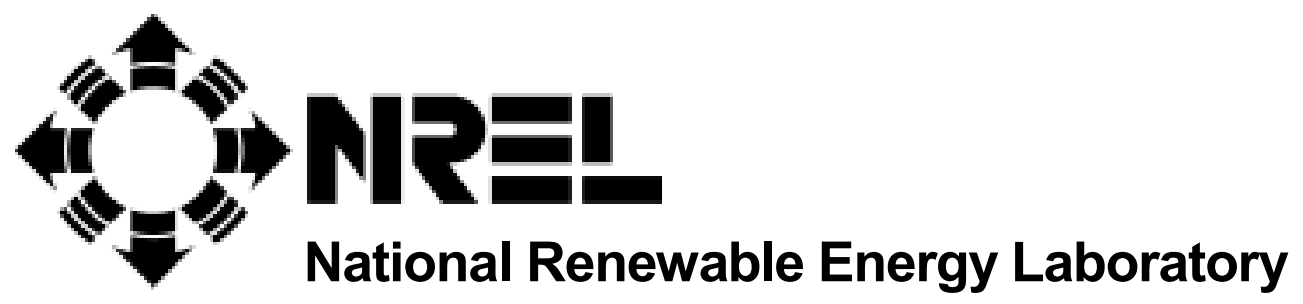

1617 Cole Boulevard

Golden, Colorado 80401-3393

NREL is a U.S. Department of Energy Laboratory

Operated by Midwest Research Institute • Battelle • Bechtel

Contract No. DE-AC36-99-G010337 


\section{NOTICE}

This report was prepared as an account of work sponsored by an agency of the United States government. Neither the United States government nor any agency thereof, nor any of their employees, makes any warranty, express or implied, or assumes any legal liability or responsibility for the accuracy, completeness, or usefulness of any information, apparatus, product, or process disclosed, or represents that its use would not infringe privately owned rights. Reference herein to any specific commercial product, process, or service by trade name, trademark, manufacturer, or otherwise does not necessarily constitute or imply its endorsement, recommendation, or favoring by the United States government or any agency thereof. The views and opinions of authors expressed herein do not necessarily state or reflect those of the United States government or any agency thereof.

Available electronically at http://www.osti.gov/bridge

Available for a processing fee to U.S. Department of Energy

and its contractors, in paper, from:

U.S. Department of Energy

Office of Scientific and Technical Information

P.O. Box 62

Oak Ridge, TN 37831-0062

phone: 865.576 .8401

fax: 865.576.5728

email: reports@adonis.osti.gov

Available for sale to the public, in paper, from:

U.S. Department of Commerce

National Technical Information Service

5285 Port Royal Road

Springfield, VA 22161

phone: 800.553.6847

fax: 703.605.6900

email: orders@ntis.fedworld.gov

online ordering: http://www.ntis.gov/ordering.htm 


\section{Acknowledgments}

I thank Sandy Butterfield, Jim Johnson, and Lee Fingersh for their invaluable expertise, enthusiasm, and guidance on the hub design. I acknowledge Murel O'Neal's skill in supervising the construction of the hub and willingness to incorporate my numerous design changes. I thank my academic advisor, William F. Weldon, for his expertise, advice, and support, and I acknowledge Scott Larwood's and Allyson Turk's help in proofreading my many drafts.

Presented to the faculty of the Graduate School of the University of Texas at Austin in partial fulfillment of the requirements for the degree of Master of Science in Engineering, The University of Texas at Austin, December 1997. 


\section{Abstract}

Researchers at the National Wind Technology Center (NWTC) in Golden, Colorado, began performing the Unsteady Aerodynamics Experiment in 1993 to better understand the unsteady aerodynamics and structural responses of horizontal-axis wind turbines. The experiment consists of an extensively instrumented, downwind, three-bladed, 20-kilowatt wind turbine. In May 1995, I received a request from the NWTC to design a two-bladed hub for the experiment. For my thesis, I present the results of the mechanical design, analysis, and testing of the hub.

The hub I designed is unique because it runs in rigid, teetering, or independent blade-flapping modes. In addition, the design is unusual because it uses two servomotors to pitch the blades independently. These features are used to investigate new load reduction, noise reduction, blade pitch optimization, and yaw control techniques for two-bladed turbines.

I used a methodology by G. Phal and W. Bietz to design the hub. The hub meets all the performance specifications except that it achieves only $90 \%$ of the specified teeter range.

In my thesis, I focus on the analysis and testing of the hub body. I performed solid-mechanics calculations, ran a finite-element analysis simulation, and experimentally investigated the structural integrity of the hub body. Both the predicted and experimental results indicate that the hub body is structurally adequate. 


\section{Table of Contents}

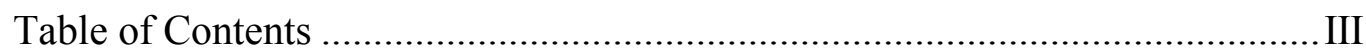

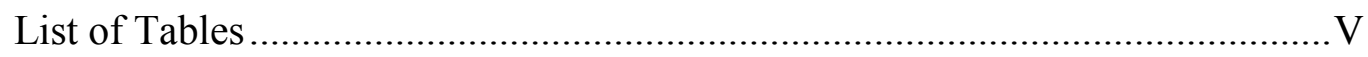

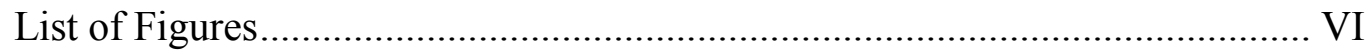

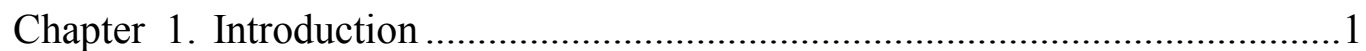

1.1 The History and Present State of Wind Energy ..........................1

1.1.1 Description of Modern Wind Turbines.................................2

1.1.2 Two-Bladed vs. Three-Bladed Designs ................................

1.2 The Need to Design an Experimental Two-Bladed Hub ............5

1.2.1 The Unsteady Aerodynamics Experiment ............................5

1.3 Project History and Scope ………...........................................6

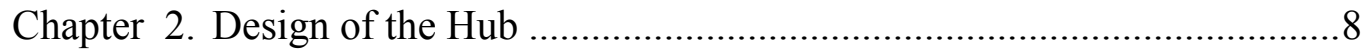

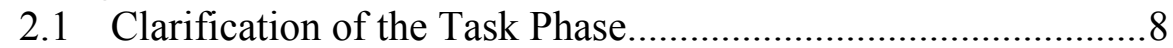

2.1.1 Problem Statement and Scope ........................................... 8

2.1.2 Design Specifications ……………………………….......

2.2 Conceptual Design Phase ………………………....................12

2.2.1 Hub Body Solution Principles .............................................14

2.2.2 Pitch Actuator Solution Principles......................................20

2.2.3 Cone Angle Linkage Solution Principles...........................22

2.2.4 Teeter-Bearing Solution Principles......................................22

2.2.5 Thrust-Bearing Solution Principles ....................................23

2.2.6 Teeter Damper Solution Principles......................................25

2.3 Embodiment and Detailed Design Phases ...............................28

Chapter 3. Predicted Strength of the Hub Body................................................29

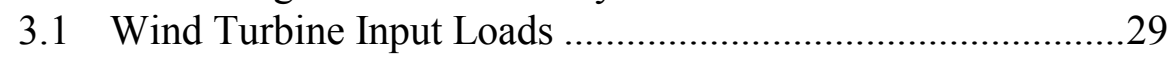

3.2 Strength-of-Materials Calculations ………………………….......34

3.2.1 Simplifying Assumptions ………………………….........34

3.2.2 Analytical Calculations for the Flapwise Load Case .........36

3.2.3 Analytical Calculations for Lead-Lag Load Case ..............43

3.3 Finite-Element Analysis .........................................................47

3.3.1 FEA Meshing and Modeling Assumptions........................48

3.3.2 Input Loads ...................................................................50

3.3.3 Finite-Element Analysis Results.........................................51

3.4 Comparison of Analytical and Finite-Element Results ............53 
Chapter 4. Experimental Results ..................................................................54

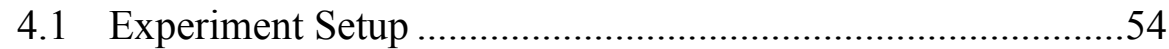

4.1.1 Load Application .............................................................57

4.1.2 Data Acquisition .............................................................58

4.1.3 Test Procedure ……………………………………........59

4.2 Discussion and Comparison of the Flapwise Load Case

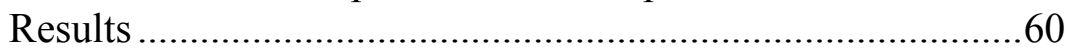

4.2.1 Hard-Link Mount Observations ..........................................60

4.2.2 Teeter-Pin Observations …………………………….......61

4.2.3 Hub Body Observations ...................................................62

4.3 Discussion and Comparison of the Lead-Lag Load Case

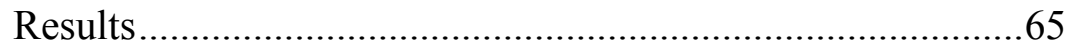

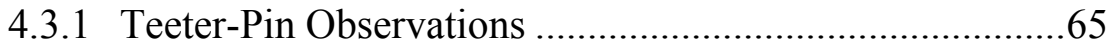

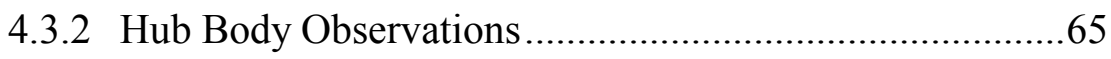

Chapter 5. Conclusions and Recommendations.................................................69

5.1 Design Methodology …………………………....................69

5.2 Analysis and Testing ...........................................................

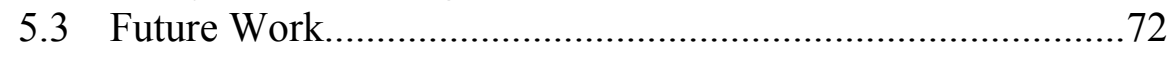

Appendix A. Hub Body Experiment Data.........................................................73

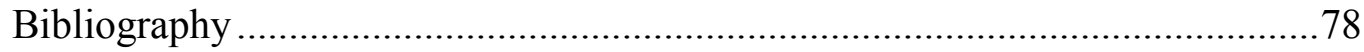




\section{List of Tables}

Table 2.1. Hub Specifications List. .............................................................10

Table 2.2. Hub Components and Their Functions...........................................13

Table 3.1. List of Primary Calculations Performed on the Hub. .......................29

Table 3.2. Hub Reactions Resulting from Aerodyanmic and Inertial Loads.......31

Table 3.3. Parameters Used to Calculate the Lift on Each Blade..........................32

Table 3.4. Load Relationships for the Flapwise Load Case. .............................37

Table 3.5. Input and Reaction Forces for the Hub Body Flapwise Load Case...38

Table 3.6. Geometric Properties for the Cross Sections of Interest....................40

Table 3.7. Loads and Stresses Due to the Flapwise Load Set. ...........................43

Table 3.8. Load Relationships for the Lead-Lag Load Case. ............................44

Table 3.9. Input and Reaction Forces for the Hub Body Analytical Analysis for the Lead-Lag Load Case. ...............................................................45

Table 3.10. Load and Stress Calculation Summary for the Lead-Lag Load Case Analytical Analysis. .................................................................47

Table 3.11. Summary of Results for the Analytical Analysis. .........................47

Table 3.12. Summary of Results for the Numerical Analysis. ..........................52

Table 3.13. Comparison of the Analytical and Numerical Stress Values. ..........53

Table 4.1. Dial Gauge Locations for the Lead-Lag and Flapwise Experimental

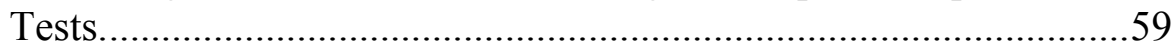

Table 4.2. Flapwise Stiffness Values for the Hub Body....................................64

Table 4.3. Structural Stiffness Values for the Hub Body during Lead-Lag Loading. 67 


\section{List of Figures}

Figure 1.1. Horizontal-axis and vertical-axis wind turbines ............................

Figure 1.2. Horizontal-axis wind turbine configurations. ............................... 3

Figure 1.3. Schematic of the AWT-26 nacelle and rotor.................................4

Figure 2.1. The Unsteady Aerodynamics Experiment.....................................12

Figure 2.2. Two-bladed hub concept variant..................................................14

Figure 2.3. Drawings of the center-clamping and box-style body principles.....16

Figure 2.4. Load paths through the box-style and center-clamping body solution principles........................................................................... 17

Figure 2.5. Photograph of the pitch actuation system. ..................................21

Figure 2.6. AWT-26 teeter-bearing assembly. ..........................................24

Figure 2.7. Centered thrust-bearing adjuster principle used in the final design. 25

Figure 2.8. Teeter damper mechanism for the AWT-26 machine......................26

Figure 2.9. Telescoping guide for the teeter dampers. .................................27

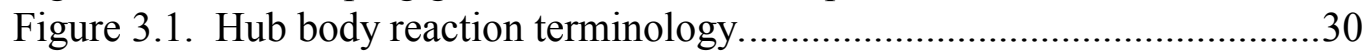

Figure 3.2. Worst-case aerodynamic scenarios. ................................................33

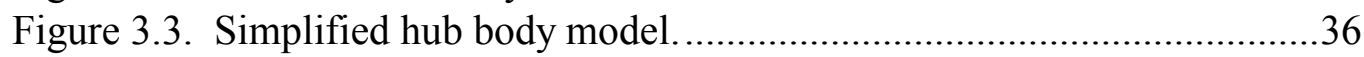

Figure 3.4. Free-body side view and front view for the flapwise load case.......37

Figure 3.5. Free-body, shear, and bending moment diagrams of the web for the

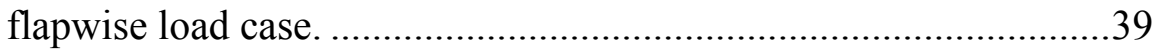

Figure 3.6. Web sections of interest for the analytical calculations. ..................40

Figure 3.7. Approximate geometry of cross section C-D.................................41

Figure 3.8. Approximate geometry of cross section A-B...............................41

Figure 3.9. Approximate geometry of cross section E-F..................................42

Figure 3.10. Free-body front view for the lead-lag case.................................44

Figure 3.11. Free-body diagram of the web for the lead-lag load case................46

Figure 3.12. Loads and boundary conditions for the finite-element analysis......50

Figure 3.13. Von Mises stress plot for the flapwise load case. ...........................51

Figure 3.14. Von Mises stress plot for the lead-lag load case............................52

Figure 4.1. Photograph of the experiment setup...............................................55

Figure 4.2. Close-up photograph of the flapwise test configuration. .................55

Figure 4.3. Close-up photograph of the lead-lag test configuration..................56

Figure 4.4. Photograph of the test stand.....................................................57

Figure 4.5. Photograph of a hard-link mount. ............................................60

Figure 4.6. Predicted and experimental deflections for the flapwise load case. 62

Figure 4.7. Predicted and experimental deflections for the lead-lag load case. 66 


\section{Introduction}

In this thesis, I describe the design, analysis, and testing of an experimental, twobladed, teetering, wind turbine hub. In this chapter, I present a brief history of wind turbine technology, an overview of modern wind turbines, and a description of the design problem.

\subsection{The History and Present State of Wind Energy}

Humans have been developing wind turbines for more than 2000 years. According to D.J. De Renzo in his book Wind Power: Recent Developments, the first wind turbines were most likely simple vertical-axis mills used to grind grain in Persia around 200 B.C. By the $11^{\text {th }}$ century A.D., windmills had spread throughout the Middle East, and by the $13^{\text {th }}$ century, returning Crusaders introduced the technology to Europe [1].

By the $14^{\text {th }}$ century, the Dutch had the leading windmill technology. The Dutch used windmills extensively to drain the marshes and lakes of the Rhine River delta. In the $16^{\text {th }}$ century, Holland began building wind-powered paper mills, oil mills, and sawmills.

By the early $20^{\text {th }}$ century, windmills were used extensively throughout the world to pump water in rural areas. This mode of water pumping is still important today for those in developing countries and for those living beyond the reach of power lines.

In the early 1980s, wind energy development in modern countries focused on generating electricity from centralized arrays of wind turbines called wind farms [2]. The high oil prices resulting from the U.S. oil crises in the late 1970s made wind farms feasible. As a result, the U.S. wind industry grew at an unprecedented rate. However, at the end of that decade, the oil crises eased and U.S. tax exemptions expired, causing the wind turbine boom to subside.

Recently, the wind industry has begun to boom again, and wind energy has become the fastest-growing energy source. According to Paul Gipe, in 1996 more than 25,000 wind turbines worldwide generated more than 7 terawatt-hours (TWh), or roughly $1 \%$ of the world's annual electricity demand. By the year 2000 , wind energy generation is expected to increase $60 \%$ to 11 TWh [3]. 
New engineering technologies have decreased the installed price of wind energy from 35 cents per kilowatt-hour (kWh) in 1980 to less than 5 cents per $\mathrm{kWh}$ today [4]. Although gas-fired turbines can produce electricity for roughly 2.5 cents per $\mathrm{kWh}$, the future of wind energy remains bright [5]. New manufacturing techniques, materials, and improved engineering technologies continue to decrease the cost of wind energy. In addition, large developing countries such as India and China have made commitments to renewable energy sources that hold great promise for the future of wind energy.

\subsubsection{Description of Modern Wind Turbines}

"Wind turbines," "wind systems," or "wind machines" are accepted terms for devices that extract power from the wind and produce mechanical or electrical power [6]. The term "wind turbine" is often reserved for machines that use rotors as wind energy collectors.

Wind turbines are classified as horizontal-axis (HAWTs) or vertical-axis turbines (VAWTs) (see Figure 1.1.) Nearly all wind turbines manufactured today are horizontal-axis. Vertical-axis machines have been plagued with bladefatigue problems. In addition, the rotors on VAWTs are typically lower than those of HAWTs. The latter positioning presents a disadvantage because the velocity of the wind decreases near the ground.

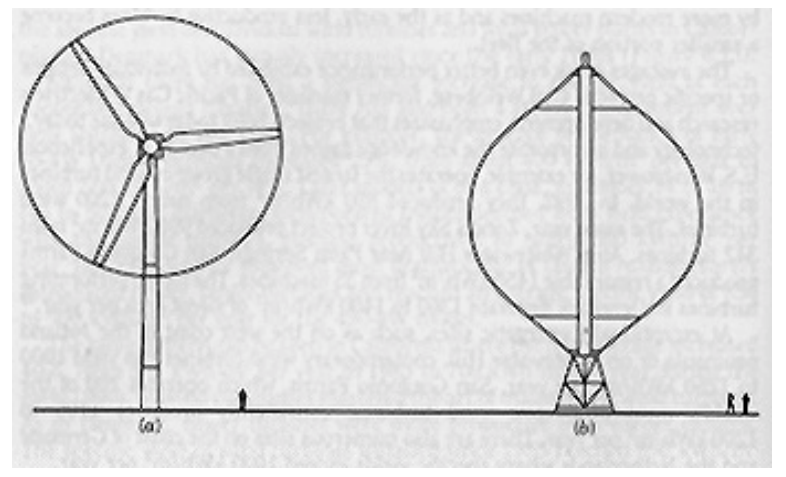

Figure 1.1. Horizontal-axis and vertical-axis wind turbines [7].

Most HAWTs have two or three blades. The blades can be oriented upwind or downwind of the tower (see Figure 1.2). Horizontal-axis wind turbines are actively or passively yawed to face the rotor into the wind. Active-yaw machines use a wind direction sensor and yaw motor to position the rotor. 
Active-yaw systems are usually used on very large machines (greater than 600 $\mathrm{kW}$ ) because active-yaw systems are more powerful and predictable.

Most small, upwind turbines (less than $100 \mathrm{~kW}$ ) are able to use a simple tail vane to maintain the proper yaw position. A common method of passively yawing 100- to $600-\mathrm{kW}$, upwind wind turbines is to use a fan mounted perpendicular to the rotor axis. The fan is connected to a yaw gear through a gearbox. The wind blows the fan until the proper yaw angle is achieved.

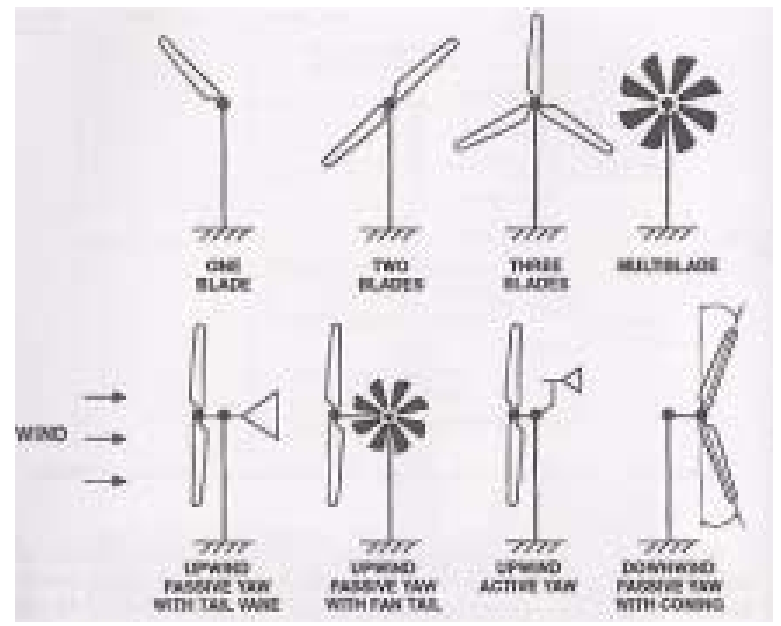

Figure 1.2. Horizontal-axis wind turbine configurations [8].

Downwind machines usually do not require a yaw-drive system because they are dynamically stable when the rotor is against the wind. Figure 1.3 is a drawing of a 275-kW, downwind, two-bladed, teetering turbine called the AWT-26, built by FloWind Corporation, a U.S. company.

The term "teetering" refers to the rotor's ability to pivot about the teeter pin like a playground seesaw. Except for the teetering components, the drive components in Figure $\mathbf{1 . 3}$ are common to most medium-to-large wind turbines. 


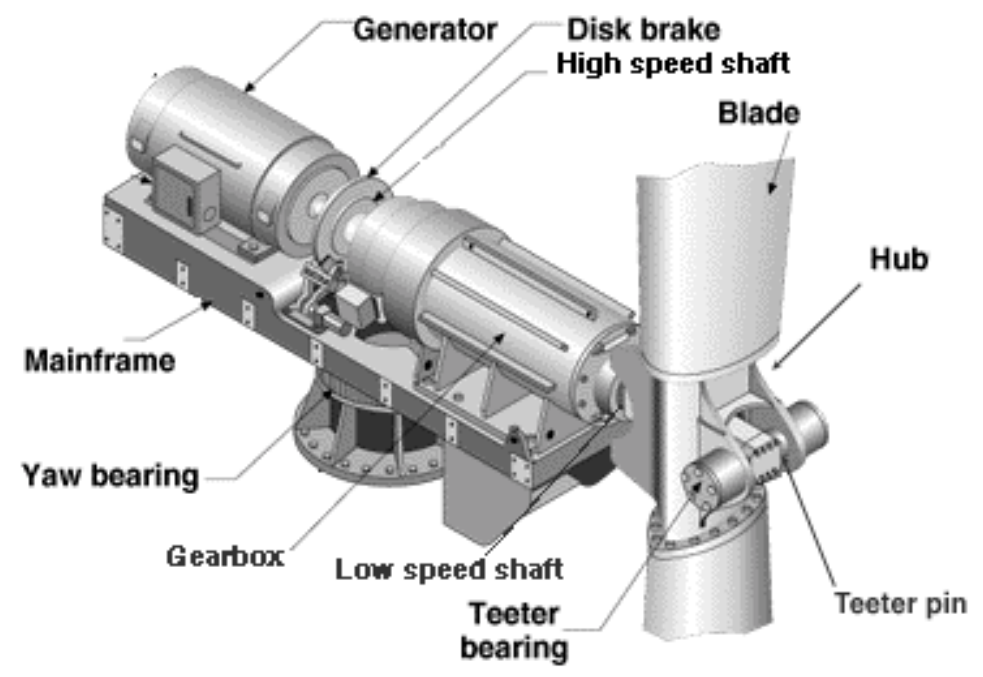

Figure 1.3. Schematic of the AWT-26 nacelle and rotor [9].

The generator, yaw assembly, and nacelle cover (not shown) are mounted to the mainframe atop the tower. The gearbox increases the angular velocity of the low-speed shaft to the synchronous speed of the generator. The disk brake on the high-speed shaft is used to stop the rotor for maintenance or emergency purposes. Although the AWT-26 has a fixed-blade pitch, many other turbines control blade pitch to regulate power.

\subsubsection{Two-Bladed vs. Three-Bladed Designs}

The most successful large turbine configurations are three-bladed upwind designs built primarily by European manufacturers. These turbines use a wind direction sensor and a yaw motor to rotate the rotor into the wind. These European turbines tend to rotate at slower velocities and are much more massive than U.S. machines.

U.S. designers tend to pursue lighter, downwind, two-bladed machines in an attempt to use materials more efficiently. Using two blades rather than three offers a significant material and weight savings. A mid-sized turbine, such as the Zond 750-kW Z-46, uses three blades, which typically weigh from 6000 to $8000 \mathrm{lb}$ each. Using fewer blades also allows designers to use lighter components such as the low-speed shaft, mainframe, and tower. 
Another advantage of two-bladed turbines is that the teetering motion greatly reduces uneven loads on the blades due to "tower shadow." Tower shadow is the increase in air turbulence as the wind flows around the tower. On downwind machines, tower shadow causes uneven loads on the blades as they rotate past the tower. Positioning a rotor downwind is advantageous because the blades can be coned downwind away from the tower. Coning the blades balances the centrifugal forces on the blades with the thrust from the wind.

Additional weight and cost savings can be made on a two-bladed, downwind rotor by making it a free-yaw machine. The latter eliminates the weight and cost of a yaw-drive mechanism. However, the behavior of such machines is often hard to predict. Some two-bladed, downwind designs have been known to "walk upwind"; that is, the machine yaws until it faces upwind.

A major disadvantage of two-bladed machines is that they are noisier. The machines must be run faster than three-bladed machines to produce the same amount of energy, and the faster rotor speeds increase blade noise. In addition, some downwind machines produce a "thumping" sound as the blades pass through the tower shadow. Many proponents of three-bladed machines argue that a three-bladed rotor is not only quieter but also more aesthetically pleasing because the rotors are more symmetric. These noise and aesthetic issues can be very important for turbines placed in high-visibility areas.

\subsection{The Need to Design an Experimental Two-Bladed Hub}

Wind turbine manufacturers can typically only afford to invest in short-term wind energy research that yields quick results (i.e., in less than five years). Most long-term wind energy research is performed at national research laboratories and universities. The National Wind Technology Center (NWTC) in Golden, Colorado, is a research facility responsible for much of the long-term wind energy research in the United States. The NWTC is a branch of the National Renewable Energy Laboratory (NREL), which is a not-for-profit laboratory that specializes in performing and managing renewable energy research for public and private clients [10].

\subsubsection{The Unsteady Aerodynamics Experiment}

One of the principal research activities at the NWTC addresses the unsteady aerodynamics and structural response of horizontal-axis wind turbines. To 
achieve this purpose, researchers at the NWTC have been performing the Unsteady Aerodynamics Experiment for the past 10 years. The experiment consists of a three-bladed, downwind, 10-meter-diameter, 20-kW wind turbine that has been modified and extensively instrumented. The instrumentation includes a special set of blades, one of which was instrumented with 155 surface-pressure taps. The data from the turbine are collected by an extensive instrumentation and data acquisition system, which simultaneously records 248 channels of data using a personal computer in a control room at the base of the tower. The data acquisition system is fastened to a boom off the front of the turbine. A video camera and lights are also mounted on the boom, and there is a camera mounted at the root of one blade [11].

A massive amount of data on three-bladed turbines has been acquired for the Unsteady Aerodynamics Experiment. However, a comprehensive database for a two-bladed machine remains to be completed.

\subsection{Project History and Scope}

In May of 1995, NREL scientists Sandy Butterfield and Jim Johnson offered me an NREL fellowship to work with NWTC engineers on the design of a twobladed hub to be installed for the Unsteady Aerodynamics Experiment. The hub was unique because it could be run in rigid, teetering, or independent bladeflapping modes. In addition, the proposed design was unusual because it would pitch the blades independently.

Butterfield and Johnson wanted to run the hub as a rigid, two-bladed machine to compare data (such as wind inflow, power production, tower structural modes, and aerodynamic structural responses of the rotating blades) to data from a threebladed machine. In addition, they sought to use the teetering and flapping modes with the independent blade pitch feature to investigate new load reduction, noise reduction, blade pitch optimization, and yaw-control techniques.

Because I had to return to the University of Texas (UT) at Austin to begin graduate school in the fall, my appointment at NREL to design the hub would only last three months. My project responsibilities included: (1) establishing reasonable input loads, (2) designing and modeling the hub, and (3) specifying the hub hardware, such as the pitch motors and bearings. The expected result of my efforts was a set of working drawings and a list of vendor-purchased components that engineers at the NWTC could use to build the hub. 
The hub construction and testing were not originally included in the scope of my tasks because of the brevity of my appointment. However, after the summer of 1995, the NWTC hired me to coordinate the construction and testing of the hub while I attended graduate school at UT. The testing and construction of the hub began in April 1996 at UT in Austin and continued through July 1996.

At the time of this writing, engineers at NREL are instrumenting and installing the hub for the Unsteady Aerodynamics Experiment at the NWTC. No fieldtesting has occurred yet. Thus, for this thesis, I did not describe the installation, instrumentation, or field-testing of the hub. 


\section{Design of the Hub}

I used a methodology based the Phal and Bietz design. This methodology, which is presented in their book Engineering Design: A Systematic Approach, provides a rational, systematic strategy for solving design problems [12]. The methodology has four major phases: (1) clarification of task, (2) conceptual design, (3) embodiment design, and (4) detailed design. I followed the Phal and Bietz methodology whenever possible; however, time and resource constraints forced me to tailor the methodology to my needs.

\subsection{Clarification of the Task Phase}

The first step in the Phal and Bietz methodology is to clarify the task; the objective of which is to identify the problem and collect information on the requirements and constraints necessary to solve the problem. These requirements and constraints are then compiled in a specifications list. The list is used throughout the design process to establish priorities needed to make design decisions.

\subsubsection{Problem Statement and Scope}

Although the problem was described in the introduction of this thesis, the problem and scope are summarized below for continuity with the Phal and Bietz design methodology.

Problem: Design a two-bladed hub for the Unsteady Aerodynamics Experiment, which features independent blade-pitch adjustment and can be run in the rigid, teetering, or flapping modes.

Scope of Design: My initial design responsibilities were primarily limited to the design, analysis, and structural bench-testing of the hub. NREL engineer Lee Fingersh designed the electrical system components, such as the servomotor, servo controller, and data acquisition equipment. Only the hub was to be modified. The NWTC requested I use the nacelle, pitch shafts, blades, and boom from the three-bladed rotor.

Scope of Testing: My project included only structural testing. The NWTC was responsible for field-testing the hub. 
Scope of Construction: One prototype hub assembly and one fully operational hub assembly were required to be built. The design was not intended to be mass-produced. The NWTC was responsible for designing and mounting the data acquisition instrumentation on the hub.

\subsubsection{Design Specifications}

After discussing the design requirements with Butterfield and Johnson, I drafted the specifications list presented in Table 2.1. The first column of Table 2.1 lists the design requirements and the second column lists the quantification for each requirement. A description of each requirement and quantification follows Table 2.1. 
Table 2.1. Hub Specifications List

\begin{tabular}{|c|c|}
\hline Requirement & Quantification \\
\hline \multicolumn{2}{|l|}{ Geometry } \\
\hline Fit on a Grumman Aerospace WS33 turbine & Not applicable \\
\hline $\begin{array}{l}\text { Fit instrumented blades used on the Unsteady } \\
\text { Aerodynamics }\end{array}$ & Not applicable \\
\hline Rotor diameter & $\begin{array}{l}\text { Same diameter as the three-bladed hub } \\
(396 \text { in }+-.5 \text { in) }\end{array}$ \\
\hline \multicolumn{2}{|l|}{ Operation } \\
\hline Design for a five-year life & 500 hrs of operating time \\
\hline Run at same rpm as three-bladed hub & $72 \mathrm{rpm}$ \\
\hline Withstand hurricane wind conditions & $144 \mathrm{mph}$ winds \\
\hline Provide a rigid operating mode & $0^{\circ}$ of play \\
\hline Provide a teetering operating mode & $10^{\circ}$ to $-10^{\circ}$ teeter range \\
\hline $\begin{array}{l}\text { Allow the machine to be modified at a later date to } \\
\text { run in a flapping operating mode }\end{array}$ & $10^{\circ}$ to $-10^{\circ}$ flap range per blade \\
\hline Allow manual cone angle adjustments & $\begin{array}{l}10^{\circ} \text { to }-10^{\circ} \text { per blade from the nominal cone angle of } \\
3.42^{\circ}\end{array}$ \\
\hline $\begin{array}{l}\text { Allow an active cone angle adjustment system to be } \\
\text { installed at a later date }\end{array}$ & Not applicable \\
\hline Allow for $120^{\circ}$ independent pitch angle adjustment & $30^{\circ} / \mathrm{sec}, 92 \mathrm{ft}-\mathrm{lbf}$ per blade, $.5^{\circ}$ backlash \\
\hline Provide generic mounts for teeter damper designs & Not applicable \\
\hline \multicolumn{2}{|l|}{ Data acquisition } \\
\hline Allow flap angle and teeter angle monitoring & within $.05^{\circ}$ resolution \\
\hline Allow for pitch angle monitoring & within $.1^{\circ}$ resolution \\
\hline $\begin{array}{l}\text { Provide a mounting location for the primary data } \\
\text { acquisition system (the boom) }\end{array}$ & Not applicable \\
\hline Time & Designed within 3 months \\
\hline Permitted cost of the design and construction & Approximately $\$ 100,000$ \\
\hline
\end{tabular}

Geometry Specifications: As listed in Table 2.1, the hub had to be mounted on a vintage WS33 wind turbine built in the 1980s by Grumman Aerospace. The NWTC planned to remove the three-bladed hub on the turbine and replace it with the two-bladed hub.

The two-bladed hub had to be compatible with the custom-built blades on the Unsteady Aerodynamics Experiment. The Unsteady Aerodynamics Experiment uses a standard Grumman WS33 hub, but the pitch shafts were modified to fit the custom blades. 
The diameter of the two-bladed rotor was required to be within .5 in of the threebladed rotor when coned at the same angle $\left(3.42^{\circ}\right)$. This similarity permits easy comparison of the two-bladed data with the three-bladed data.

Performance Specifications: The Unsteady Aerodynamics Experiment turbine is used solely for research purposes. The turbine is run only with an operator present. Lee Fingersh estimated that the three-bladed hub had been run for only 50 hours in the past three years. In light of this estimate, the specification that the two-bladed hub be designed to withstand 500 hours of operation over five years is conservative.

The NWTC site has seasonal winds at speeds upwards of 100 miles per hour (mph). Butterfield requested that the hub be designed to withstand hurricaneforce winds of $144 \mathrm{mph}$. Butterfield requested that the hub be designed so that it could be modified at a later date to run with independently flapping blades.

The NWTC required that the hub have generic mounts for teeter dampers so that the different dampers could be tested. In addition, the generic mounts were necessary to give the NWTC the option to install an active blade-flapping system or to run the turbine as a rigid two-bladed machine.

The blades were required to have a $120^{\circ}$ pitch-angle adjustment. Furthermore, the pitch actuators needed to provide $92 \mathrm{ft}-1 \mathrm{bf}$ of torque at angular velocities up to $30^{\circ}$ per second on each blade. This angular velocity is high compared to that of most wind turbines. For example, in the three-bladed Unsteady Aerodynamics Experiment, the rotor pitches the blades at approximately $10^{\circ}$ per second [13]. The motivation for specifying these fast velocities was to have the potential to actively adjust the pitch angle during turbine operation to reduce the effects of turbulent wind loads.

The three-bladed hub has a $3.42^{\circ}$ cone angle. (Each blade is rotated downwind $3.42^{\circ}$ from the rotor plane of rotation.) Coned blades are used to balance the moment created by the centripetal load on the blades with the moment caused by the wind. The Unsteady Aerodynamics Experiment data indicate that, at $3.42^{\circ}$, these moments cancel at wind speeds of approximately $20 \mathrm{mph}$. The Specifications required that the two-bladed hub cone angle be manually adjustable over a range of $10^{\circ}$ to $-10^{\circ}$ from the nominal cone angle of $3.42^{\circ}$. In addition, engineers at the NWTC wanted the option to install a system at a later date that would adjust the cone angle while the turbine is operating. 
Data Acquisition Specifications: The NWTC engineers planned extensive instrumentation for the hub. They requested that I leave room to mount optical encoders used to measure the blade-flap angles and the blade-pitch angles. In addition, I had to provide a means for them to mount a 353-lb tripod boom to hold the data acquisition system, video camera, and lights (see Figure 2.1)[14].

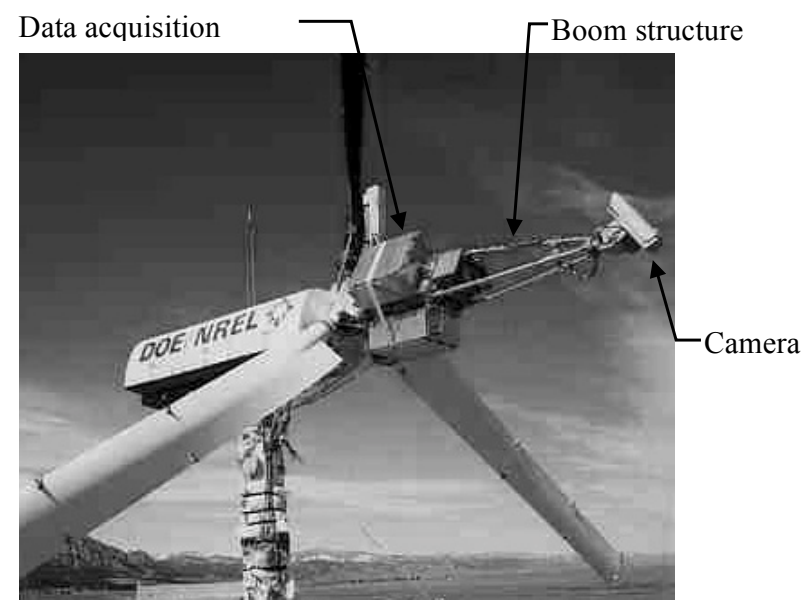

Figure 2.1. The Unsteady Aerodynamics Experiment.

Cost Specifications: NREL needed only one fully operational two-bladed hub. This task was small relative to the Unsteady Aerodynamics Experiment budget. Thus, extensive cost calculations were deemed unnecessary. The total budget for the design labor, materials, and construction was approximately $\$ 100,000$, which did not include the cost of installing and testing the turbine.

\subsection{Conceptual Design Phase}

I began the conceptual design of the hub by identifying the function(s) of each hub component (see Table 2.2). The next step was to create solution principles for each function. According to Phal and Bietz, solution principles are possible methods of performing a function [15]. For example, the function of the pitch actuation system is to rotate the pitch shaft. For this function, I decided to use a linear mechanical actuator, a linear hydraulic actuator, or a servomotor. 
Table 2.2. Hub Components and Their Functions

\begin{tabular}{|l|l|}
\hline \multicolumn{1}{|c|}{ Hub Component } & $\begin{array}{l}\text { Transfers the loads from the blades and dampers to the low- } \\
\text { speed shaft; positions the barrels, teeter dampers, and hard } \\
\text { link }\end{array}$ \\
\hline Pitch actuation system & Rotates the pitch shafts to the desired blade-pitch angle \\
\hline Cone angle control system & Maintains the desired cone angle \\
\hline Teetering hinge and bearings & Provides an axis for teetering or flapping \\
\hline Thrust-bearing adjuster & Locates the hub body on the teeter pin \\
\hline Teeter damper mounts & $\begin{array}{l}\text { Provides mounts for the teeter dampers, teeter hard link, } \\
\text { and flap actuators }\end{array}$ \\
\hline
\end{tabular}

After finding solution principles for each function, the next step in the Phal and Bietz methodology is to systematically combine these principles to create one or more concept variants. A concept variant is a solution to the overall problem. I did not have time to investigate all possible combinations of solution principles as recommended by Phal and Bietz. Instead, I used a system of elimination and preference to create one concept variant. This concept variant is presented in Figure 2.2. I describe the solution principles, their selection, and the resulting concept variant in the following sections. 


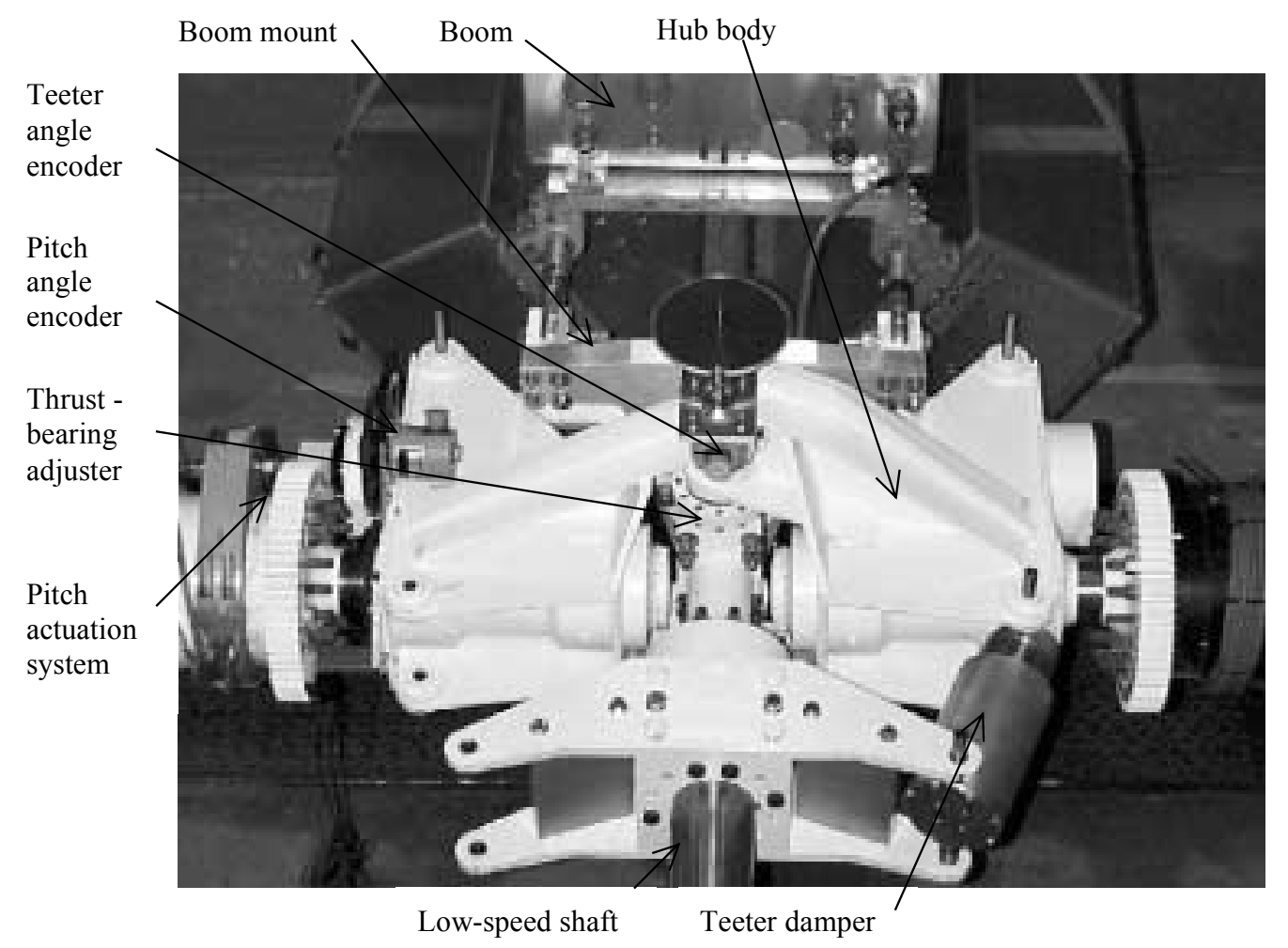

Figure 2.2. Two-bladed hub concept variant.

\subsubsection{Hub Body Solution Principles}

I refer to the main load-bearing assembly as the hub body. The primary function of the hub body is to transfer the loads from the blades to the low-speed shaft. The hub body also provides a mount for the teeter dampers, hard link, and boom. My goal for the hub body was to design an easily manufactured structure that could withstand high wind loads and be readily modified to fit different instrumentation.

My highest priority was to ensure that the hub would be rigid enough to withstand the specified loads. Thus, the primary criterion I used to evaluate the hub body principles was what Phal and Bietz called the "principle of direct and short force transmission path." This principle states the following: "If a force or 
moment is to be transmitted from one place to another with the minimum possible deformation, then the shortest and most direct force transmission path is the best" [16]. This principle helped ensure that I chose a structure that minimized the use of materials and deformation of the hub.

The secondary criterion I used was "modification flexibility," which refers to the degree a component can be modified after construction. For example, a hub body that accepts several different types of teeter damper mechanisms, or which provides many faces to attach instrumentation, has a high degree of modification flexibility.

The final criterion I used to qualify principles was the ability to manufacture the design. I eliminated hub solution principles that the NWTC could not feasibly make and I gave preference to designs that were easily fabricated. For example, weldments were preferred to castings because the materials and equipment required to make a weldment were readily available.

The specifications required that the two-bladed hub use the same blades, pitch shafts, and pitch-shaft-bearing assemblies in the same positions as the threebladed hub. To create solution principles for the hub body, I drafted a scale drawing that included only these components in their proper positions. I then used the drawing to sketch methods of transferring the wind loads to the lowspeed shaft. I reviewed and modified these sketches with Sandy Butterfield and Jim Johnson to help eliminate impractical solutions, modify existing principles, and derive other solution principles.

I divided the hub body solution principles into two categories: the "centerclamping body" principles and the "box-style body" principles (see Figure 2.3). The distinguishing feature of the box-style body is that the low-speed shaft attaches to a box that holds the teeter pin at each end. In the center-clamping body principle, the teeter pin is clamped to the low- speed shaft at the center of the teeter pin. 


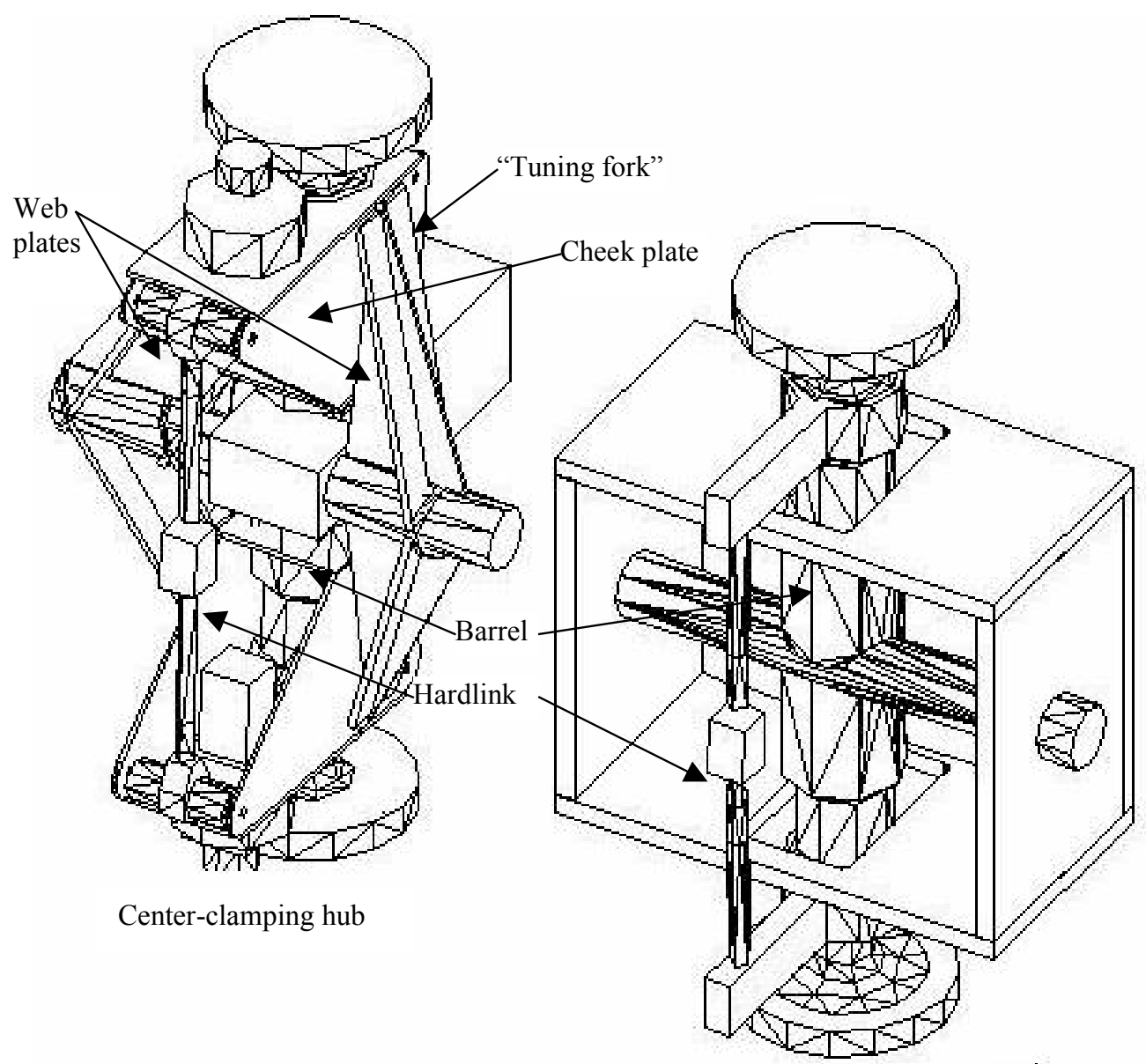

Box-style hub

Figure 2.3. Drawings of the center-clamping and box-style body principles.

\subsubsection{Box-Style Body}

The box-style body principle was appealing because it had many flat faces to attach instrumentation and was easily fabricated. It also provided an easy mount for the boom on the front of the box. The barrels, teeter pin, and teeter dampers were also relatively easy to mount.

The box-style principle was the first practical hub body principle Johnson, Butterfield, and I created. Although the box-style body principle adequately fulfilled the specifications, it had an indirect load path that resulted in a heavy and bulky design. 
The load path in this principle originates at the blades, runs through each barrel, into the teeter pin, and around each plate to the low-speed shaft (see Figure 2.4). Because I was adhering to the Phal and Bietz "principle of direct and short force transmission path," I decided to design a body with a lighter, more efficient means of transferring the loads from the teeter pin to the low-speed shaft.

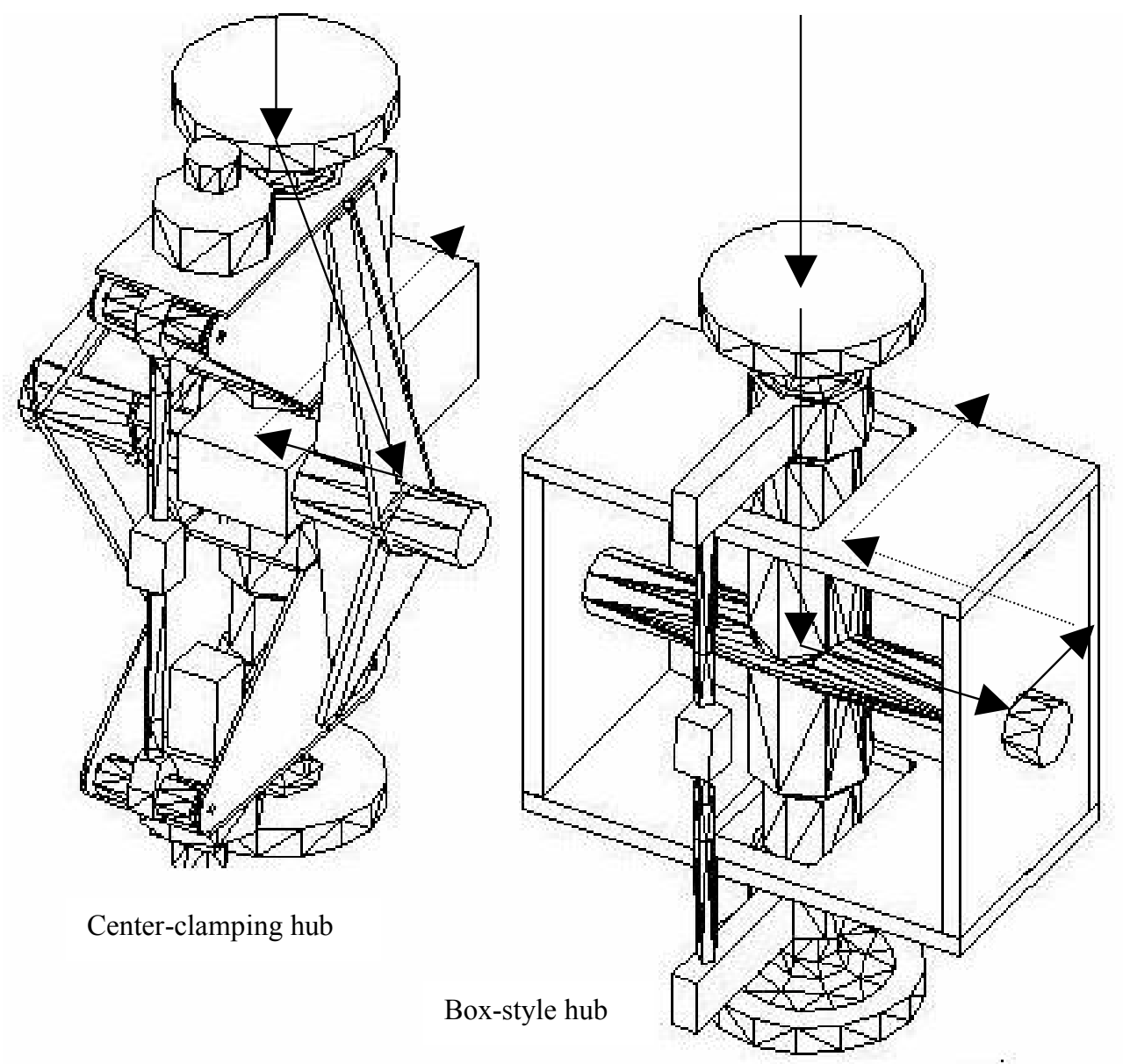

Figure 2.4. Load paths through the box-style and center-clamping body solution principles. 


\subsubsection{Center-Clamping Body}

The next practical principle developed was the center-clamping body principle. In this principle, the hub clamps the teeter pin at the teeter pin center. The primary reason I chose this configuration, rather than the box-style principle, was that it resulted in a more direct load path. In the center-clamping principle, the loads originate at the blades, travel through the barrel to the hub body, into each end of the teeter pin, and down the center of the hub directly to the lowspeed shaft. This load path is more rigid in transmitting the rotor operating torque and the braking and gravity loads.

I considered several construction methods to build the center-clamping principle. The strongest construction would most likely have been a casting. A casting would have allowed a direct load path with no sharp transitions. This cost could not be justified because only one hub would be built.

Another construction option was to build a weldment. I determined that a weldment could be made nearly as strong as a casting but at a reasonable cost. In the weldment design, I tried to position a plate in each of the primary load directions. The side webs on the hub body, or what I termed "web plates" (see Figure 2.3), transfer the moments in the rotor plane directly to the teeter pin and resist the centripetal loads. I strengthened the webs against buckling by welding "tuning forks" to them. The tuning forks also help transfer loads to the teeterbearing housings and resist the bending moments that are out of the rotor plane.

I briefly considered variations on the plates principle. The principle I most seriously considered used mechanical steel tubing in place of the web plates, with the idea that a thick- walled tube would be resistant to any buckling to which the plates might be subjected. The tube would also have better resisted the torsion loads from teeter impacts. I chose not to develop this variation because it would have been difficult to miter the mechanical steel tubing to the teeter pin and the barrels.

One principle that I overlooked during conceptual design was machining the entire hub from billet aluminum using computer numerically controlled (CNC) machines. This idea was suggested to me at the end of the design process by the machine shop manager at The University of Texas Center for Electromechanics, Murel O’Neal. 
O'Neal believed that milling the entire assembly from one piece might be easier and cheaper than machining, jigging, and welding the many plates. Another advantage was that a billet structure would have resulted in a stiff geometry very similar to that obtained from the casting principle. The structure might have had strength advantages over a casting in that it could be have been made from highstrength aluminum. In addition, the less-dense aluminum would have permitted the use of a high moment of inertia structure without a severe weight penalty. One disadvantage of using aluminum is that it is more difficult to weld. Therefore, any field modifications to the hub that required welding would be hard to make. Despite this disadvantage, I felt this fabrication technique was a viable option that should be considered in future designs.

I encountered a difficulty with the center-mounting hub principle halfway through the embodiment design stage. The difficulty stemmed from my assumption that the boom could be mounted on the hard link, the rigid link between the two barrels used when running the turbine in a teetering mode (see Figure 2.4). During the conceptual design stage, I overlooked the fact that mounting the boom on the hard link makes a variable coning system nearly impossible to implement. In light of this discovery, I decided that the boom must mount rigidly to the low- speed shaft off the end of the teeter pin cap.

Although mounting the boom off the teeter pin cap alleviated the variable coning system conflict, this new mounting location created a new problem: the same bolts used to mount the teeter pin also had to support the boom. This additional load on the teeter pin cap bolts reduced the safety factor against exceeding the bolt-clamping force from ten to five. These bolts are critical because the entire rotor and boom will fall off if they fail.

The size of the teeter-pin cap bolts could not be increased because the space between the barrels was relatively small. This space was limited by the rotor diameter constraint. So, to prevent a catastrophic failure of the teeter-pin bolts, I specified that high-strength bolts (above Society of Automotive Engineers [SAE] Grade 8) be used to fasten the teeter cap. In addition, I specified that the bolt strain be measured with a micrometer during installation to ensure proper pre-load. I also specified that the bolt lengths be measured at specified intervals to ensure that the pre-load is maintained.

If I had anticipated this change earlier in the design process, I could have taken several actions. One option would have been to use a longer teeter pin, which 
would have allowed me to use a longer teeter-pin cap with more bolts in it. I also could have requested that the NWTC allow me to increase the rotor diameter 1 inch. The larger rotor diameter would have permitted me to use larger teeter-pin cap bolts. Finally, I could have developed the box-style body further before committing to the center-mounting hub. The box-style body was much more conducive to mounting the boom.

\subsubsection{Pitch Actuator Solution Principles}

The specifications required that the blade-pitch system rotate each blade independently with $92 \mathrm{ft}-\mathrm{lbf}$ of torque at $15^{\circ}$ per second. One common method of pitching blades is to drive a rod from the nacelle through the center of the low-speed shaft. The linear motion of the rod is converted to rotational motion of the blades via a linkage at the base of each blade. The three-bladed hub on the Unsteady Aerodynamics Experiment uses this push-rod system. However, this system was not suitable for the two-bladed hub because the teetering and blade-flapping motions complicated the push-rod linkage design.

Another method of pitching the blades is to use actuators mounted on the hub to pitch the blades. The actuators are usually hydraulic or electromechanical. The primary advantages of hydraulic systems are that they are easy to regulate and are capable of producing large pitching moments. A disadvantage is that the hydraulic equipment, such as pumps, regulators, and actuators, must all be mounted on the rotating hub. Thus, only large wind turbines have room to use hydraulics.

I decided not to use a hydraulic system to pitch the blades because I did not have space to mount the hydraulic equipment on the hub. In addition, the cost and complexity of a hydraulic system was difficult to justify for such a small wind turbine.

An electromechanical actuator was much easier to fit. I decided to use a $.75 \mathrm{ft}-$ lbf (peak) servomotor and spur gear assembly mounted at the base of each blade for pitch actuation (see Figure 2.5). In addition to the 4:1 spur gear ratio, I attached a 100:1 gear head to each servomotor. The resulting 400:1 gear ratio should output a peak torque on the blades of roughly $300 \mathrm{ft}-\mathrm{lbf}$ at speeds up to $68^{\circ}$ per second with less than $.3^{\circ}$ of backlash. This predicted performance exceeds the torque specifications threefold and the backlash and speed specifications roughly twofold. 
Servomotors were chosen rather than simpler DC motors because of their selfcorrecting ability. That is, if one of the motors is forced from a specified angular position, the servo controller senses the error and signals the motor to return to the specified position.

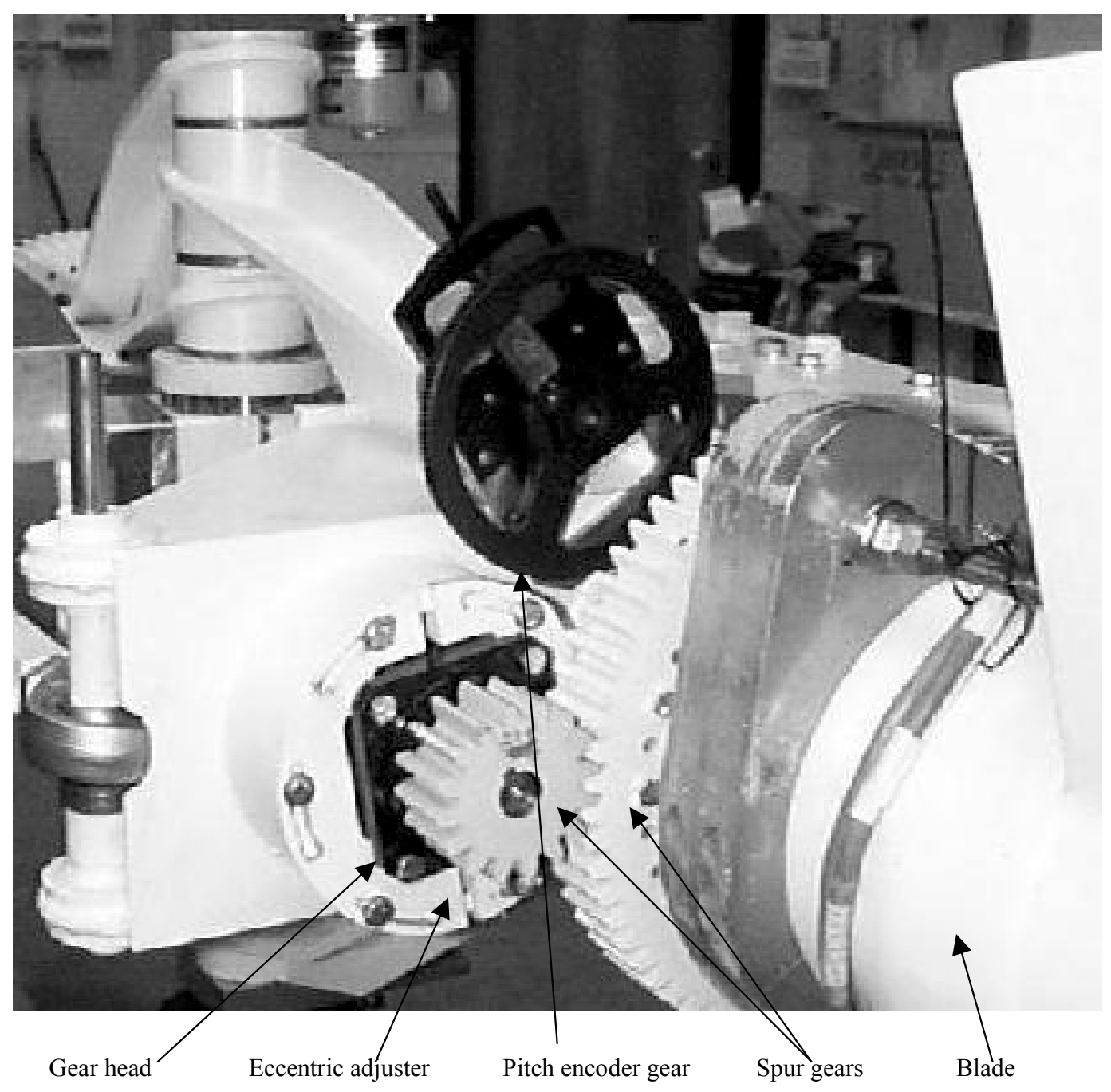

Figure 2.5. Photograph of the pitch actuation system. 


\subsubsection{Cone Angle Linkage Solution Principles}

The three-bladed hub has a $3.42^{\circ}$ cone angle (each blade is rotated $3.42^{\circ}$ from the rotor plane of rotation). The specifications required that the two-bladed hub cone angle be manually adjustable over a range of $10^{\circ}$ to $-10^{\circ}$ from the nominal cone angle of $3.42^{\circ}$. In addition, the NWTC wanted the option to later install a system to adjust the cone angle actively and a system to flap the blades independently.

The simplest way to manually adjust the cone angle was to install a link between the two barrels. I called this link the "hard link." The length of the hard link determines the cone angle. The link is made from a turnbuckle with rod ends at each end so that the angle would be easy to adjust manually. The two-bladed hub can be positioned at cone angles $-9^{\circ}$ to $23^{\circ}$ from the plane of rotation. Beyond this range, the hub body impacts the low-speed shaft or the boom mount.

The hard link is designed so that the turnbuckle can be replaced with a hydraulic or electromechanical actuator. Inserting an actuator into the hard link allows the coning angle to be adjusted while the turbine is running. To run the turbine in an independent blade-flapping mode, the hard link can be removed and the dampers can be replaced with actuators.

I designed the hard link to accommodate a 10,000-lbf force sensor. The force sensor will help measure the thrust loads on the blades. In addition, the force sensor data will help size actuators for the active coning and independent bladeflapping systems. Based on Unsteady Aerodynamics Experiment data, I anticipate the force sensor will measure approximately $2000 \mathrm{lbf}$ in $45-\mathrm{mph}$ winds.

\subsubsection{Teeter-Bearing Solution Principles}

Needle bearings, bronze journal bearings, and composite bearings have all been used as teeter bearings on previous machines. Needle bearings often wear out prematurely on wind turbines because the teeter angles are too small to rotate each needle bearing one full revolution. As a result, the bearings do not receive adequate lubrication, which causes premature bearing failure. 
I chose to use filament-wound, composite GAR-MAX bearings made by Garlock Bearings, Inc. GAR-MAX bearings have a bearing surface liner of wound poly-tetrafluoroethylene (PTFE) and high-strength fibers encapsulated by an epoxy resin. The PTFE liner permits the bearings to be run without oil or grease. I chose to use GAR-MAX bearings because Garlock claims that they are superior in applications "where the relative motion is not sufficient to promote circulation of the oil or grease used with more conventional bearings" [17]. In addition, GAR-MAX bearings are designed for high-load, low-speed applications in which shock loads are encountered. Shock loads may be induced in the teeter bearings during teeter impacts.

The teeter bearings have a 2-in inside diameter. Each half of the hub uses one 3in-long bearing and two 2 -in-long bearings. The load each bearing will be subjected to in $45-\mathrm{mph}$ winds is roughly $800 \mathrm{lbf}$. The pressure resulting from this load is very small (160 psi) compared to the dynamic capacity of the bearings $(20,000 \mathrm{psi})$. The manufacturer predicted the bearings will last 2500 hours without lubrication if they are properly sealed from contaminates such as sand and dust and 600 hours in light dust conditions. According to specifications, the hub should last 500 hours. I chose not to seal the bearings because of the complexity the seals would add.

\subsubsection{Thrust-Bearing Solution Principles}

The thrust bearings support the hub when the blades are positioned horizontally. I considered two principles for the thrust-bearing adjuster. The pre-load on the thrust bearings could either be adjusted from the end or from the center of the teeter pin. The "end-adjuster" principle is used on the AWT-26 design (see Figure 2.6). On the AWT-26, the thrust bearing on each side of the hub is forced against the end of the teeter pin with the end cap. In this manner, the hub position is fixed on the teeter pin. 


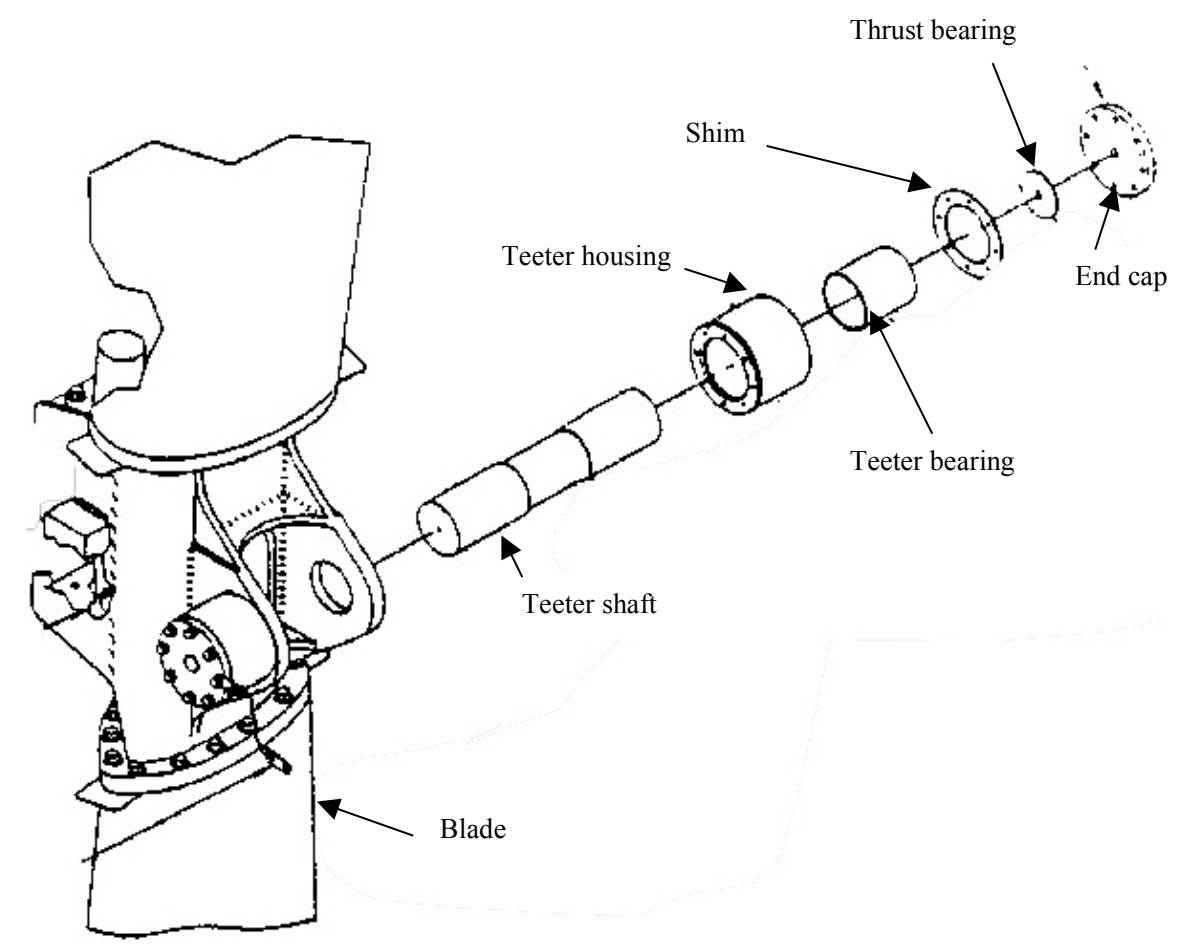

Figure 2.6. AWT-26 teeter-bearing assembly [18].

I chose to use a variation of the end-adjuster principle (see Figure 2.7). My design uses thrust-bearing adjusters, which are metal rings tapped for ten 3/8-indiameter set screws. The set screws press against the teeter pin cap to force the inboard journal bearing housings outboard. When the hub is positioned as shown in Figure 2.7, the weight of the hub and both blades (roughly $650 \mathrm{lbf}$ ) rests on the inboard thrust bearing, which lies on the upper adjuster.

Although neither thrust-bearing adjuster principle has a significant advantage, I chose to implement the center adjuster principle. I chose this principle so that I could mount an optical encoder on each end of the teeter pin to monitor the blade-flap angle. 


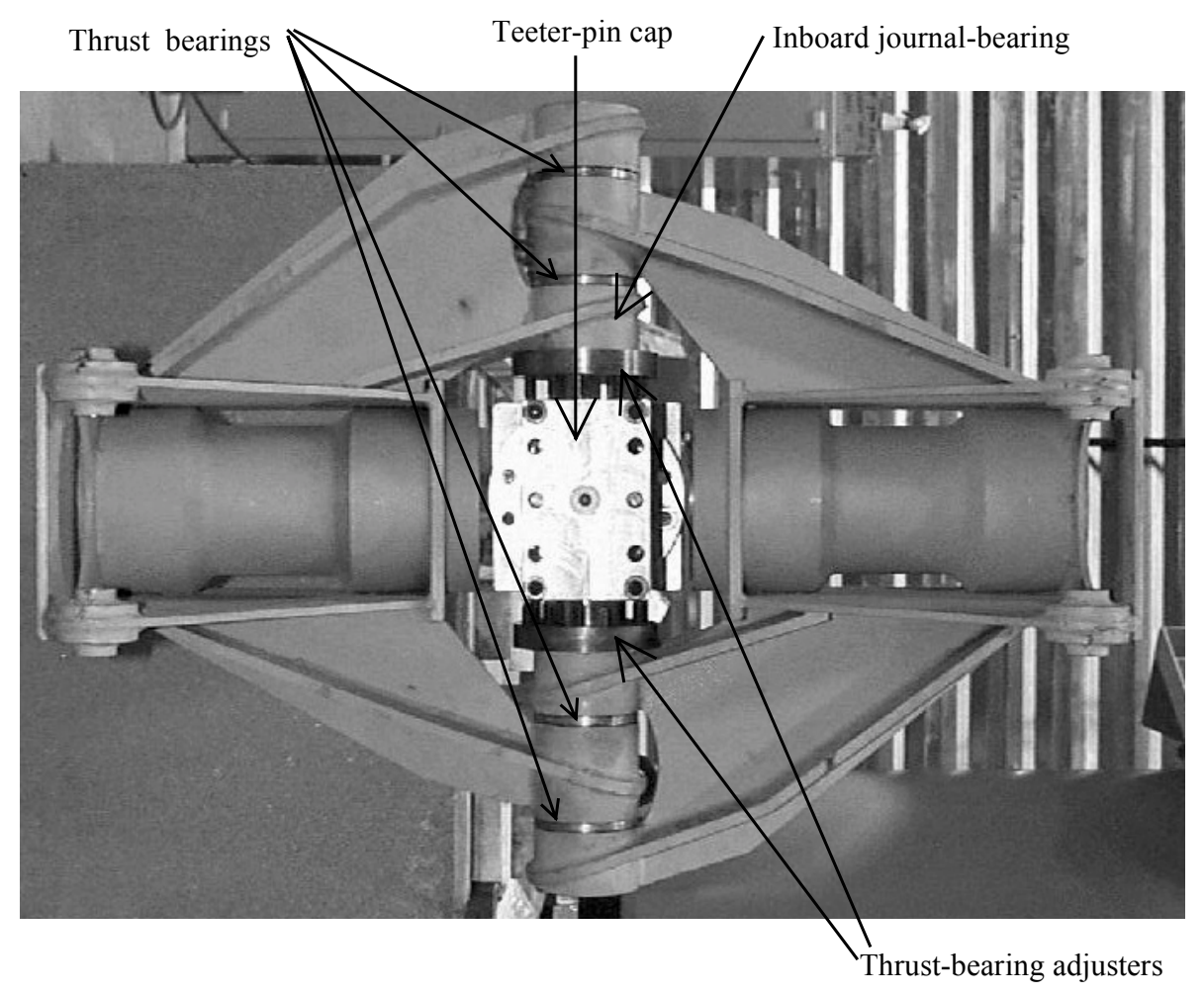

Figure 2.7. Centered thrust-bearing adjuster principle used in the final design.

In my design, the surface area of each thrust bearing is $3.387 \mathrm{in}^{2}$. Thus, the peak pressure in the thrust bearings is approximately 200 pounds per square inch (psi). The thrust bearings are made from SAE 1018 steel discs. They were greased during installation. According to Mark's Standard Handbook for Mechanical Engineers, 2000 psi is a safe pressure for hardened-steel collars on bronze rings during intermittent service [19]. Although I used greased, SAE 1018 steel rings instead of bronze, the pressure on the rings is an order of magnitude lower than 2000 psi. Thus, I anticipate the SAE 1018 steel bearings will withstand the 500-hour life specification.

\subsubsection{Teeter Damper Solution Principles}

The specifications called for a teeter damper mount, which is compatible with a variety of dampers. These mounts permit the NWTC to test different dampers. We considered using oil-filled dampers and elastomeric dampers. I chose to use elastomeric dampers made by Jarret Inc. because they are more compact and durable than oil-filled dampers. 
The generic damper mounts were also designed to give the NWTC the option to install an active flapping system or a rigid link in place of the dampers. The link would enable the hub to be run as a rigid two-bladed machine.

The AWT-26 machine has a solidly mounted teeter damper, which is activated through a sliding motion (see Figure 2.8). Experience with the AWT-26 machine has shown that the side loading of the teeter damper piston should be avoided if possible because it causes premature damper failures.

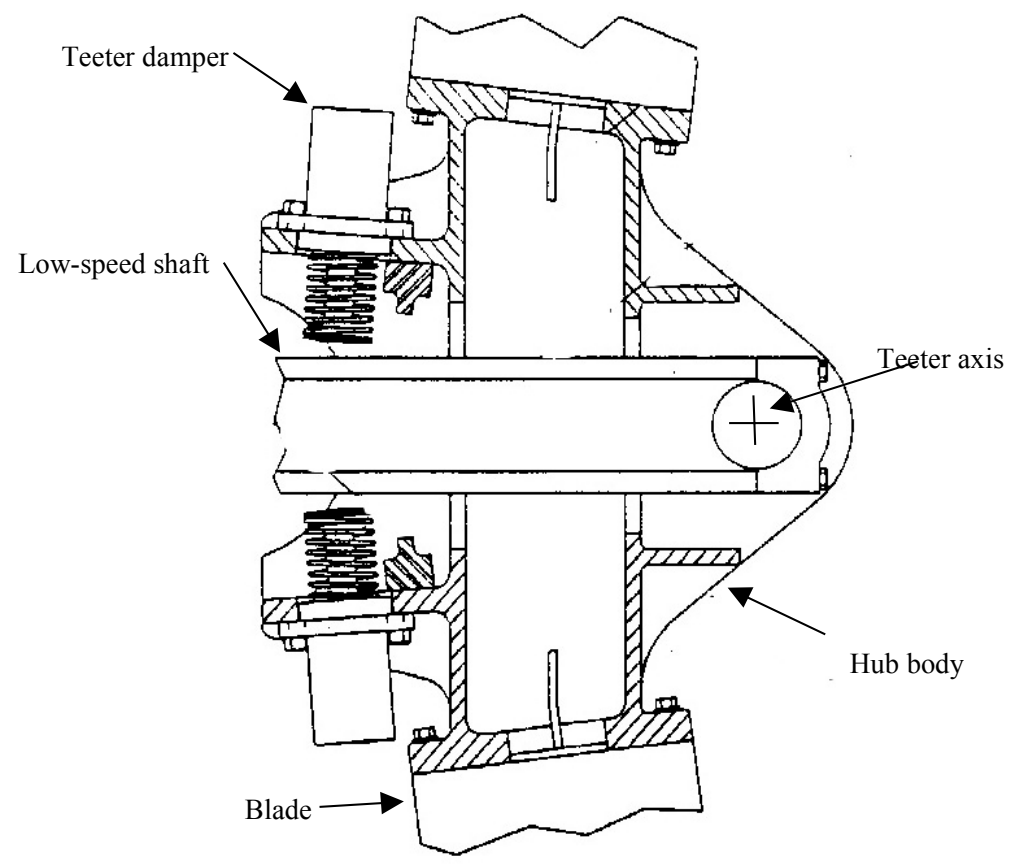

Figure 2.8. Teeter damper mechanism for the AWT-26 machine.

In my design, I used pins to support the damper at each end. Using pins at each end minimized the damper side loading because they limited loading to tension and compression.

To pin the damper at each end, I designed a telescoping guide for the damper. The damper guide I designed is presented in Figure 2.9. On one side of the guide, the damper fits inside a stainless-steel tube with an outside diameter of 3.5 in. The other side of the guide consists of a 4-in ID bronze journal bearing inserted into an aluminum sleeve. The Jarret damper impacts a 10,000-lbf 
button force sensor that is mounted to the end of the aluminum sleeve. The button force sensor will measure the magnitude of the teeter impacts. I estimated the magnitude of the teeter impacts using a numerical simulation code called YAWDYN. Using this code, I predicted that the most severe teeter impact will result in $7120 \mathrm{lbf}$ of compression on the damper.

My main concern when designing the telescoping guide was to ensure that it would not cock when it was fully extended. To prevent the guide from cocking, I designed the guide so that the journal bearing and stainless-steel tube had as much overlap as possible when the guide was fully extended. In addition, I positioned the damper assembly so that its cylindrical axis is tangent to the teetering motion of the hub when the guide is fully extended. As an added precaution, I had the inside diameter of the journal bearing and the outside diameter of the stainless-steel tube precision-ground to ensure the sliding surfaces are round and that they have a minimum running clearance $(0.0013 \mathrm{in})$.

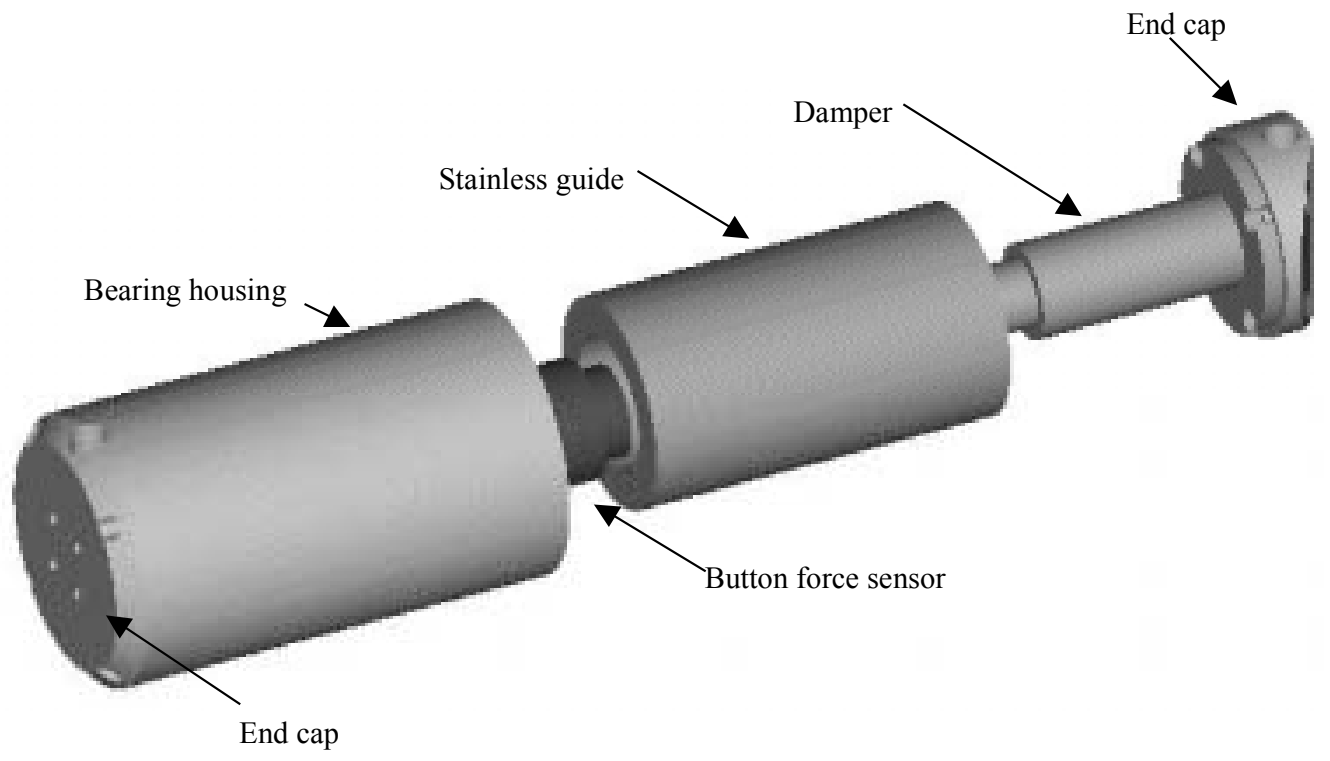

Figure 2.9. Telescoping guide for the teeter dampers. 


\subsection{Embodiment and Detailed Design Phases}

In the embodiment design stage, the designer develops the chosen concept variant. The steps of embodiment design include creating and selecting preliminary layouts, refining the preliminary layouts to form detailed layouts, and then evaluating the detailed layouts against the technical and economic criteria. The details of the embodied design are then finalized in the detailed design stage so that production of the part may begin.

I only had enough time to make one preliminary layout. I drafted an orthographic drawing of the selected concept variant using AutoCAD R12. I used this layout to perform analytical calculations on the strength and performance of the hub. For example, I calculated the necessary diameters of bolts, the thickness of the plates on the hub body, and the size of the blade-pitch servomotor.

Once I was confident that the chosen concept would work, I developed a cardboard model of the hub body. This model was extremely useful in reviewing my work with Butterfield, Johnson, and Fingersh, allowing us to identify changes that would increase the strength of the hub body, the ability to manufacture the hub body, and the ability to instrument the hub.

After I made these changes, I spent one week performing analytical stress and strain calculations on the hub body and its components. (The results of these calculations are presented in Chapter 3.) After confirming the structural integrity of the hub body, I drafted working drawings and presented the design to the entire NWTC.

I oversaw the construction and testing of the hub prototype at The University of Texas at Austin Center for Electromechanics under the supervision of professor Weldon. The prototype was used to correct errors in the working drawings and test the structural integrity of the hub before constructing the final assembly. The results of this testing are presented in Chapter 4. 


\section{Predicted Strength of the Hub Body}

The hub components and systems I analyzed are listed in Table 3.1. In this thesis, I focus on the hub body because it was the most difficult component to analyze. I predicted the structural integrity of the hub body during the conceptual design phase using closed-form analytical calculations. After the hub was built, I performed a numerical finite-element analysis as an academic exercise. I did not perform the numerical analysis during the conceptual design phase because I had little experience with finite-element analysis software then.

In this chapter, I present the analytical (closed-form) and numerical (finiteelement analysis) results for the hub body. Section 3.1 describes the loads I used in the analyses. Section 3.2 presents the analytical results, and Section 3.3 presents the numerical results. I compare the numerical and analytical results in Section 3.4.

Table 3.1. List of Primary Calculations Performed on the Hub

\begin{tabular}{|l|l|}
\hline \multicolumn{1}{|c|}{ System } & \multicolumn{1}{c|}{ Calculations Performed } \\
\hline Teeter pin & Analytical stress calculations \\
\hline $\begin{array}{l}\text { Adapter, teeter pin cap, servomotor cap } \\
\text { bolts }\end{array}$ & Analytical stress calculations \\
\hline Pitch shaft & Analytical stress calculations \\
\hline Hub shaft & Analytical stress calculations \\
\hline Damper plates & Analytical and numerical calculations \\
\hline Teeter pin journal bearings & Analytical lifetime calculations \\
\hline Hub body & $\begin{array}{l}\text { Analytical, numerical, and experimental } \\
\text { calculations }\end{array}$ \\
\hline Boom mount & Analytical stress calculations \\
\hline Damper and hard-link bolts & Analytical and experimental stress calculations \\
\hline
\end{tabular}

\subsection{Wind Turbine Input Loads}

I considered aerodynamic, inertial, and gravitational effects on hub body. The loads these effects have on the hub are generally referred to as thrust load, radial load, lead-lag moment, and flapwise moment (see Figure 3.1). The load cases I considered and the induced loads are presented in Table 3.2. The derivations of these loads are discussed below. 


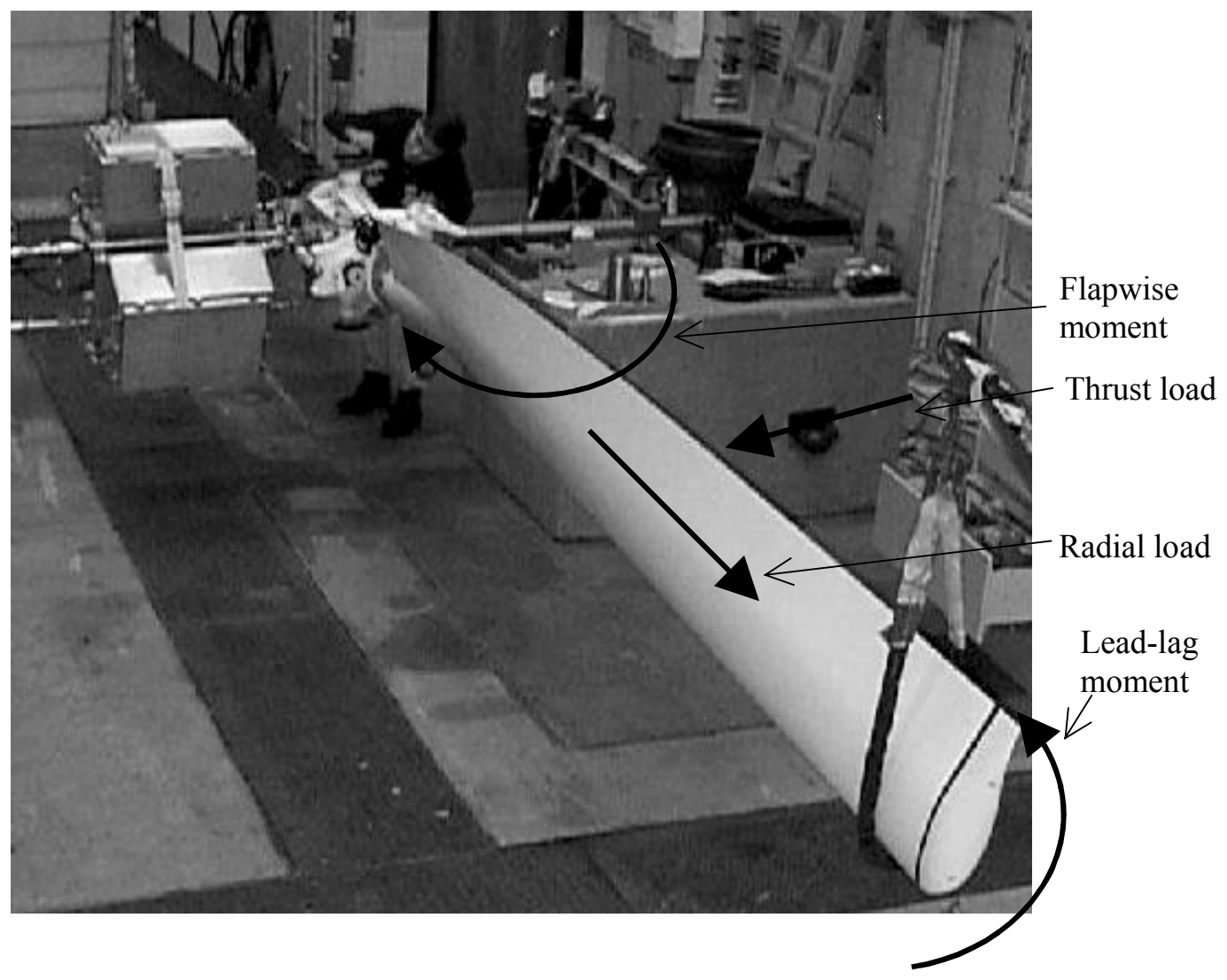

Figure 3.1. Hub body reaction terminology. 
Table 3.2. Hub Reactions Resulting from Aerodyanmic and Inertial Loads

\begin{tabular}{|c|c|c|c|c|c|c|c|}
\hline \multirow[t]{2}{*}{ Hub Reaction } & \multicolumn{4}{|c|}{ Aerodynamic Load Scenarios } & \multicolumn{3}{|c|}{ Inertial Load Scenarios } \\
\hline & 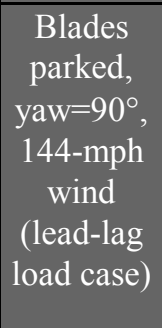 & $\begin{array}{c}\text { Blades } \\
\text { parked, } \\
\text { yaw }=0^{\circ}, \\
144-\mathrm{mph} \\
\text { wind } \\
\text { (flapwise } \\
\text { load case) }\end{array}$ & $\begin{array}{l}\text { One blade } \\
\text { feathers } \\
\text { during } \\
\text { operation } \\
\text { (pitch- } \\
\text { failure } \\
\text { load case) }\end{array}$ & \begin{tabular}{|c|} 
Data from \\
three- \\
bladed \\
hub \\
operating \\
in \\
45 -mph \\
winds
\end{tabular} & $\begin{array}{c}\text { Centripetal } \\
\text { force at } \\
90 \mathrm{rpm}\end{array}$ & \begin{tabular}{|c|} 
Emergency \\
stop
\end{tabular} & $\begin{array}{l}\text { Teeter } \\
\text { impact }\end{array}$ \\
\hline $\begin{array}{l}\text { Flapwise } \\
\text { moment per } \\
\text { blade (ft-lbf) }\end{array}$ & - & 17957 & - & 3333 & - & 1000 & 8900 \\
\hline $\begin{array}{l}\text { Lead-lag } \\
\text { moment per } \\
\text { blade (ft-lbf) }\end{array}$ & 17957 & - & 17957 & 3333 & - & - & - \\
\hline $\begin{array}{l}\text { Torque on the } \\
\text { hub (ft-lbf) }\end{array}$ & - & - & 17957 & - & - & 2000 & - \\
\hline $\begin{array}{l}\text { Thrust on each } \\
\text { blade (lbf) }\end{array}$ & 1907 & 1907 & 1907 & 300 & - & - & - \\
\hline $\begin{array}{l}\text { Radial force on } \\
\text { each blade (lbf) }\end{array}$ & - & - & 3370 & 3370 & 3370 & 3370 & - \\
\hline $\begin{array}{l}\text { Hard link tension } \\
\text { or compression }\end{array}$ & - & 24911 & - & - & - & - & - \\
\hline
\end{tabular}

The blades and hub together weigh approximately $650 \mathrm{lb}$. Thus, the gravitational loads were negligible compared to the aerodynamic and inertial loads. The aerodynamic loads produced the largest hub reactions; therefore, they were used as the primary design loads. Aerodynamic loads are caused by airflow and its interaction with the stationary and moving parts of a wind turbine. The magnitudes of the aerodynamic loads depend on factors such as the rotational speed of the rotor, average wind speed, turbulence, air density, and the aerodynamic shape of the wind turbine components.

Sandy Butterfield requested that the hub be designed to withstand steady winds of $144 \mathrm{mph}$ when parked. I multiplied the load resulting from this extreme condition by a 1.4 safety factor at Butterfield's request. This calculation results in a thrust load of 1907 lbf on each blade (see Equation 3.1 and Table 3.3). 


\section{Lift $=.5 *$ air density $*$ lift coefficient $*$ chord $*$ span $*$ speed $^{2} *$ safety factor gravitational constant}

Equation 3.1. Formula for calculating aerodynamic lift.

Table 3.3. Parameters Used to Calculate the Lift on Each Blade

\begin{tabular}{|c|c|}
\hline Parameter & Value \\
\hline Air density & $3.613 * 10^{-5} \mathrm{lb} / \mathrm{in}^{3}$ \\
\hline Lift coefficient & 1.5 \\
\hline Blade chord & $17.85 \mathrm{in}$ \\
\hline Blade span & $169.3 \mathrm{in}$ \\
\hline Wind speed & $2,534 \mathrm{in} / \mathrm{sec}$ \\
\hline Safety factor & 1.4 \\
\hline Gravitational constant & $386.4 \mathrm{in} / \mathrm{sec}^{2}$ \\
\hline
\end{tabular}

I have sketched the three worst-case aerodynamic scenarios in Figure 3.2. The first two scenarios could occur if the turbine is parked at $90^{\circ}$ or $0^{\circ}$ yaw angles and the blades are pitched to achieve maximum lift. I call these scenarios the "lead-lag load case" and the "flapwise load case." The third scenario could occur if one blade pitches during operation to achieve minimum lift while the other blade pitches to achieve maximum lift. This condition is possible if the pitch system malfunctions; thus, I call this the "pitch-failure load case."

I checked the validity of the aerodynamic loads using data from the Unsteady Aerodynamics Experiment three-bladed hub. Although the data I have for the three-bladed hub were recorded in 45-mph winds, the loads I designed the twobladed hub to withstand are roughly five times greater than the peak operating loads. This indicates that the aerodynamic loads I designed the hub to withstand are realistic. 

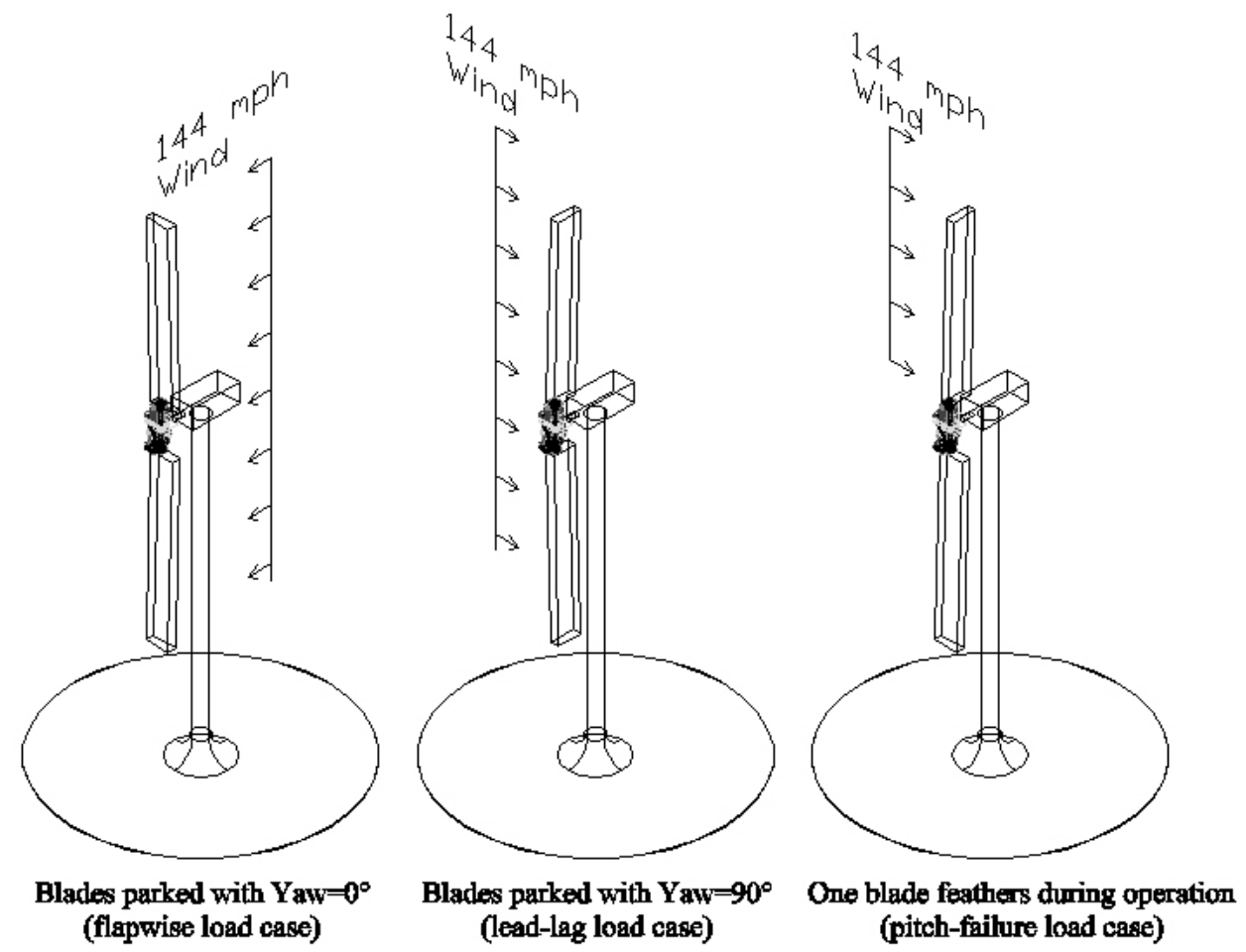

Figure 3.2. Worst-case aerodynamic scenarios.

The inertial loads I considered result from the centripetal force on the blades, the torque on the rotor, and braking during an emergency stop. The operating speed of the three-bladed hub is $72 \mathrm{rpm}$. I calculated the effect of the centripetal loads by assuming that the rotor was in an over speed condition operating at $90 \mathrm{rpm}$. Each half of the rotor weighs roughly $295 \mathrm{lb}$ (each blade weighs $158 \mathrm{lb}$ ) and the center of gravity for each half lies 48.5 in from the center of the rotor. The resulting centripetal load is $3370 \mathrm{lbf}$ per blade.

The loads from an emergency stop result from the disk brake. The disk brake exerts $2000 \mathrm{ft}-\mathrm{lbf}$ on the rotor. This torque is transmitted to the blades. I assumed that each blade was subjected to one-half of this torque.

Estimating the magnitude and frequency of teeter impacts was extremely difficult because so many factors were involved (such as wind speed, wind turbulence, the amount of free teeter, blade design, and hub design), and I found no research documentation on the subject. 
I estimated the magnitude of the teeter impacts using a numerical simulation code called YAWDYN. I had little time to learn the intricacies of YAWDYN or run extensive case studies. Thus, the flapwise moment in Table 3.2 is only a rough, conservative estimate of the peak teeter impact. YAWDYN predicted that the most severe teeter impact occurs at a yaw angle of $45^{\circ}$ with no teeter damping in 144-mph winds. The result of this impact was a flapwise bending moment of $8900 \mathrm{ft}-1 \mathrm{bf}$, which causes $7120 \mathrm{lbf}$ of compression on the damper.

\subsection{Strength-of-Materials Calculations}

In this section, I present the strength-of-materials calculations (or analytical

calculations) I performed to determine the effects of the design loads. The aerodynamic loads were used as the design loads because they produce the largest forces on the hub. Of the aerodynamic loads, the most problematic forces are the flapwise and lead-lag bending moments. The lead-lag load case and the pitch-failure load case have the same lead-lag bending effect on the hub. Because of this similarity, I only discuss the results of the flapwise load case and lead-lag load case.

The design loads subject the hub body to uni-axial, bi-axial, and tri-axial stresses. I used the maximum-shear-stress theory to determine when these stresses will cause the hub to fail. The maximum-shear-stress theory predicts that if the three principal stresses are ordered $\sigma_{1}>\sigma_{2}>\sigma_{3}$, then yielding occurs when either the difference between $\sigma_{1}$ and $\sigma_{3}$ exceeds the material yield strength or the shear stress exceeds half of the material yield strength [20]. The maximum-shear-stress theory was good for my design purposes because it is quick and easy to use. Furthermore, the maximum-shear-stress theory is a conservative predictor of failure.

\subsubsection{Simplifying Assumptions}

In this section, I present the simplifying assumptions I used for the analytical calculations. I discuss the assumptions below and display the model in Figure 3.3 .

Assumption 1) I assumed the hub was symmetric about the Z-X plane. The hub body actually consists of a small web, a large web, and three journal-bearing housings. The small web is attached to 
one journal bearing housing and the large web is attached to the other two housings. My simplified model assumed that the two webs were identical. This assumption was conservative because it resulted in higher stress values.

Assumption 2) I assumed that the teeter-pin axis was on the same Y-Z plane as the barrel centerline axis. On the prototype and final assembly, the $\mathrm{X}$ coordinate of the teeter-pin axis is actually positioned 2 in downwind of the barrel axis. Thus, on the prototype, the webs are slanted so that they reach from the teeter pin to the top of the barrel. By assuming the teeter pin axis was on the same $\mathrm{Y}-\mathrm{Z}$ plane as the barrel centerline, I could position the tuning forks vertically as in Figure 3.4. This was not a conservative assumption because it reduced the stress values in the hub. However, it was necessary to simplify the numerical model. I made this assumption in this analysis so that I could compare the analytical results with the numerical results.

Assumption 3) I conservatively assumed that the teeter pin, hard-link, blades, pitch-shaft, bearing housings, and barrel were rigid. On the real hub, the deflections of these components lessen the loads on the hub body.

Assumption 4) I assumed the magnitude of buckling was negligible because the plate members are relatively short compared to their width. 


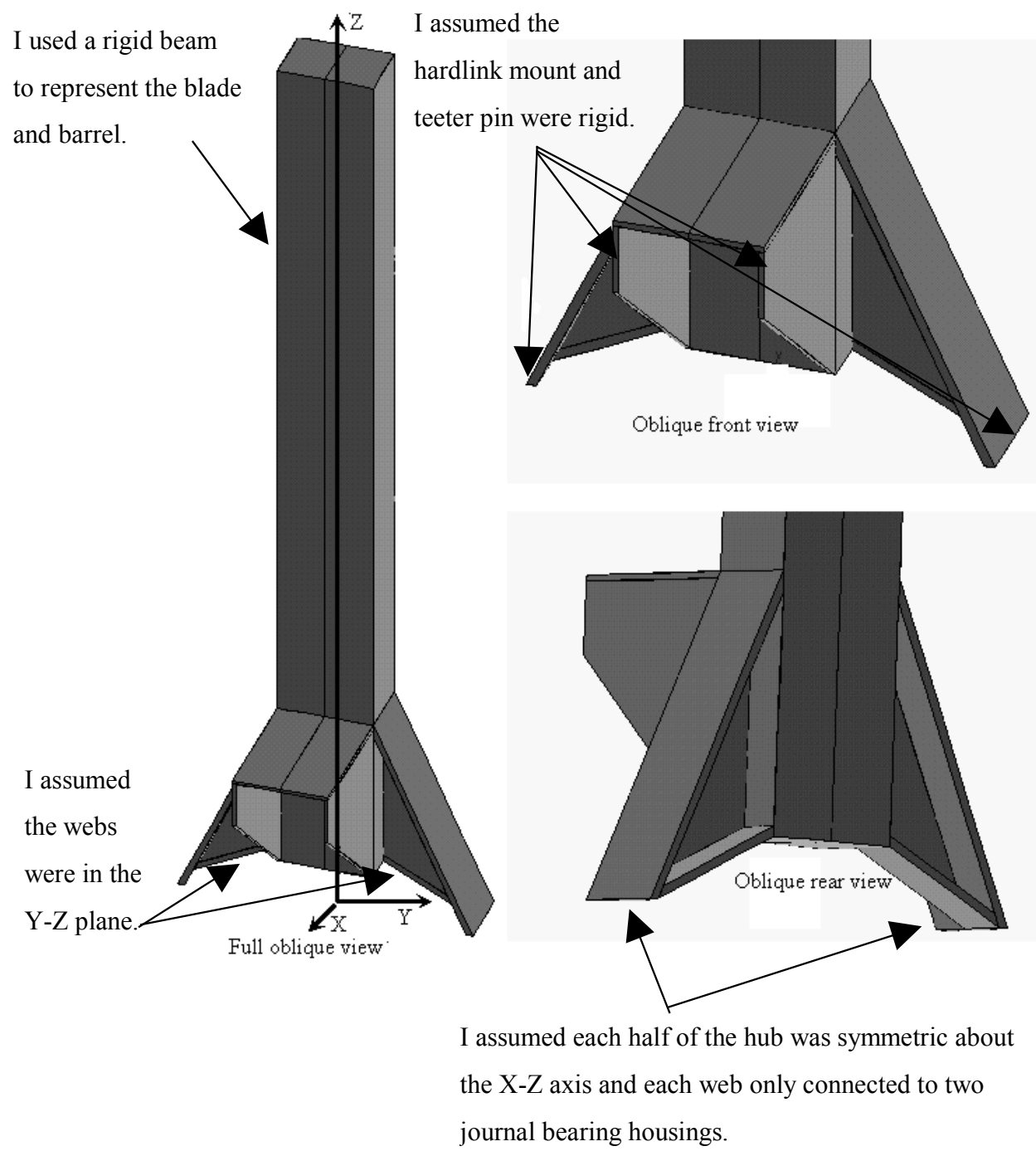

Figure 3.3. Simplified hub body model.

\subsubsection{Analytical Calculations for the Flapwise Load Case}

A free-body diagram for the hub body is presented in Figure 3.4. The diagram includes both the loads for the flapwise load case and the relevant hub dimensions. The hub body is made from American Society for Testing and Materials (ASTM) A36 steel with a minimum yield strength of $36 \mathrm{kpsi}$ and an ultimate strength of $58 \mathrm{kpsi}$. Using the free-body diagram in Figure 3.4, I determined the force and moment relationships in Table 3.4 and the reaction magnitudes in Table 3.5. 


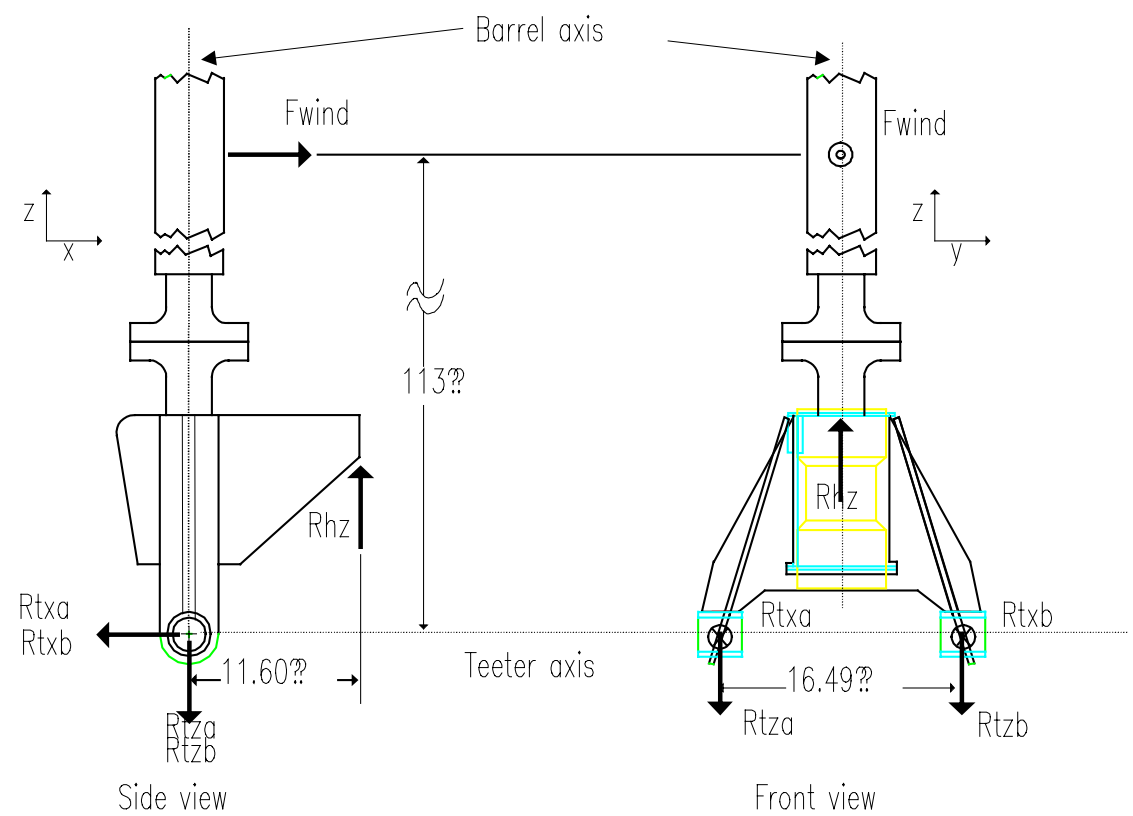

Figure 3.4. Free-body side view and front view for the flapwise load case.

Table 3.4. Load Relationships for the Flapwise Load Case

\begin{tabular}{|l|l|}
\hline \multicolumn{1}{|c|}{ Action } & \multicolumn{1}{|c|}{ Relation (lbf) } \\
\hline Summing the moments about the Y-axis & $\mathrm{R}_{\mathrm{hz}}=9.74 \mathrm{~F}_{\mathrm{wind}}$ \\
\hline Summing the moments about the X-axis & $\mathrm{R}_{\mathrm{tza}}=\mathrm{R}_{\mathrm{tzb}}$ \\
\hline Summing the moments about the Z-axis & $\mathrm{R}_{\mathrm{txa}}=\mathrm{R}_{\mathrm{txb}}$ \\
\hline Summing the forces in the X direction & $\mathrm{F}_{\mathrm{wind}}=\mathrm{R}_{\mathrm{txa}}+\mathrm{R}_{\mathrm{txb}}$ \\
\hline Summing the forces in the $\mathrm{Z}$ direction & $\mathrm{R}_{\mathrm{hz}}=\mathrm{R}_{\mathrm{tza}}+\mathrm{R}_{\mathrm{tzb}}$ \\
\hline
\end{tabular}


Table 3.5. Input and Reaction Forces for the Hub Body Flapwise Load Case

\begin{tabular}{|c|c|}
\hline $\begin{array}{c}\text { Input Load or } \\
\text { Reaction }\end{array}$ & Force (lbf) \\
\hline $\mathrm{F}_{\text {wind (thrust on one blade) }}$ & 1907 \\
\hline $\mathrm{R}_{\mathrm{txa}}$ & 953 \\
\hline $\mathrm{R}_{\mathrm{txb}}$ & 953 \\
\hline $\mathrm{R}_{\mathrm{tza}}$ & 9288 \\
\hline $\mathrm{R}_{\mathrm{tzb}}$ & 9288 \\
\hline $\mathrm{R}_{\mathrm{hz}}$ & 18576 \\
\hline
\end{tabular}

From the reactions presented in Table 3.5, it is apparent that the horizontal loads and reactions $R_{t x a}, R_{t x b}$, and $F_{\text {wind }}$ are small compared to the vertical loads and reactions $R_{t z a}, R_{t z b}$, and $R_{h z}$. Thus, I neglected the effect of the reactions $R_{t x a}$ and $\mathrm{R}_{\mathrm{txb}}$. Furthermore, because the barrel was assumed to be a rigid structure, I only investigated the stresses in the webs. I have drawn a free-body, shear, and bending moment diagram for the webs in Figure 3.5. 


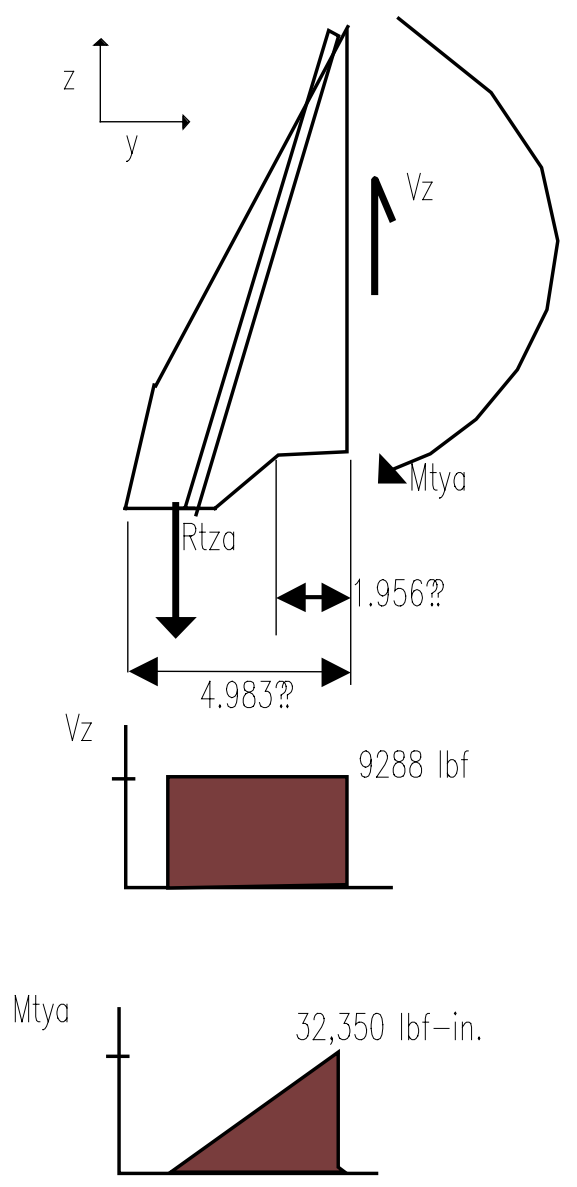

Figure 3.5. Free-body, shear, and bending moment diagrams of the web for the flapwise load case.

Figure 3.6 depicts the areas of concern in the web. I calculated the shear stresses and bending moments at each of the sections. I analyzed section E-F because the bending moment is highest at that location. I analyzed section A-B because the section modulus there is smaller than at section E-F; however, the bending moment is still relatively high. I analyzed section C-D because the tensile forces from reaction $\mathrm{R}_{\mathrm{tza}}$ act on a very small area at that section. The geometric properties for cross sections A-B, C-D, and E-F are summarized in Table 3.6. I have drawn the sections A-B, C-D, and E-F in Figure 3.7, Figure 3.8, and Figure 3.9 on the following pages. 


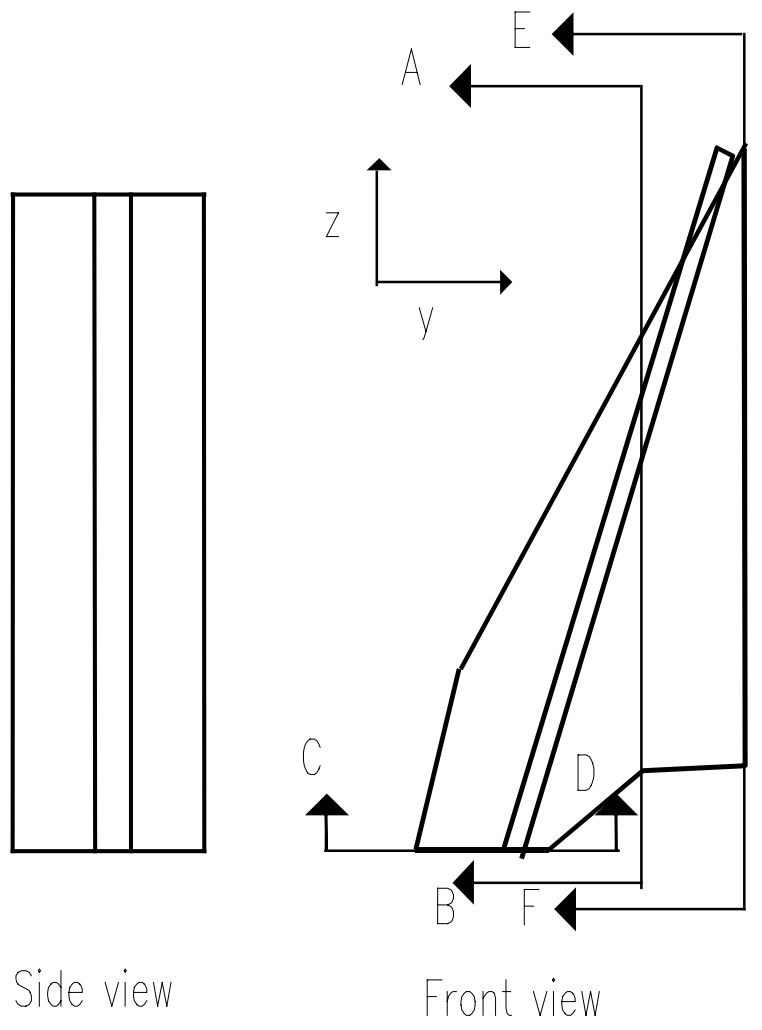

Figure 3.6. Web sections of interest for the analytical calculations.

Table 3.6. Geometric Properties for the Cross Sections of Interest

\begin{tabular}{|c|c|c|c|c|}
\hline & $\begin{array}{c}\text { Area } \\
\left(\mathbf{i n}^{2}\right)\end{array}$ & $\begin{array}{c}\text { Area Moment of Inertia (I) } \\
\left(\text { in }^{\mathbf{4}}\right)\end{array}$ & $\begin{array}{c}\mathbf{C} \\
(\text { in) }\end{array}$ & $\begin{array}{c}\text { Section Modulus } \\
\left(\text { in }^{3}\right)\end{array}$ \\
\hline Section A-B & 3.575 & 18.86 & 5.335 & 3.535 \\
\hline Section C-D & 2.250 & 0.58 & 1.500 & 0.387 \\
\hline Section E-F & 4.050 & 46.08 & 6.945 & 6.635 \\
\hline
\end{tabular}




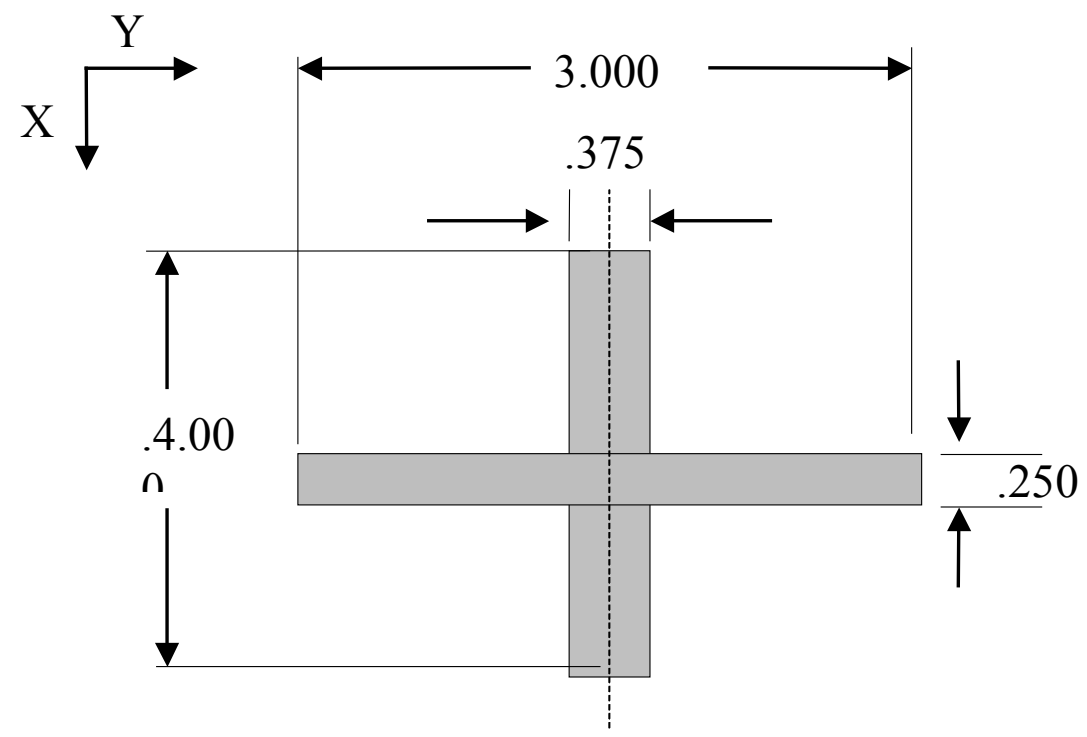

Figure 3.7. Approximate geometry of cross section C-D.
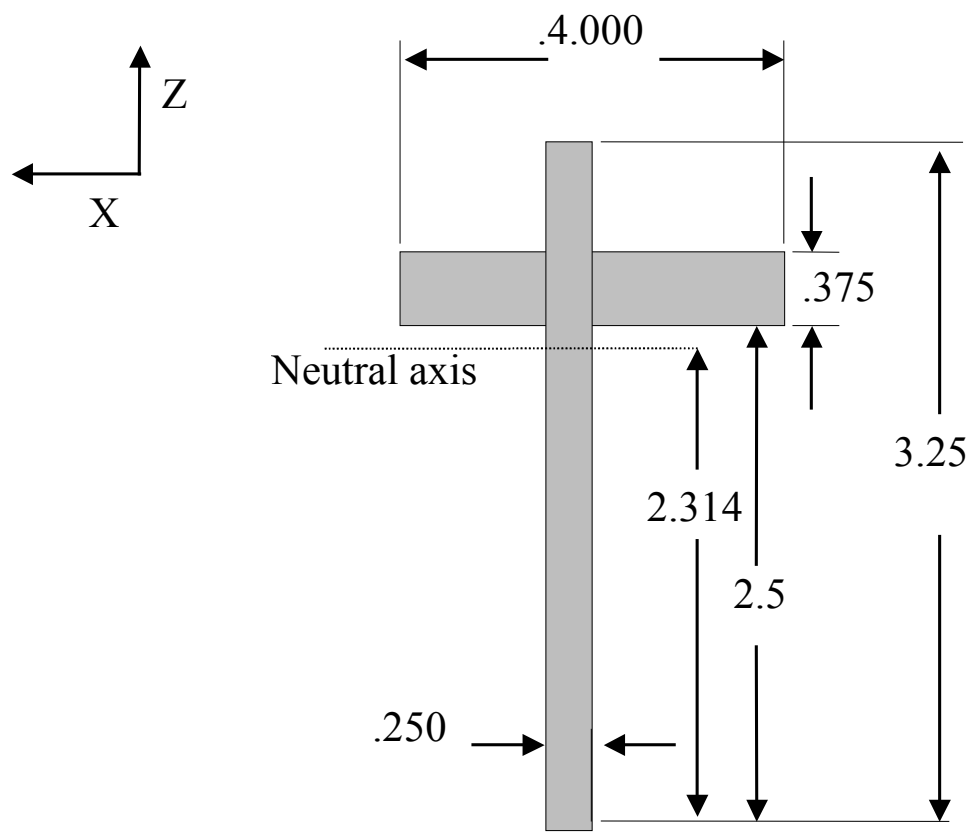

Figure 3.8. Approximate geometry of cross section A-B. 


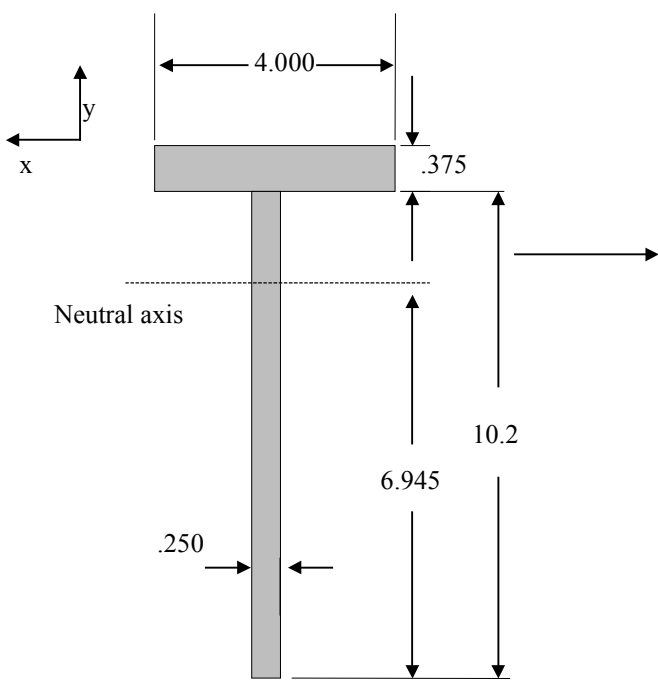

Figure 3.9. Approximate geometry of cross section E-F.

The shear stress, bending-moment stress, and tensile-stress formulas are presented in Equation 3.2. I present the results of these calculations in Table 3.7, where I have printed the values of most concern in bold print.

$$
\begin{aligned}
& \text { Bending Stress }=\frac{M c}{I}=\frac{M}{\text { Section modulus }} \\
& \text { Tensile Stress }=\frac{\text { Tensile force }}{\text { Area }} \\
& \text { Shear Stress }=\frac{\text { Shear force }}{\text { Area }}
\end{aligned}
$$

Equation 3.2. Stress formulas used in the analytical analysis. 
Table 3.7. Loads and Stresses Due to the Flapwise Load Set

\begin{tabular}{|l|c|c|c|c|c|c|}
\hline & $\begin{array}{c}\text { Bending } \\
\text { Moment } \\
(\mathrm{lbf}-\mathrm{in})\end{array}$ & $\begin{array}{c}\text { Shear } \\
\text { Force (lbf) }\end{array}$ & $\begin{array}{c}\text { Tension or } \\
\text { Compression } \\
(\mathrm{lbf})\end{array}$ & $\begin{array}{c}\text { Bending Stress } \\
(\mathrm{psi})\end{array}$ & $\begin{array}{c}\text { Shear } \\
\text { Stress } \\
(\mathrm{psi})\end{array}$ & $\begin{array}{c}\text { Tensile } \\
\text { Stress } \\
(\mathrm{psi})\end{array}$ \\
\hline Section A-B & 14,183 & 9,288 & - & $\mathbf{5 , 1 3 9}$ & 2,598 & - \\
\hline Section C-D & 0 & 0 & 9,288 & 0 & 0 & $\mathbf{4 , 1 2 8}$ \\
\hline Section E-F & 32,350 & 9,288 & - & 4,876 & 2,293 & - \\
\hline
\end{tabular}

The highest stresses at each of these areas are the bending stresses at section A-B $(5,139 \mathrm{psi})$, the tensile stress at section C-D (4,128 psi), and the bending stress at section E-F (4,876 psi). All three of these values are significantly lower than the material-yield strength $(36,000 \mathrm{psi})$; therefore, I conclude that this section's strength is adequate.

\subsubsection{Analytical Calculations for Lead-Lag Load Case}

The free-body diagram used for the lead-lag load case is presented in Figure 3.10. Summing the forces and moments in the free-body diagram yielded the relationships in Table 3.8. The magnitudes of the reactions are presented in Table 3.9. 


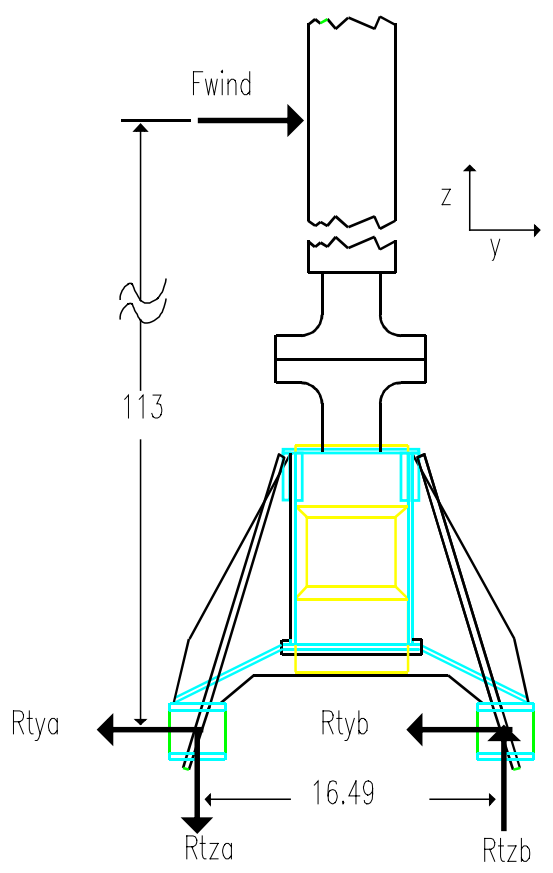

Figure 3.10. Free-body front view for the lead-lag case.

Table 3.8. Load Relationships for the Lead-Lag Load Case

\begin{tabular}{|l|l|}
\hline \multicolumn{1}{|c|}{ Action } & \multicolumn{1}{c|}{ Relation (lbf) } \\
\hline Summing the moments about the $\mathrm{X}$-axis & $\mathrm{R}_{\mathrm{tzb}}=6.86 \mathrm{~F}_{\mathrm{wind}}$ \\
\hline Summing the forces in the $\mathrm{Z}$ direction & $\mathrm{R}_{\mathrm{tza}}=\mathrm{R}_{\mathrm{tzb}}$ \\
\hline Summing the forces in the $\mathrm{Y}$ direction & $\mathrm{F}_{\mathrm{wind}}=\mathrm{R}_{\mathrm{tya}}+\mathrm{R}_{\mathrm{tyb}}$ \\
\hline Using symmetry arguments & $\mathrm{R}_{\mathrm{tya}}=\mathrm{R}_{\mathrm{tyb}}$ \\
\hline
\end{tabular}


Table 3.9. Input and Reaction Forces for the Hub Body Analytical Analysis for the LeadLag Load Case

\begin{tabular}{|c|c|}
\hline $\begin{array}{c}\text { Input Load or } \\
\text { Reaction }\end{array}$ & Force (lbf) \\
\hline $\mathrm{F}_{\text {wind (thrust on one blade) }}$ & 1907 \\
\hline $\mathrm{R}_{\mathrm{tza}}$ & 13087 \\
\hline $\mathrm{R}_{\mathrm{tzb}}$ & 13087 \\
\hline $\mathrm{R}_{\mathrm{tya}}$ & 953 \\
\hline $\mathrm{R}_{\mathrm{tyb}}$ & 953 \\
\hline
\end{tabular}

From the reactions presented in Table 3.9, it is apparent that the horizontal reactions $\left(\mathrm{R}_{\mathrm{tya}}\right.$ and $\left.\mathrm{R}_{\mathrm{tyb}}\right)$ are small compared to the vertical reactions $\left(\mathrm{R}_{\mathrm{tza}}\right.$ and $\left.\mathrm{R}_{\mathrm{tzb}}\right)$. Thus, I neglected the horizontal reactions. Furthermore, because the barrel and teeter pin were assumed to be rigid, only the stresses in each web were investigated. Figure 3.11 presents the free-body, shear, and bendingmoment diagrams. 


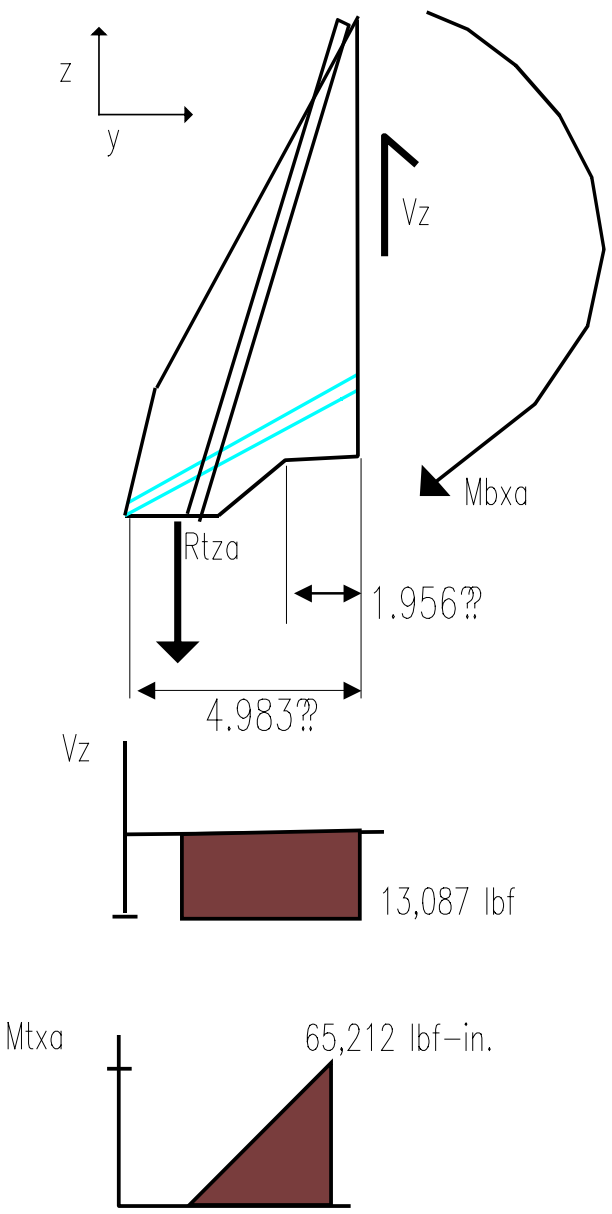

Figure 3.11. Free-body diagram of the web for the lead-lag load case.

The calculations for the lead-lag load case are summarized in Table 3.7, where I have printed the values of most concern in bold print. The highest stresses are the bending stresses at section A-B, the tensile stress at section $\mathrm{C}-\mathrm{D}$, and the bending stress at section E-F. 
Table 3.10. Load and Stress Calculation Summary for the Lead-Lag Load Case Analytical Analysis

\begin{tabular}{|l|l|r|r|r|r|r|}
\hline & $\begin{array}{l}\text { Bending } \\
\text { Moment } \\
\text { (lbf-in) }\end{array}$ & $\begin{array}{c}\text { Shear } \\
\text { Force } \\
\text { (lbf) }\end{array}$ & $\begin{array}{c}\text { Tension } \\
\text { (lbf) }\end{array}$ & $\begin{array}{c}\text { Bending } \\
\text { Stress } \\
\text { (psi) }\end{array}$ & $\begin{array}{c}\text { Shear } \\
\text { Stress } \\
\text { (psi) }\end{array}$ & $\begin{array}{c}\text { Tensile Stress } \\
\text { (psi) }\end{array}$ \\
\hline $\begin{array}{l}\text { Section } \\
\text { A-B }\end{array}$ & 39,614 & 13,087 & - & $\mathbf{1 1 , 2 0 6}$ & 3,661 & - \\
\hline $\begin{array}{l}\text { Section } \\
\text { C-D }\end{array}$ & 0 & 954 & 13,087 & 0 & 424 & $\mathbf{5 , 8 1 6}$ \\
\hline $\begin{array}{l}\text { Section } \\
\text { E-F }\end{array}$ & 65,213 & 13,087 & - & $\mathbf{9 , 8 2 9}$ & 3,231 & \\
\hline
\end{tabular}

Table 3.11 lists the largest stresses at each of the sections of interest for both the lead-lag and flapwise load cases. Section A-B is the critical section for both load cases. Thus, I used section A-B to determine the safety factor for the hub body. The stress at section A-B from hurricane wind loads is 11,206 psi. The yield strength of ASTM A36 steel is 36,000 psi. Using the maximum-shear-stress failure model, the analytical results predict that the hub has a safety factor of three against failure.

An additional margin of safety is due to the fact that yielding does not necessarily constitute a hub failure in this application. The structure will most likely yield to a position that relieves some of the load. In addition, strain hardening will also produce localized strengthening. The magnitude of these phenomena is difficult to predict, but they add to the margin of safety.

Table 3.11. Summary of Results for the Analytical Analysis

\begin{tabular}{|c|c|c|}
\hline & $\begin{array}{l}\text { Peak Stress in the Flapwise } \\
\text { Load Case }\end{array}$ & $\begin{array}{c}\text { Peak Stress in the Lead- } \\
\text { Lag Load Case }\end{array}$ \\
\hline Section A-B & 5,139 & 11,206 \\
\hline Section C-D & 4,128 & 5,816 \\
\hline Section E-F & 4,876 & 9,829 \\
\hline
\end{tabular}

\subsection{Finite-Element Analysis}

I used the commercial finite-element analysis code ANSYS to perform a linear static analysis on the hub body. The simulation was performed at the University 
of Texas Mechanical Engineering RISC Computer Laboratory using 32-Bit IBM Power Stations with 64 megabytes of RAM.

I used the distortion-energy theory (also called the shear-energy, von Mises Hencky, or octahedral-shear-stress theories) to determine when the hub will fail. The distortion-energy theory predicts that yielding will occur when the effective stress, $\sigma^{\prime}$, is greater than or equal to the material shear stress. The effective stress is calculated using the three principal stresses $\left(\sigma_{1}, \sigma_{2}, \sigma_{3}\right)$ in the following formula [21]:

$$
\sigma^{\prime}=\left(\frac{\left(\sigma_{1}-\sigma_{2}\right)^{2}+\left(\sigma_{2}-\sigma_{3}\right)^{2}+\left(\sigma_{1}-\sigma_{3}\right)^{2}}{2}\right)^{1 / 2}
$$

Equation 3.3. Formula for the von Mises stress due to tri-axial stresses.

The von Mises stress requires more computation than calculating the maximum shear stress, but it gives more realistic (less conservative) stress values than the maximum-shear-stress theory. Thus, the distortion-energy-theory is well suited to computational methods.

\subsubsection{FEA Meshing and Modeling Assumptions}

The finite element code I used was the university edition of ANSYS 5.3. The university edition limits the number of nodes in a meshed model to 8000 nodes. I experimented with several element types, meshes, and mesh density parameters to find a satisfactory mesh with fewer than 8000 nodes. The mesh I used was made of 10-noded, tetrahedral quadratic solid elements and had 7600 nodes. The following assumptions were necessary to reduce the model to a size I could mesh.

Assumption 1) I modeled only one-half of the hub body because the hub is comprised of two identical halves.

Assumption 2) I used symmetry boundary conditions. The hub body is symmetric across the barrel except that the web on one side of the barrel attaches to two journal bearing housings and the other side of the barrel attaches to one journal bearing housing. For the finite-element analysis, I assumed that the hub was symmetric about the barrel and that each web only attached to 
one journal-bearing housing (see Figure 3.12). This

assumption was conservative because it raised the stress values in the hub.

Assumption 3) I assumed the teeter-pin axis was on the same $\mathrm{Y}-\mathrm{Z}$ plane as the barrel centerline axis. On the prototype and final assembly, the $\mathrm{X}$ coordinate of the teeter-pin axis is positioned 2.5 in downwind of the barrel axis. Thus, on the prototype, the webs are slanted $\left(15^{\circ}\right.$ from vertical) so that they reach from the teeter pin to the top of the barrel. By assuming the teeter-pin axis was on the same $\mathrm{Y}-\mathrm{Z}$ plane as the barrel centerline axis, the tuning forks could be positioned vertically. This was not a conservative assumption because it reduced the stress values in the hub. However, it was necessary to make the model simple enough to mesh.

Assumption 4) I excluded the hard-link mounts and test stand from the model. Modeling the hard link and test stand required too many nodes. Instead, I applied displacement constraints where the hub body mounted to the test stand. That is, I restricted the motion of the hard-link mounts and teeter pin (see Figure 3.12). This was not a conservative assumption. The assumption neglected the flexure of the test stand and hard link. Therefore, this assumption resulted in higher stress values.

Assumption 5) I constrained the blade-flapping degree of freedom at the teeter pin. The hub should have a rotational degree of freedom about the Y-axis. However, the tetrahedral element I used has no rotational degrees of freedom. This assumption caused bending stresses on the hub body at the teeter pin. Therefore, this assumption resulted in more conservative results.

Assumption 6) I applied the loads to a square beam, which represented the pitch shaft. The beam required fewer nodes to model than a shaft (see Figure 3.12). This assumption had little effect on the results because the shaft and beam can both be considered rigid structures. 


\subsubsection{Input Loads}

I investigated the results of the aerodynamic scenarios I described in Section 3.1. I applied loads on the finite-element analysis model at the same location as on the prototype I bench-tested. The center of the blade surface is 113 in from the teeter-pin axis; however, the beam used in the bench testing was only 60 in long. Thus, to apply an equivalent bending moment to the hub body, I increased the magnitude of the wind load applied to the 60 -in beam. This had the effect of increasing the shear load on the hub; therefore, it is a conservative assumption.

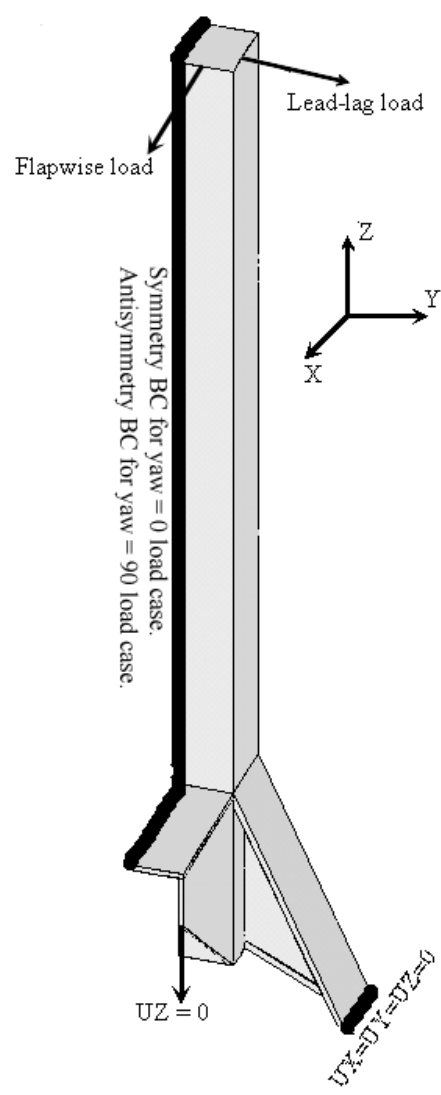

Figure 3.12. Loads and boundary conditions for the finite-element analysis. 


\subsubsection{Finite-Element Analysis Results}

In each case, solutions took approximately 20 minutes to reach. The error in the results was estimated by creating a contour plot of the structural energy error, or SERR, in the solution. The energy error is similar in concept to strain energy. The ANSYS manual describes the SERR as "a measure of the discontinuity of the stress field from element to element" [22]. The structural energy error levels at the areas of interest in my model were below $1.4 \%$, which is acceptable for this analysis.

I plotted contour plots of the von Mises stresses to determine the areas of high stresses. Figure 3.13 and Figure 3.14 are contour plots of the von Mises stresses for the flapwise and lead-lag load cases. The areas of interest in the finite-element analysis are the same in the analytical analysis (see Figure 3.6). I have listed the peak von Mises stress at each of the sections of interest in Table 3.12. I have also listed the deflection at the end of the beam where the loads were applied.

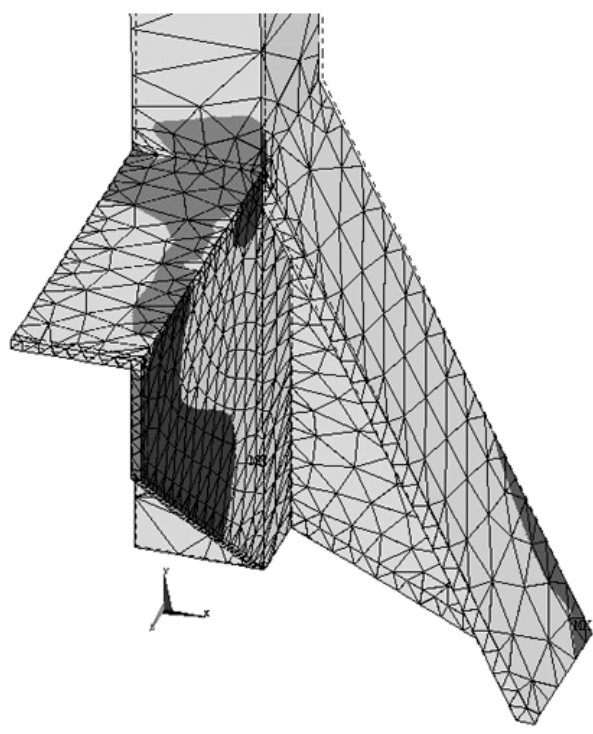

Oblique View

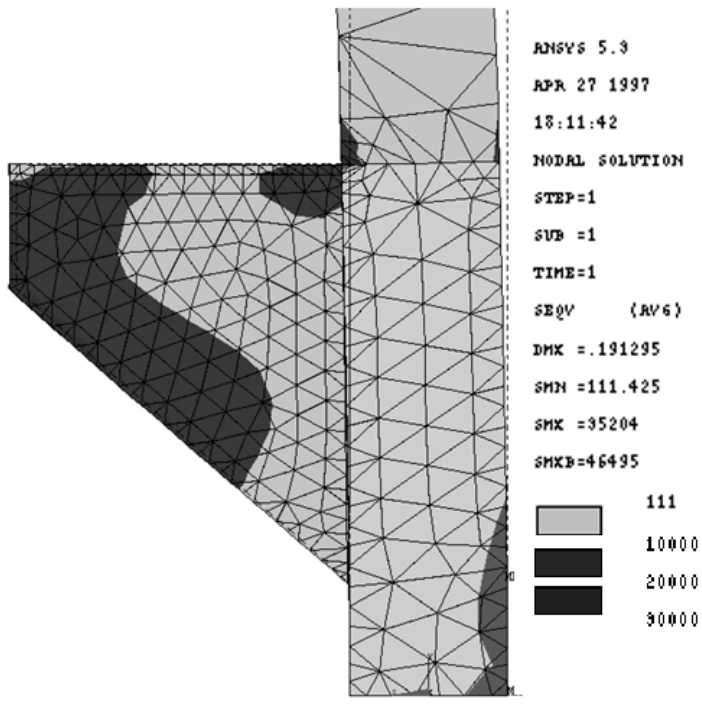

Side View

Figure 3.13. Von Mises stress plot for the flapwise load case. 


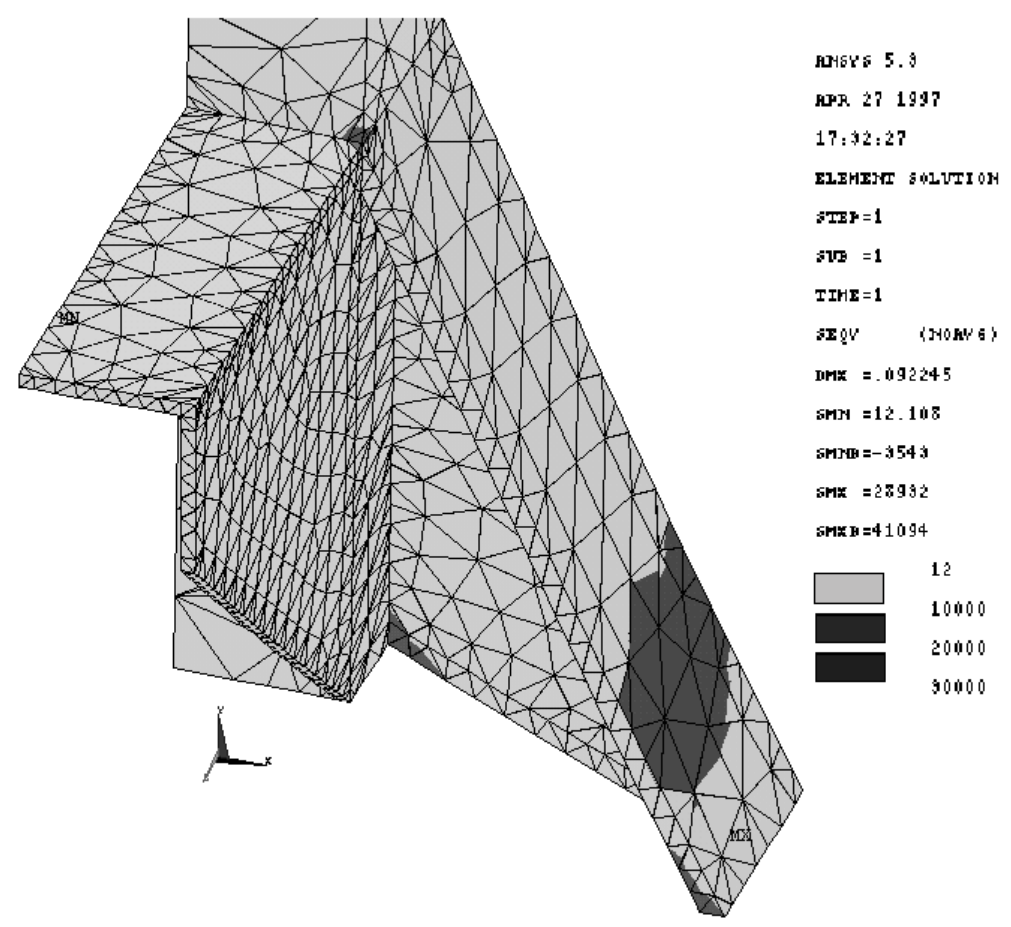

Figure 3.14. Von Mises stress plot for the lead-lag load case.

Table 3.12. Summary of Results for the Numerical Analysis

\begin{tabular}{|c|c|c|c|c|}
\hline & \multicolumn{2}{|c|}{ Flapwise Load Case } & \multicolumn{2}{c|}{ Lead-Lag Load Case } \\
\hline & $\begin{array}{c}\text { Peak von Mises } \\
\text { stress (psi) }\end{array}$ & $\begin{array}{c}\text { X deflection } \\
\text { at input load } \\
\text { (in) }\end{array}$ & $\begin{array}{c}\text { Peak von } \\
\text { Mises stress } \\
\text { (psi) }\end{array}$ & $\begin{array}{c}\text { Z deflection } \\
\text { at input load } \\
\text { (in) }\end{array}$ \\
\hline Section A-B & 11,017 & - & 10,500 & - \\
\hline Section C-D & $\mathbf{3 5 , 2 0 4}$ & - & $\mathbf{1 9 , 2 2 4}$ & - \\
\hline Section E-F & 10,789 & - & 13,300 & - \\
\hline End of beam & - & .191 & - & .09224 \\
\hline
\end{tabular}

The distortion-energy theory predicts that the failure will occur when the von Mises stress exceeds the material-yield strength (36 kpsi in this case). In Table 3.12, the stress at section C-D for the flapwise load case exceeds the materialyield strength. This stress value is misleading. The stress was caused by my assumption that I could neglect the Z-axis rotational degree of freedom at the section C-D. By neglecting the Z-axis rotational degree of freedom, the moment about the Z-axis caused bending stresses in section $\mathrm{C}$-D. The bending stresses 
caused the peak stress to occur at the edges of the section C-D as shown in Figure 3.13. If I could include the $\mathrm{Z}$-axis rotational degree of freedom in this model, I would expect to see uniform tensile stress across section C-D of similar magnitude to the stress I predicted analytically $(4,128 \mathrm{psi})$.

\subsection{Comparison of Analytical and Finite-Element Results}

Table 3.13 presents a comparison of the analytical and numerical results. With the exception of the stress values at section $\mathrm{C}-\mathrm{D}$, the values agree reasonably well considering the extent of my assumptions in each analysis.

Table 3.13. Comparison of the Analytical and Numerical Stress Values

\begin{tabular}{|l|l|l|l|l|}
\hline & \multicolumn{2}{|l|}{ Flapwise Load Case Stresses } & \multicolumn{2}{l|}{ Lead-Lag Load Case Stresses } \\
\hline & $\begin{array}{l}\text { Analytical } \\
\text { Calculations }\end{array}$ & $\begin{array}{l}\text { Numerical } \\
\text { Calculations }\end{array}$ & $\begin{array}{l}\text { Analytical } \\
\text { Calculations }\end{array}$ & $\begin{array}{l}\text { Numerical } \\
\text { Calculations }\end{array}$ \\
\hline Section A-B & 5,139 & 11,017 & 11,206 & 10,500 \\
\hline Section C-D & 4,128 & $\mathbf{3 5 , 2 0 4}$ & 5,816 & $\mathbf{1 9 , 2 2 4}$ \\
\hline Section E-F & 4,876 & 10,789 & 9,829 & 13,300 \\
\hline
\end{tabular}

I explained in the previous section that the stress levels for the flapwise load case at section $\mathrm{C}$-D are high because I had to constrain the $\mathrm{Y}$-axis rotational degree of freedom. However, for the lead-lag load case, the high stress values at section C-D result from other factors. First, the area of section C-D is smaller in the numerical model than the analytical model by $33 \%$. (This difference in geometry was necessary to obtain a model that could be meshed.) Thus, all tensile stresses in the numerical model were roughly $33 \%$ larger than those in the analytical model. Second, the analytical model assumed there was no bending moment at section C-D about the Y-axis for the lead-lag load case. However, in the numerical model, bending does occur at this section. These bending loads have a significant effect on section $\mathrm{C}$-D because the section modulus at that section is small (.065).

I believe the true stress at section C-D for the lead-lag load case is between what the analytical and numerical results predict. The analytical results tend to be low because I neglected the bending in section C-D. On the other hand, the numerical results tend to be high because I reduced the area of section C-D by $33 \%$ in the finite-element analysis model. A more accurate finite-element analysis model would be necessary to better approximate the stress at this section. 


\section{Experimental Results}

Bench testing of a hub body prototype was performed at The University of Texas at Austin Center for Electromechanics to verify the analytical results. Two load cases were investigated. The load cases simulated the flapwise and lead-lag load scenarios described in Chapter 3. This chapter discusses the setup, execution, and results of the testing.

\subsection{Experiment Setup}

Figure 4.1 is a photograph of the experiment. I designed a steel test stand used to mount one-half of the hub. The test stand could be rotated $90^{\circ}$ to accommodate both load cases (see Figure 4.2 and Figure 4.3). The test stand was fabricated from 1-in-thick plate steel (see Figure 4.4). To secure the hub to the test stand, a 2.5-in-diameter, SAE 1018 steel teeter pin was installed into the bearing housings. An aluminum teeter-pin clamp was machined to fasten the teeter pin onto the test stand. The test stand then was bolted to a load plate using 1-in-diameter all-thread.

I used a 4-in by 2-in piece of SAE 1018 steel flat to simulate the hard link. The steel flat was pinned at one end to the aluminum teeter-pin clamp with a $3 / 4$-indiameter grade 8 bolt and pinned at the other with a $5 / 8$-in-diameter grade 8 bolt through the hard-link mounts. 


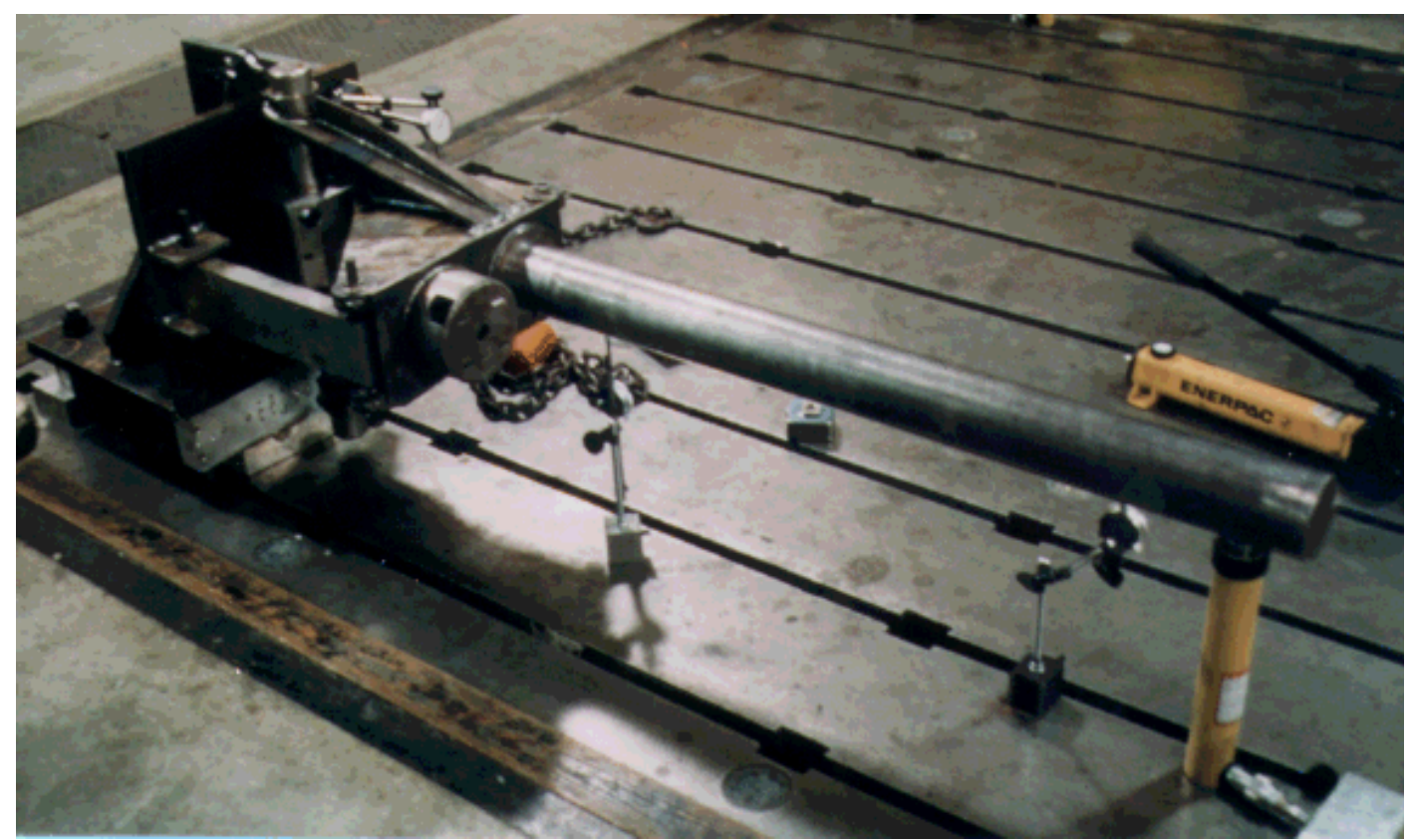

Figure 4.1. Photograph of the experiment setup.

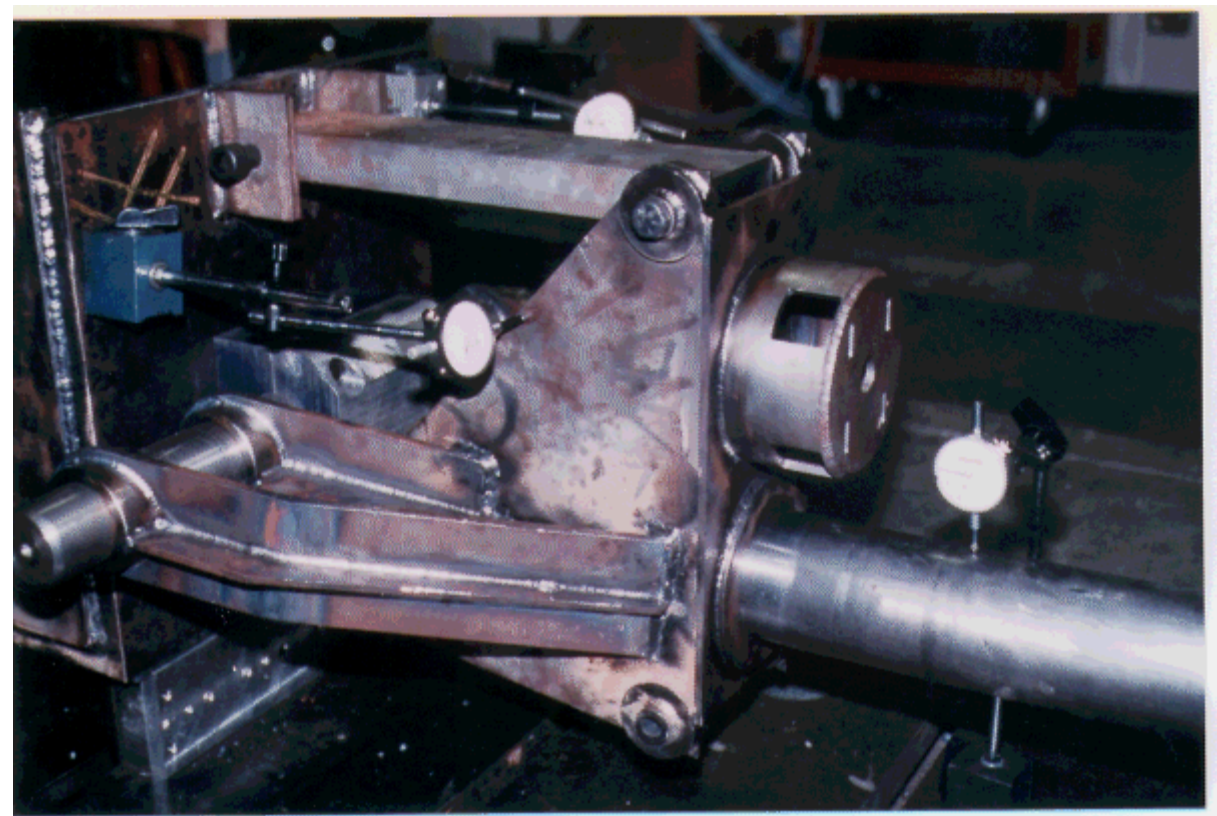

Figure 4.2. Close-up photograph of the flapwise test configuration. 


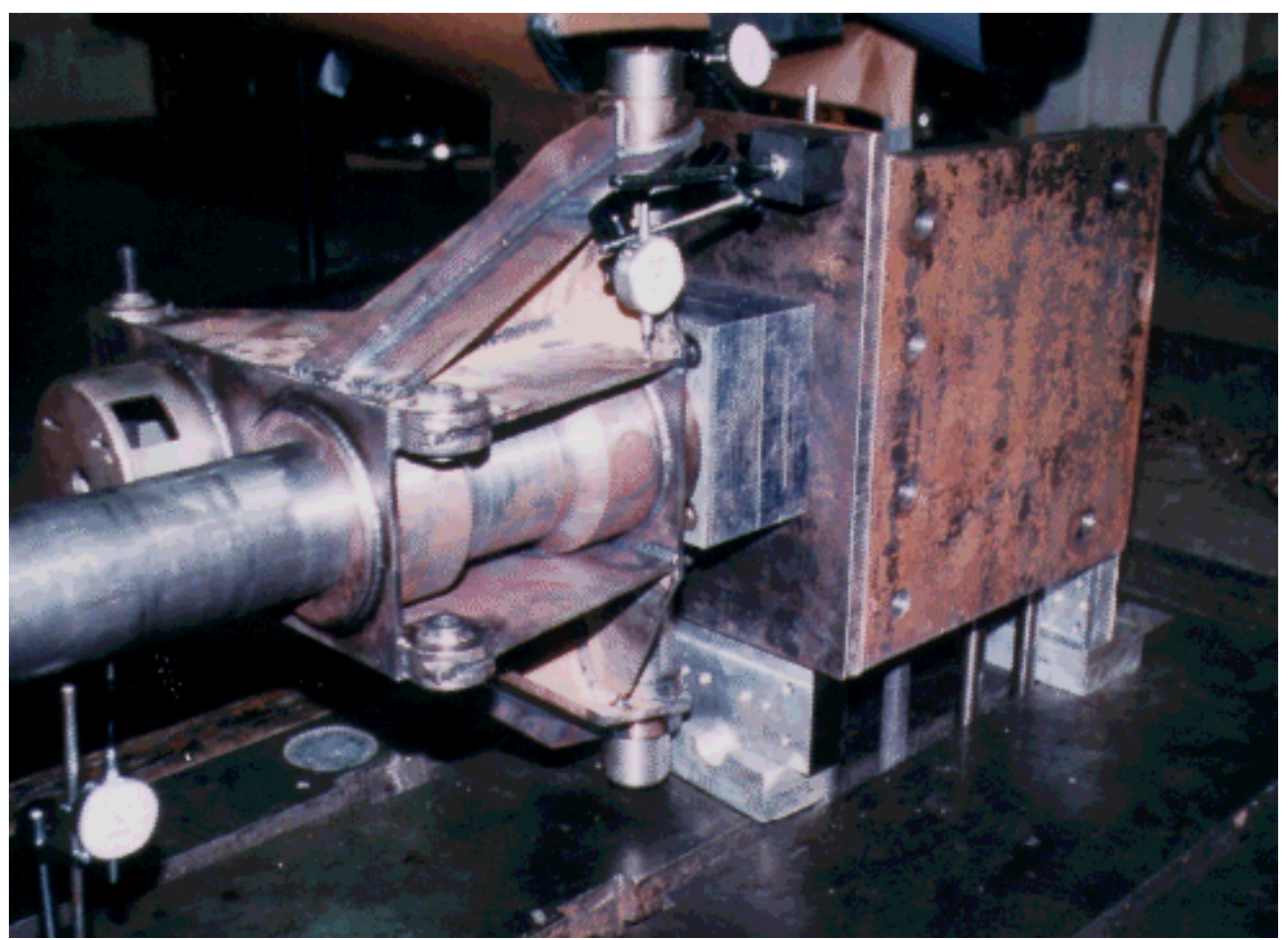

Figure 4.3. Close-up photograph of the lead-lag test configuration. 


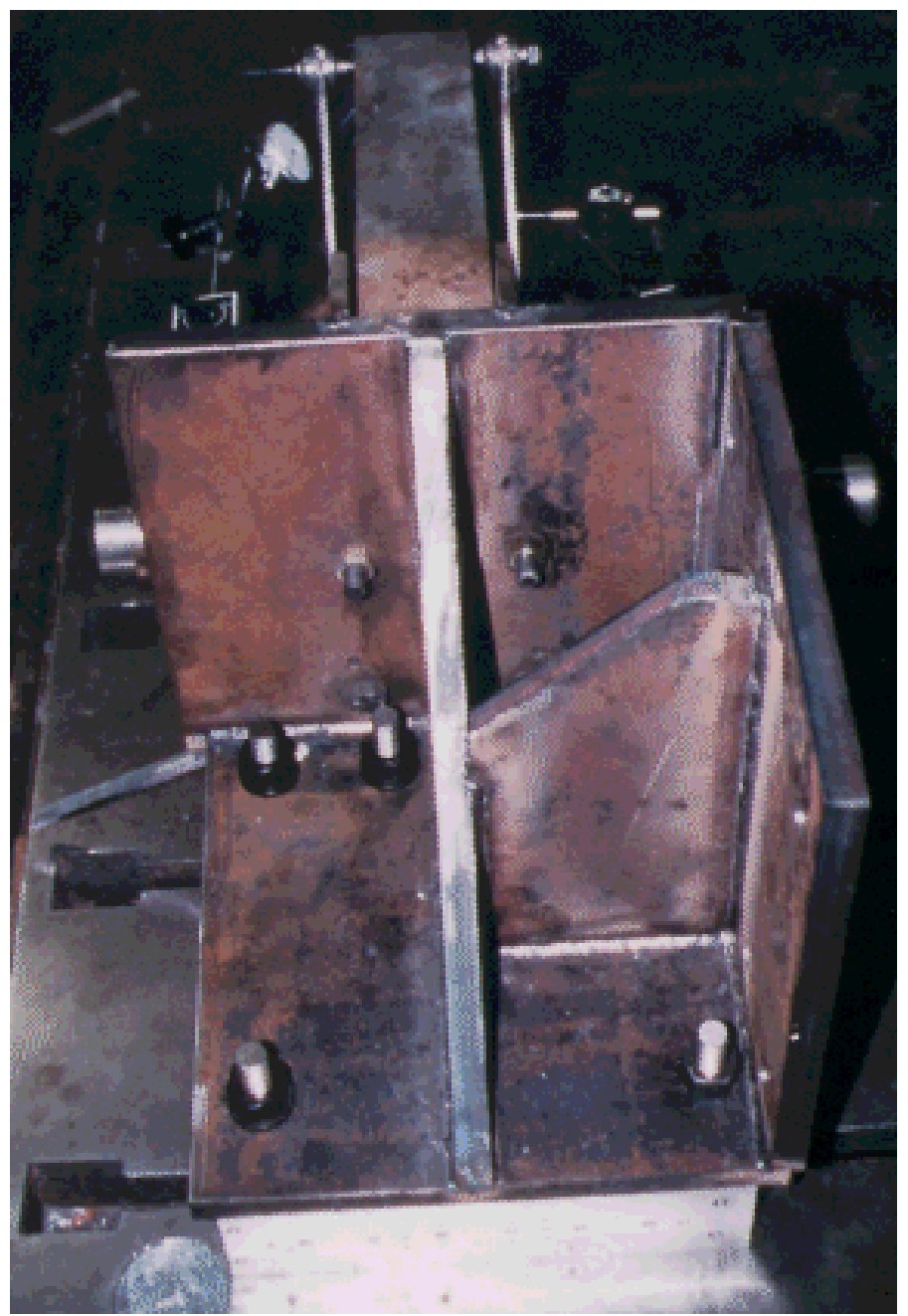

Figure 4.4. Photograph of the test stand.

\subsubsection{Load Application}

A 4-in-diameter SAE 1018 steel bar was inserted into the barrel where the blade pitch shaft would normally be installed. The loads were applied to the end of the bar using an Enerpac brand hydraulic hand pump and cylinder. I applied the loads at the end of the steel bar 60 in from the teeter-pin axis (the same location as in the numerical calculations). 
The loads, which were measured using the pressure gauge on the pump, were obtained by multiplying the pressure by the effective area of the hydraulic cylinder. I used a different hydraulic cylinder for each load case because the height of the hub changed when I rotated the test stand. The cylinder used for the flapwise load case (model number RC 102) has an effective area of $2.24 \mathrm{in}^{2}$ and a stroke of 2 in. The cylinder used for the lead-lag bending test (model number RC 1010) has an effective area of $2.24 \mathrm{in}^{2}$ and a stroke of $10 \mathrm{in}$. The hand pump (model number P-392) was rated at 10,000 psi and had a 2000-psi gauge installed with a resolution of 10 psi.

\subsubsection{Data Acquisition}

Originally, I intended to estimate the stresses and strains in the hub during testing using a brittle lacquer. This testing technique involves painting the hub with a special lacquer paint that changes color under ultraviolet light as the structure is strained. Unfortunately, the brittle lacquer paint was not available at the time of testing. I also considered using strain gauges to estimate the strain in the structure. However, time constraints prevented us from being able to install the necessary strain gauges.

Ultimately, the hub body deflections were measured using dial gauges at four different locations. The precise locations of the dial gauges and the intended function of each are presented in Table 4.1. 
Table 4.1. Dial Gauge Locations for the Lead-Lag and Flapwise Experimental Tests

\begin{tabular}{|c|l|l|l|}
\hline $\begin{array}{c}\text { Dial Gauge } \\
\text { Station }\end{array}$ & \multicolumn{1}{|c|}{ Function } & \multicolumn{1}{c|}{$\begin{array}{c}\text { Flapwise Load Case } \\
\text { Position }\end{array}$} & \multicolumn{1}{c|}{$\begin{array}{c}\text { Lead-Lag Load Case } \\
\text { Position }\end{array}$} \\
\hline $\mathbf{1}$ & $\begin{array}{l}\text { Measures the } \\
\text { displacement of } \\
\text { the input load }\end{array}$ & $\begin{array}{l}\text { On the bottom of the } \\
\text { mechanical steel tubing, } \\
53.4 \text { in from teeter-pin } \\
\text { centerline (at the input } \\
\text { load) }\end{array}$ & $\begin{array}{l}\text { On the bottom of the } \\
\text { mechanical steel tubing, } \\
53.4 \text { in from teeter-pin } \\
\text { centerline (at the input load) }\end{array}$ \\
\hline $\mathbf{2}$ & $\begin{array}{l}\text { Enables the angle } \\
\text { of the mechanical } \\
\text { steel tubing to be } \\
\text { calculated }\end{array}$ & $\begin{array}{l}\text { On the top of the } \\
\text { mechanical steel tubing, } \\
21.8 \text { in from teeter-pin } \\
\text { centerline (near the point } \\
\text { where the mechanical } \\
\text { steel tubing enters the } \\
\text { barrel) }\end{array}$ & $\begin{array}{l}\text { On the top of the mechanical } \\
\text { steel tubing, 21.8 in from } \\
\text { teeter-pin centerline (near } \\
\text { the point where the } \\
\text { mechanical steel tubing } \\
\text { enters the barrel) }\end{array}$ \\
\hline \multirow{3}{*}{$\mathbf{4}$} & $\begin{array}{l}\text { Measures the } \\
\text { buckling of the } \\
\text { cheek plates }\end{array}$ & $\begin{array}{l}\text { 9.3 in radially from the } \\
\text { teeter-pin centerline on } \\
\text { the cheek plate face }\end{array}$ & $\begin{array}{l}\text { Measures the } \\
\text { teeter-pin centerline on the } \\
\text { cheek plate face }\end{array}$ \\
\hline $\begin{array}{l}\text { deflection of the } \\
\text { teeterpin during } \\
\text { lead-lag loading } \\
\text { and hardlink } \\
\text { during flapwise } \\
\text { loading }\end{array}$ & $\begin{array}{l}\text { teeterpin centerline on the } \\
\text { hard-link mount }\end{array}$ & $\begin{array}{l}\text { in from the end of the } \\
\text { teeter pin on the side that } \\
\text { only has one bearing } \\
\text { housing }\end{array}$ \\
\hline
\end{tabular}

\subsubsection{Test Procedure}

The test procedure consisted of first setting up the assembly for flapwise testing as shown in Figure 4.1. Next, the cylinder was pre-loaded to remove the lash in the indicators and slack in the test fixture (approximately 50 -lb force was necessary). At this point, the dial indicators were set to the zero position. The deflection at station one was incremented $.100 \mathrm{in}$, and the load necessary to reach this deflection was recorded. The deflections at stations two, three, and four were also recorded at this point, and the hub was visually examined for signs of failure. Next, the deflection at station one was incremented an additional $.100 \mathrm{in}$, and the corresponding loads and deflections were recorded. The procedure was repeated until we reached $4500 \mathrm{lbf}$ (125\% of the design load). After we completed the flapwise test, we rotated the hub $90^{\circ}$ and repeated the procedure for the lead-lag load case. 


\subsection{Discussion and Comparison of the Flapwise Load Case Results}

The experiment data are presented in Appendix A. This section presents qualitative observations made during the experiment and a comparison of the predicted results with the experimental results for the flapwise load case.

\subsubsection{Hard-Link Mount Observations}

I expected that the first failure signs on the hub body would be cracked welds at the hard-link mounts. The hard-link mounts are made from an SAE 1018 steel tube with a 5/8-in inner diameter and a $1 / 4$-in wall thickness. The tubes are welded to what I call "doublers." The doublers are 3/8-in thick, SAE 1018 steel disks that are welded to the tube and the hub (see Figure 4.5). Although the intent of the tubes and doublers is to spread the load from the hard-link pin to the cheek plates, they make the stresses in the hard-link mounts difficult to predict. I anticipated that failure in the hard-link mounts would first become evident when the welds cracked or the bore in the tubes deformed.

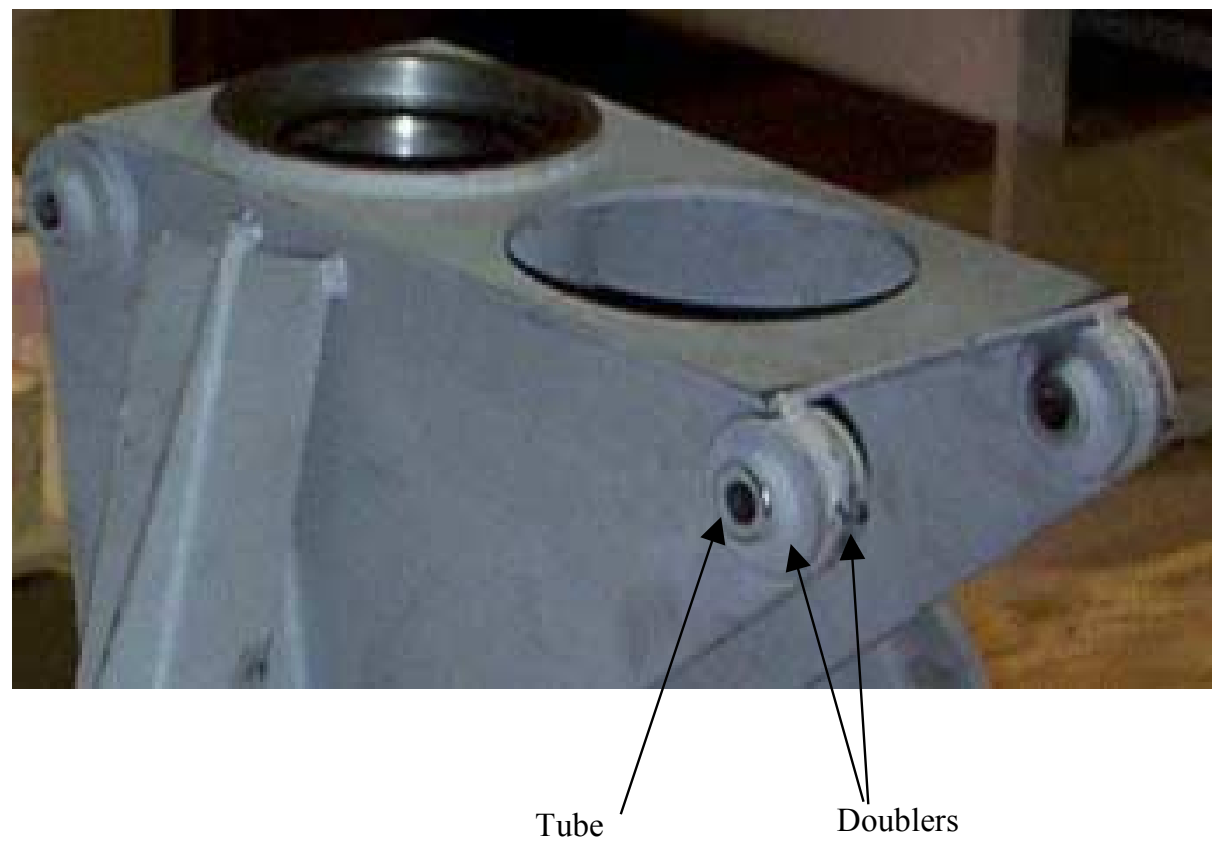

Figure 4.5. Photograph of a hard-link mount. 
In the experiment, a 4-in by 2-in piece of SAE 1018 steel flat was used to simulate the hard link. The shank of a 5/8-in-diameter bolt simulated the hardlink pin. The bore in the flat for the bolt was approximately .05 in larger than the bolt shank. These clearances allowed the bolt to flex significantly during the test.

The flexure of the hard-link bolts was visually apparent during the experiment. The bolts flexed so much that they yielded and were permanently bent. Although the hard-link bolt yielded during testing, it did not fracture or crack. Because the bolt did not break, there was no need to increase the size or strength of the hardlink pin. In fact, it is desirable that a replaceable component, such as the hardlink pin, yield before a nonreplaceable component.

The hard-link bolt flexure had to be taken into account when comparing the numerical and experimental results. The magnitudes of the bolt deflections were measured during testing using the dial gauge positioned on the hard-link mount at station four. At the peak load, the deflection of the hard-link bolts allowed the hard-link mount to translate $.065 \mathrm{in}$.

\subsubsection{Teeter-Pin Observations}

At the peak test load, the teeter-pin clamp in the experiment exerted a bending moment on the teeter pin that caused bending stresses of approximately $40 \mathrm{kpsi}$ in the teeter pin. The teeter-pin flexure that resulted from these bending stresses was visually apparent during the experiment. Unfortunately, I did not record the flexure of the teeter pin because I did not deem that information important at the time of testing. That data would have been useful for correcting the experimental results so that they could be compared to the numerical results.

I did not measure the teeter-pin flexure because I knew that the stress in the teeter pin would be more severe during bench-testing than during a windstorm. The deformation will be less during a windstorm because the hub will be parked and yawed out of the wind. In this configuration, the two halves of the hub will apply bending moments in opposite directions, thus canceling the bending effects on the teeter pin. 


\subsubsection{Hub Body Observations}

The hub body fared well during testing. I did not visually detect any cracked welds or permanently deformed components. In fact, after the test was completed and the loads were relieved, the dial gauges on the mechanical steel bar and the cheek plates returned to their original readings. This implies that the hub body suffered primarily elastic deformations.

Further proof that the hub body suffered primarily elastic deformations is given by Figure 4.6. This figure is a plot of the predicted and experimental loads induced when the hub is deflected in the flapwise direction. Figure 4.6 shows that the relationship between the applied load and deflection is linear.

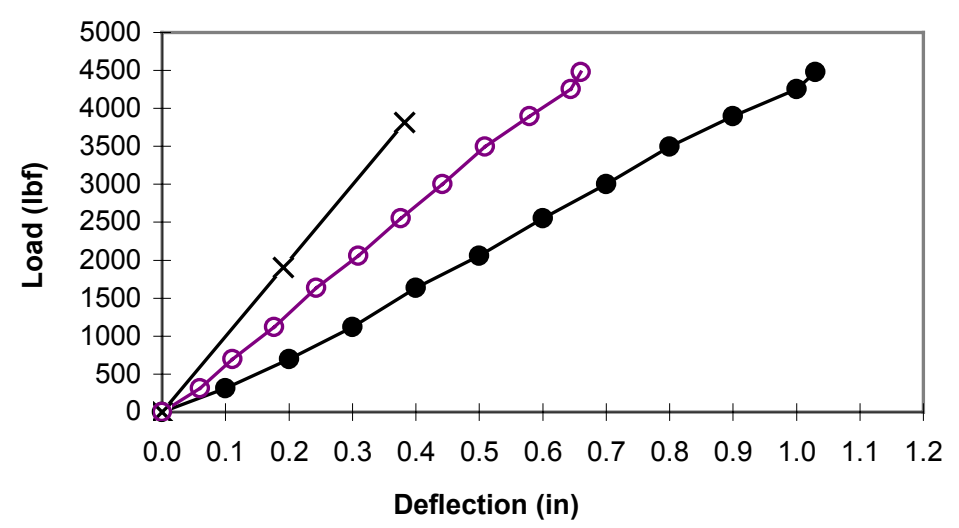

- Flapwise experimental resuts $\quad-X$ - Flapwise numerical results

0 - Corrected flapwise experimental results

Figure 4.6. Predicted and experimental deflections for the flapwise load case.

Ideally, I could have compared the experimental results with the predicted results using the stresses in the hub body. To make this comparison, I needed to measure or calculate the hub body stresses or strains during testing. Unfortunately, the four dial gauges used during testing did not provide enough strain information to calculate the stresses at the areas of interest. Thus, I could not compare the results using stress. 
However, I did compare the predicted and experimental results using stiffness. The stiffness of the hub was computed for the experimental results by finding the slope of the curves in Figure 4.6. The stiffness for the predicted results was calculated using the deflections from the finite-element simulation. To obtain the predicted stiffness, I divided the load on the finite-element analysis model by the corresponding deflection at the end of the mechanical bar. This calculation results in a stiffness of 9,984 lbf/in for the flapwise load case.

Figure 4.6 presents raw data and corrected data for the flapwise test. I corrected the experiment data so that I could better compare the predicted and experimental results. During the experiment, the flexure of the hard-link bolts, teeter pin, and test stand reduced the apparent stiffness of the hub assembly. I could not include this flexure in my finite-element analysis model because of the limited version of ANSYS I used.

To correct for the flexure in the hard-link bolts, I used trigonometry to estimate that station one (the input load) deflected 3.3 in for every inch the hard-link bolts deflected. I corrected for the flexure by multiplying the measured translation of the hard-link mount by 3.3 and subtracting this figure from the deflections measured at station one. This correction amounted to a $25 \%$ increase in the measured stiffness of the hub body.

I used strength-of-materials calculations to correct for the teeter-pin flexure because I did not measure the teeter-pin deflection during the flapwise test. I assumed that the teeter pin was a cantilevered bar with an end load. I calculated the deflection of the teeterpin using the flexure formula given by Shigley and Mischke [23]. I then related the deflection of the teeter pin back to the deflection at the input load using trigonometric formulas. This correction increased the stiffness values by approximately $11 \%$.

I believe that the test stand flexed because we did not properly tension the allthread rod used to clamp it to the load plate. We did not use a torque wrench to properly tighten the nuts on the all-thread. Thus, it is likely that the all-thread stretched during testing.

Unfortunately, I did not measure the test stand deflections during the experiment. However, I did correct for the lengthening of the all-thread rod used to fasten the test stand to the load plate. To calculate this correction, I assumed 
that the bolts had no pre-tension. I approximated the deflection of the bolt using the equation for the extension of a uniform bar [24] under an axial load. I then related the deflection of the test stand to the deflection at the input load using trigonometric formulas. This correction increased the stiffness values by approximately $5 \%$.

Table 4.2 presents the predicted and experimental flapwise stiffness of the hub body. Although the corrections I made for the hard link, teeter pin, and test stand flexure increased the experimental stiffness by $53 \%$, the experimental stiffness is still $32 \%$ lower than the predicted stiffness.

Table 4.2. Flapwise Stiffness Values for the Hub Body

\begin{tabular}{|c|c|c|}
\hline $\begin{array}{c}\text { Predicted } \\
\text { Stiffness } \\
(\mathbf{l b f} / \text { in) }\end{array}$ & $\begin{array}{c}\text { Experimental } \\
\text { Stiffness } \\
(\mathbf{l b f} / \text { in) }\end{array}$ & $\begin{array}{c}\text { Corrected } \\
\text { Experimental Stiffness } \\
(\mathbf{l b f} / \text { in) }\end{array}$ \\
\hline 9,984 & 4,441 & 6,823 \\
\hline
\end{tabular}

I believe the remaining difference between the predicted and experimental results is primarily due to the simplifying assumptions I made on the finiteelement model. As described in Section 3.2.1, I made several assumptions in the finite-element model necessary to reduce the model to a manageable size.

One assumption I was not able to account for was the fifth assumption in section 3.2.1. This assumption neglects the $\mathrm{Y}$-axis rotational degree of freedom of the teeter pin. The hub was designed to rotate about the teeter pin. Thus, section $\mathrm{C}$ $\mathrm{D}$ should have had an unconstrained rotational degree of freedom about the $\mathrm{Y}$ axis. However, the tetrahedral element used in the finite element model has no rotational degrees of freedom. Thus, the rotational degrees of freedom had to be neglected at this section. This assumption caused bending stresses to form at the section $\mathrm{C}-\mathrm{D}$, which did not occur in the experiment. These bending stresses artificially increased the stiffness of the numerical model.

In summary, it was difficult to compare the numerical and experimental results because I had very little strain data from the experiment. In addition, the finiteelement model was much simpler than the experiment. I corrected the experiment data analytically, but the experimental stiffness was still $32 \%$ less than the experimental stiffness. A more valid comparison of the numerical model could have been made if I could have included the test fixture in the 
finite-element model or if the flexure of the test stand had been measured during the experiment.

Despite the $32 \%$ difference in the predicted and experimental results, the test was still a success. I was able to ease my concern that the hard-link mounts would fail, and I learned that the hard-link pins are most likely the first item to fail.

\subsection{Discussion and Comparison of the Lead-Lag Load Case Results}

This section presents the qualitative observations and quantitative results of the lead-lag testing, as well as a comparison of the predicted results with the experimental results for the lead-lag load case. As in the previous section, I made the comparison using the stiffness of the hub body.

\subsubsection{Teeter-Pin Observations}

The primary purpose of the lead-lag testing is to ensure the hub body structure is structurally adequate in the lead-lag direction. Unlike the flapwise load case, the teeter-pin loading is negligible in the lead-lag load case because the bending moments from each half of the hub cancel each other. However, in the experiment, only one-half of the hub was loaded. This uneven loading subjected the teeter pin to unrealistic bending moments. This teeter-pin loading caused the teeter pin to flex. At the peak load, this deflection amounted to $.138 \mathrm{in}$. I had to account for this flexure when calculating the experimental stiffness of the hub body.

\subsubsection{Hub Body Observations}

After the test was completed and the loads relieved, the dial gauges on the mechanical steel bar and the cheek plates returned to their original readings. This implies that the hub body suffered primarily elastic deformations in the lead-lag load case. Further proof that the hub body structure suffered elastic deformations is given by Figure 4.7. In this figure, the relationship between the applied load and deflection is linear. 


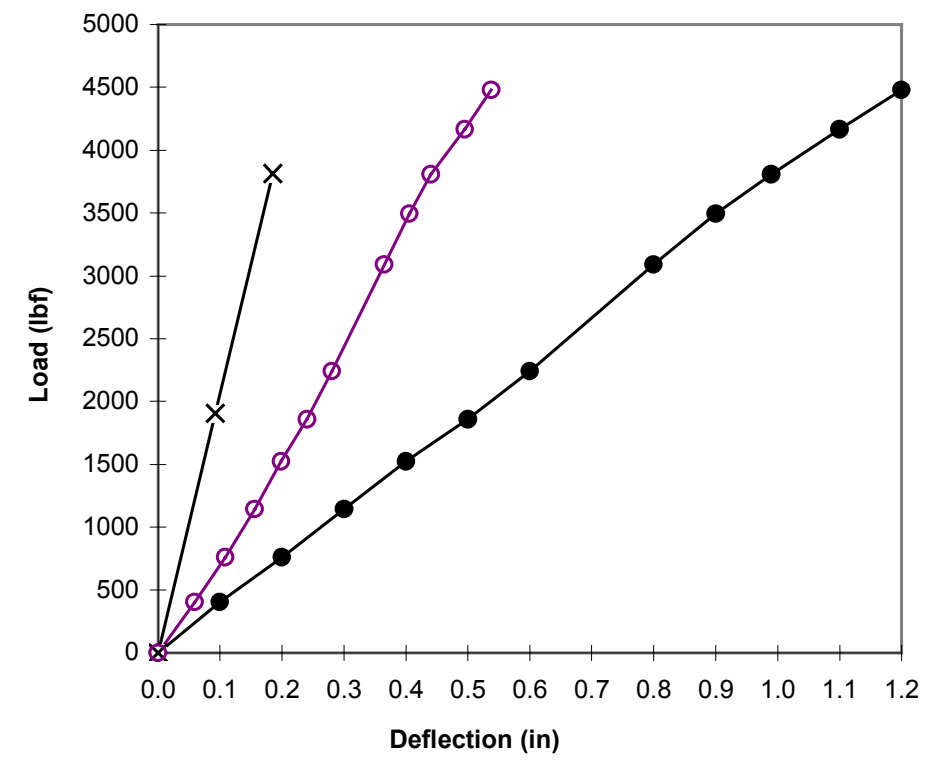

- - Lead-lag experimental results

$-\mathrm{X}$ - Lead-lag numerical results

-Corrected lead-lag experimental results

Figure 4.7. Predicted and experimental deflections for the lead-lag load case.

I corrected for the flexure of the teeter pin and hard-link clamp in the lead-lag load case using the measured deflection of the teeter pin at station four. Using trigonometry, I estimated that station one deflected 4.8 in at the input load for every inch the hard-link bolt deflected. The correction was made by multiplying the measured translation of the teeter pin by 4.8 and subtracting this figure from the deflections measured at station one. This correction increased the measured stiffness $130 \%$.

The flexure of the teeter pin was measured relative to the test stand. Again, I believe the all-thread that clamps the test stand was improperly tensioned. In addition, I was only able to use four all-thread rods (as opposed to the six used during flapwise testing) to clamp the test stand to the steel load plate.

To correct for the lengthening of the all-thread rods, I assumed that the bolts were not pre-tensioned. Thus, the deflection of the rod could be approximated using the equation for the extension of a uniform bar [25] under an axial load. I then related the deflection of the teeter pin to the deflection at the input load 
using trigonometric formulas. This all-thread correction increased the stiffness values by approximately $9 \%$.

Table 4.3 presents the stiffness of the hub body for the predicted and experimental analyses for the lead-lag load case. Although the corrections I made to the teeter pin and test stand increased the experimental stiffness values by $181 \%$, the experimental stiffness is still approximately half of the predicted stiffness. I believe the remaining discrepancy between the two values is caused primarily by flexure of the test stand and one of my simplifying assumptions for the finite-element analysis model.

I did not measure the deflection of the test stand. The corrections I made for the deflection of the test stand all-thread rods were analytical and are therefore only approximate. A more valid comparison of the numerical model could be made if the test fixture was included in the finite-element model or if the flexure of the test stand could be better measured during the experiment.

The third assumption in Section 3.2.1 assumes that the teeter-pin axis on the finite-element model is on the same $\mathrm{Y}-\mathrm{Z}$ plane as the barrel centerline axis. On the prototype, the $\mathrm{X}$ coordinate of the teeter-pin axis is positioned 2.5 in downwind of the barrel axis. Thus, the webs are slanted $15^{\circ}$ from vertical so that they reach from the teeter pin to the top of the barrel. This geometry causes torsion in the webs, which is not represented on the finite-element analysis model.

Table 4.3. Structural Stiffness Values for the Hub Body during Lead-Lag Loading

\begin{tabular}{|c|c|c|}
\hline $\begin{array}{c}\text { Numerical } \\
\text { Stiffness } \\
\text { (lbf } / \text { in) }\end{array}$ & $\begin{array}{c}\text { Experimental } \\
\text { Stiffness } \\
(\text { lbf } / \text { in })\end{array}$ & $\begin{array}{c}\text { Corrected } \\
\text { Experimental Stiffness } \\
\text { (lbf } / \text { in })\end{array}$ \\
\hline 20,630 & 3,792 & 10,668 \\
\hline
\end{tabular}

In summary, like the flapwise load case, it is difficult to obtain a good agreement between the predicted and experimental results. This difficulty stems from the simplicity of the numerical model and the lack of data recorded during the experiment.

Despite the significant difference in the predicted and experimental results, the lead-lag test was still a success. I am now confident that the hub will withstand the design load. Another benefit from the experiment is that I learned how to 
design a test, and I gained experience in building finite-element models. If further modeling of the hub is required, I will be able to better predict its response because I have a better understanding of which data to collect. I will also be able to create a more accurate finite-element analysis model. 


\section{Conclusions and Recommendations}

In this thesis, I presented the design, analysis, and testing of a two-bladed hub. This section discusses my conclusions and recommendations on my design, methodology, and testing techniques, as well as work on the hub that remains to be completed.

\subsection{Design Methodology}

Although NREL has not yet installed and tested the hub, the design should satisfy all the design specifications with only one known exception. The teeter angle range will be $18^{\circ}$ rather than $20^{\circ}$ as specified. The reason for this discrepancy is that the final geometry of the hub body varies slightly from the intended design. Specifically, the barrel is positioned approximately .1 in lower than intended. Thus, the barrel strikes the adapter bolts $2^{\circ}$ too early at each end of the teeter range.

I believe this deviation in hub geometry is due to my lack of emphasis on creating a design with wide manufacturing tolerance margins. Specifically, the tolerances I specified for jigging and welding the hub could not be held. One way I could have increased size of the tolerance zone would have been to make the hub shaft slightly longer, thus allowing the blades to rotate through the entire teeter range without hitting the bolts on the hub shaft. In future design work, I will emphasize keeping manufacturing tolerance margins as large as possible.

For future designs, I will also try to rely less on preferences to make important design decisions. I followed the Phal and Bietz methodology whenever possible; however, time and resource constraints forced me to tailor the Phal and Bietz methodology to my needs. One methodology compromise I had to make was to forgo using a quantitative set of evaluation criteria for the solution principles. Instead, I had to rely more on preference. One result of relying on preference was my premature dismissal of the box-style body principle. I regret not developing this principle further because it would have been easier to construct, and it might have made it easier to mount the boom.

My lack of manufacturing experience also affected the design. One principle I overlooked during the conceptual design stage was to machine the entire hub from billet aluminum using computer numerically controlled machines. 
Building the hub from billet may have been faster and less costly than jigging and welding the hub body structure.

In future designs of this complexity, I will try to use a parametric solid-modeling package. I designed the hub during summer 1995 using AutoCAD Release 12 on a computer with a 33-megahertz $(\mathrm{MHz}) 486$ central processing unit and 16 megabytes of RAM. I decided not to use solid-modeling features of AutoCAD R12 because they were awkward and slow.

I now use a computer with 128 megabytes of RAM and a 133-MHz Pentium CPU; in addition, I routinely use the solid-modeling features of AutoCAD. With today's hardware and software, I would strongly recommend using a parametric modeling tool such as AutoCAD Mechanical Desktop or Pro Engineer.

As the hub design became increasingly complex, it became time consuming to make any changes in the geometry of the structure. Such changes required many modifications to each view of my two-dimensional model. A parametric solidmodeling package would have allowed me to update the model more quickly. If I had used parametric modeling software, I believe I would have had more time to investigate the solution principles. Furthermore, the solid models would have made it easier for me to review my work with others.

I also recommend integrating finite-element modeling into the design process. When I began designing the hub, I had no experience with finite-element analysis software, and I did not have time to learn how to perform a finiteelement analysis. However, if I had been able to use a finite-element analysis package, I could have saved time by performing less extensive mechanics-ofsolids calculations. In addition, I would have had a better understanding of what data needed to be collected during the bench-testing. For example, I could have used the finite-element analysis results to determine where strain gauges should be applied on the hub during the experiment.

Overall, I am satisfied with the design methodology I used. It helped me design a hub that meets all but one of the design specifications. In future designs, I will place a greater emphasis on maintaining wide manufacturing-design margins and be more wary of using preferences to select solution principles. I will also try to implement design tools such as parametric solid modeling and finite-element analysis software, which will make the design processes more efficient. 


\subsection{Analysis and Testing}

According to specifications, the hub should withstand $144 \mathrm{mph}$ winds. I concluded from my stress analyses and bench-testing that the hub will meet this specification. The hub body components that were of questionable strength, however, were the hard-link mounts and the web structure of the hub body. I performed analytical and numerical calculations on these components, and I verified the calculations by bench-testing a prototype of the hub.

The analytical calculations predicted that the peak stress in the hub body $(11,200$ psi) will occur during the lead-lag load case in the web at section A-B. The finite-element analysis predicted a peak stress of $10,500 \mathrm{psi}$ at this section. This stress is roughly one-third the yield strength of the steel used in the structure. Thus, the resulting safety factor against yielding is three.

Fatigue is not likely to be a problem in the hub body. The peak operating loads measured on the three-bladed hub are roughly $20 \%$ of loads I designed the hub to withstand. Thus, I anticipate the operating loads will be roughly $20 \%$ of the design loads, or $2.1 \mathrm{kpsi}$. The endurance limit for A36 steel is approximately 30 kpsi. Thus, the safety factor against fatigue in the hub body is nearly fifteen.

Ideally, I could have compared the predicted and experimental results for the hub body based on stress; however, I could not collect sufficient strain information during the experiment to make this comparison. However, visual inspection of hub body did not reveal any cracked welds or permanent deformation. A brittlelacquer test or strain gauges would have been necessary to determine more precisely what the stresses on the hub body actually are.

I was able to compare the predicted and experimental results using stiffness. The difference between the predicted and experimental stiffness results is explained by the differences in the models. The finite-element analysis simulation did not model the rigidity of the test stand or the flexure of components such as the teeter pin and hard-link pins. A more valid comparison of the numerical model could be made if the test fixture was included in the finite-element model or if the flexure of the test stand could be better measured during the experiment. 


\subsection{Future Work}

Since 1992 the NWTC has been trying to obtain permission from the National Aeronautics and Space Administration (NASA) to run the Unsteady Aerodynamics Experiment in the 120 -ft by $80-\mathrm{ft}$ NASA-Ames wind tunnel. In 1996, NASA granted the NWTC tunnel time for the end of 1998. This testing will be unprecedented in that it has enormous potential to lead to better understanding of the aerodynamics of wind turbines.

Much work remains to be done to prepare the hub for testing. The scope of my project did not include installing, instrumenting, or preparing the hub for the NASA-Ames test. However, after completing the design of the hub, NREL offered me a one-year contract to help with this work.

At the time of this writing, I am designing the instrumentation mounts to measure the flap angle and pitch angle. I am also designing a blade-pitch hardstop and limit-switch assembly. Another task I must complete is the design and construction of the pitch control system. NWTC engineer Lee J. Fingersh and master technician Dave Jager are currently working on this task.

We expect to remove the three-bladed Unsteady Aerodynamics Experiment rotor and install the two-bladed rotor by the end of 1997 . The hub will be field-tested in 1998 and run in the 120-ft by $80-\mathrm{ft}$ NASA-Ames wind tunnel in December 1998. 


\section{Appendix A. Hub Body Experiment Data}

This appendix includes the raw and corrected test data for the flapwise and leadlag testing. Below is a table of contents for the appendix.

Table A1. Flapwise Test Data .......................74

Table A2. Corrected Flapwise Test Data ............75

Table A3. Lead-Lag Test Data.....................76

Table A4. Corrected Lead-Lag Test Data ............77 
Table A1. Flapwise Test Data

\begin{tabular}{|c|c|c|c|c|c|}
\hline & & \multicolumn{4}{|c|}{ Flapwise Dial Gauge Readings } \\
\hline $\begin{array}{c}\text { Pump } \\
\text { Pressure } \\
\text { (psi) }\end{array}$ & $\begin{array}{c}\text { Calculated } \\
\text { Load } \\
\text { (lbf) }\end{array}$ & $\begin{array}{c}\text { Station 1 } \\
\text { (in) }\end{array}$ & $\begin{array}{c}\text { Station 2 } \\
\text { (in) }\end{array}$ & $\begin{array}{c}\text { Station 3 } \\
\text { (in) }\end{array}$ & $\begin{array}{c}\text { Station 4 } \\
\text { (in) }\end{array}$ \\
\hline 0 & 0 & 0.000 & 0.100 & 0.0000 & 0.100 \\
\hline 140 & 314 & 0.100 & 0.130 & 0.0001 & 0.109 \\
\hline 310 & 694 & 0.200 & 0.162 & -0.0043 & 0.120 \\
\hline 500 & 1120 & 0.300 & 0.193 & -0.0158 & 0.126 \\
\hline 730 & 1635 & 0.400 & 0.225 & -0.0165 & 0.131 \\
\hline 920 & 2061 & 0.500 & 0.258 & -0.0165 & 0.137 \\
\hline 1140 & 2554 & 0.600 & 0.290 & -0.0200 & 0.142 \\
\hline 1340 & 3002 & 0.700 & 0.322 & -0.0230 & 0.148 \\
\hline 1560 & 3494 & 0.800 & 0.356 & -0.0260 & 0.153 \\
\hline 1740 & 3898 & 0.900 & 0.390 & -0.0287 & 0.158 \\
\hline 1900 & 4256 & 1.000 & 0.425 & -0.3200 & 0.165 \\
\hline 2000 & 4480 & 1.030 & 0.435 & -0.3250 & 0.167 \\
\hline 0 & 0 & 0.000 & 0.177 & -0.0150 & 0.151 \\
\hline
\end{tabular}


Table A2. Corrected Flapwise Test Data

\begin{tabular}{|c|c|c|c|c|}
\hline $\begin{array}{c}\text { Dial Gauge } \\
\text { Readings at } \\
\begin{array}{c}\text { Station 1 } \\
\text { (in) }\end{array}\end{array}$ & \multicolumn{3}{|c|}{ Corrections for Station 1 } & $\begin{array}{c}\text { Corrected Dial } \\
\text { Gauge Readings } \\
\text { at Station 1 } \\
\text { (in) }\end{array}$ \\
\hline & $\begin{array}{c}\text { Correction for } \\
\text { Teeter-pin Bolt } \\
\text { Flexure }\end{array}$ & $\begin{array}{c}\text { Correction for } \\
\text { Teeter-pin } \\
\text { Flexure }\end{array}$ & $\begin{array}{c}\text { Correction for } \\
\text { Stand-bolt } \\
\text { Flexure }\end{array}$ & \\
\hline 0.000 & 0.000 & 0.000 & 0.000 & 0.000 \\
\hline 0.100 & -0.030 & -0.007 & -0.003 & 0.060 \\
\hline 0.200 & -0.066 & -0.016 & -0.007 & 0.111 \\
\hline 0.300 & -0.086 & -0.025 & -0.012 & 0.177 \\
\hline 0.400 & -0.102 & -0.037 & -0.017 & 0.243 \\
\hline 0.500 & -0.122 & -0.047 & -0.022 & 0.309 \\
\hline 0.600 & -0.139 & -0.058 & -0.027 & 0.377 \\
\hline 0.700 & -0.158 & -0.068 & -0.032 & 0.442 \\
\hline 0.800 & -0.175 & -0.079 & -0.037 & 0.509 \\
\hline 0.900 & -0.191 & -0.088 & -0.041 & 0.579 \\
\hline 1.000 & -0.215 & -0.096 & -0.045 & 0.644 \\
\hline 1.030 & -0.221 & -0.101 & -0.047 & 0.660 \\
\hline 0.000 & -0.168 & 0.000 & 0.000 & -0.168 \\
\hline
\end{tabular}


Table A3. Lead-Lag Test Data

\begin{tabular}{|c|c|c|c|c|c|}
\hline & & \multicolumn{4}{|c|}{ Lead-Lag Dial Gauge Readings } \\
\hline $\begin{array}{c}\text { Pump } \\
\text { Pressure } \\
\text { (psi) }\end{array}$ & $\begin{array}{c}\text { Calculated } \\
\text { Load } \\
\text { (lbf) }\end{array}$ & $\begin{array}{c}\text { Station 1 } \\
\text { (in) }\end{array}$ & $\begin{array}{c}\text { Station 2 } \\
\text { (in) }\end{array}$ & $\begin{array}{c}\text { Station 3 } \\
\text { (in) }\end{array}$ & $\begin{array}{c}\text { Station 4 } \\
\text { (in) }\end{array}$ \\
\hline 0 & 0 & 0.000 & 0.500 & 0.000 & 0.0000 \\
\hline 180 & 403 & 0.100 & 0.470 & 0.005 & 0.0050 \\
\hline 340 & 762 & 0.200 & 0.436 & 0.012 & 0.0120 \\
\hline 510 & 1142 & 0.300 & 0.402 & 0.019 & 0.0190 \\
\hline 680 & 1523 & 0.400 & 0.368 & 0.027 & 0.0270 \\
\hline 830 & 1859 & 0.500 & 0.333 & 0.034 & 0.0340 \\
\hline 1000 & 2240 & 0.600 & 0.298 & 0.042 & 0.0465 \\
\hline 1380 & 3091 & 0.800 & 0.230 & 0.057 & 0.0706 \\
\hline 1560 & 3494 & 0.900 & 0.195 & 0.064 & 0.0776 \\
\hline 1700 & 3808 & 0.990 & 0.180 & 0.071 & 0.1486 \\
\hline 1860 & 4166 & 1.100 & 0.127 & 0.079 & 0.1566 \\
\hline 2000 & 4480 & 1.200 & 0.042 & 0.085 & 0.1626 \\
\hline
\end{tabular}


Table A4. Corrected Lead-Lag Test Data

\begin{tabular}{|c|c|c|c|}
\hline $\begin{array}{c}\text { Dial Gauge } \\
\text { Readings at } \\
\text { Station 1 } \\
\text { (in) }\end{array}$ & \multicolumn{2}{|c|}{ Corrections for Station 1 } & $\begin{array}{c}\text { Corrected Dial } \\
\text { Gauge Readings } \\
\text { at Station 1 } \\
\text { (in) }\end{array}$ \\
\hline & $\begin{array}{c}\text { Correction for } \\
\text { Teeter-Pin } \\
\text { Flexure }\end{array}$ & $\begin{array}{c}\text { Correction for } \\
\text { Stand-Bolt } \\
\text { Flexure }\end{array}$ & \\
\hline 0 & 0.000 & 0.000 & 0.000 \\
\hline 180 & -0.041 & -0.009 & 0.051 \\
\hline 340 & -0.091 & -0.016 & 0.093 \\
\hline 510 & -0.144 & -0.024 & 0.132 \\
\hline 680 & -0.202 & -0.032 & 0.166 \\
\hline 830 & -0.259 & -0.039 & 0.201 \\
\hline 1000 & -0.319 & -0.047 & 0.233 \\
\hline 1380 & -0.435 & -0.066 & 0.300 \\
\hline 1560 & -0.494 & -0.074 & 0.332 \\
\hline 1700 & -0.550 & -0.081 & 0.360 \\
\hline 1860 & -0.605 & -0.088 & 0.407 \\
\hline 2000 & -0.662 & -0.095 & 0.443 \\
\hline & & & \\
\hline
\end{tabular}




\section{Bibliography}

1. De Renzo, D.J. (1979). Wind Power: Recent Developments. New Jersey:Noyes Data Corporation, pp. 5-7.

2. Gipe, P. (1995). Wind Energy Comes Of Age. John Wiley \& Sons, pp. 1213.

3. Gipe, P. (Spring 1997). Wind Stats Newsletter; Vol. 10, No. 2, p. 8.

4. U.S. Department of Energy. Wind Energy Program Overview. Fiscal Years 1995 and 1996, p 2.

5. Ibid.

6. Hunt, D.V. (1981). Wind Power: A Handbook on Wind Energy Systems. Litton Educational Publishing, p. 527.

7. Gipe, P. (1995). Wind Energy Comes of Age. John Wiley \& Sons, p. 172.

8. Ibid., p. 176.

9. Overview of NREL. (January 1997). http://www.nrel.gov/lab/overview.html.

10. Ibid.

11. Simms, D.A.; Butterfield, C.P. (1994). "Full-Scale Wind Turbine Rotor Aerodynamics Research." European Wind Energy Conference-1994; October 10-14, 1994; Thessaloniki, Greece. Golden, CO: National Renewable Energy Laboratory; pp 1-2.

12. Phal, G; Bietz, W. (1988). Engineering Design a Systematic Approach. United Kingdom: Biddles Ltd; pp. 40-43.

13. Fingersh, L. J. (June 1995). Personal communication. NREL, Colorado. 14. Ibid. 
15. Phal, G; Bietz, W. (1988). Engineering Design a Systematic Approach. United Kingdom: Biddles Ltd; pp. 40-43.

16. Ibid., p. 197

17. Garlock Bearings, Inc. Catalog \#881, p 1.

18. AWT 26 Operation and Maintenance Manual. (1993).

19. Marks, Lionel S. (1987) Marks' standard handbook for mechanical engineers. McGraw-Hill, pp. 8-125.

20. Mischke, C.R.; Shigley, J.E. (1989). Mechanical Engineering Design. $5^{\text {th }}$ edition. McGraw-Hill, p. 250.

21. Ibid.

22. ANSYS Basic Analysis Procedures Guide. (1995). pp. 5-34.

23. Mischke, C.R.; Shigley, J.E. (1989). Mechanical Engineering Design. $5^{\text {th }}$ edition. McGraw-Hill, p. 735.

24. Ibid., p. 93.

25. Ibid. 
Public reporting burden for this collection of information is estimated to average 1 hour per response, including the time for reviewing instructions, searching existing data sources,

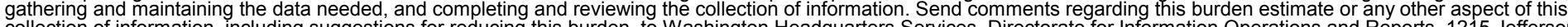

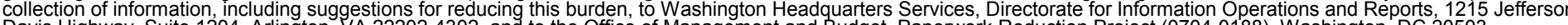
Davis Highway, Suite 1204, Arlington, VA 22202-4302, and to the Office of Management and Budget, Paperwork Reduction Project (0704-0188), Washington, DC 20503.
1. AGENCY USE ONLY (Leave blank)
2. REPORT DATE June 2002
3. REPORT TYPE AND DATES COVERED
Technical Report

4. TITLE AND SUBTITLE

The Mechanical Design, Analysis, and Testing of a Two-Bladed Wind Turbine Hub

5. FUNDING NUMBERS

6. AUTHOR(S)

TA: WER2.1460

Jason Rust Cotrell

7. PERFORMING ORGANIZATION NAME(S) AND ADDRESS(ES)

National Renewable Energy Laboratory

8. PERFORMING ORGANIZATION REPORT NUMBER

1617 Cole Blvd.

Golden, CO 80401-3393

NREL/TP-500-26645

9. SPONSORING/MONITORING AGENCY NAME(S) AND ADDRESS(ES)

National Renewable Energy Laboratory

1617 Cole Blvd.

Golden, CO 80401-3393

10. SPONSORING/MONITORING AGENCY REPORT NUMBER

NREL/TP-500-26645

11. SUPPLEMENTARY NOTES

12a. DISTRIBUTION/AVAILABILITY STATEMENT

National Technical Information Service

12b. DISTRIBUTION CODE

U.S. Department of Commerce

5285 Port Royal Road

Springfield, VA 22161

13. ABSTRACT (Maximum 200 words)

Researchers at the National Wind Technology Center (NWTC) in Golden, Colorado, began performing the Unsteady Aerodynamics Experiment in 1993 to better understand the unsteady aerodynamics and structural responses of horizontalaxis wind turbines. The experiment consists of an extensively instrumented, downwind, three-bladed, 20-kilowatt wind turbine. In May 1995, I received a request from the NWTC to design a two-bladed hub for the experiment. For my thesis, I present the results of the mechanical design, analysis, and testing of the hub.

The hub I designed is unique because it runs in rigid, teetering, or independent blade-flapping modes. In addition, the design is unusual because it uses two servomotors to pitch the blades independently. These features are used to investigate new load reduction, noise reduction, blade pitch optimization, and yaw control techniques for two-bladed turbines.

I used a methodology by G. Phal and W. Bietz to design the hub. The hub meets all the performance specifications except that it achieves only $90 \%$ of the specified teeter range.

In my thesis, I focus on the analysis and testing of the hub body. I performed solid-mechanics calculations, ran a finiteelement analysis simulation, and experimentally investigated the structural integrity of the hub body.

14. SUBJECT TERMS

wind turbine; turbine testing; two-bladed wind turbine hub; wind turbine design analysis

15. NUMBER OF PAGES

16. PRICE CODE

17. SECURITY CLASSIFICATION OF REPORT Unclassified
18. SECURITY CLASSIFICATION OF THIS PAGE Unclassified
19. SECURITY CLASSIFICATION OF ABSTRACT Unclassified
20. LIMITATION OF ABSTRACT

UL 